Check for updates

Cite this: J. Mater. Chem. A, 2020, 8 , 24943

Received 20th August 2020

DOI: $10.1039 / \mathrm{d} 0 \mathrm{ta0} 8190 \mathrm{f}$

rsc.li/materials-a
Accepted 23rd October 2020

\section{Recent advances in 2D/nanostructured metal sulfide-based gas sensors: mechanisms, applications, and perspectives}

\author{
Hongyu Tang, (D) a Leandro Nicolas Sacco, ${ }^{a}$ Sten Vollebregt, ${ }^{a}$ Huaiyu Ye, (D) bc \\ Xuejun Fan ${ }^{\star d}$ and Guoqi Zhang ${ }^{\star a}$
}

\begin{abstract}
$2 \mathrm{D}$ and nanostructured metal sulfide materials are promising in the advancement of several gas sensing applications due to the abundant choice of materials with easily tunable electronic, optical, physical, and chemical properties. These applications are particularly attractive for gas sensing in environmental monitoring and breath analysis. This review gives a systematic description of various gas sensors based on $2 \mathrm{D}$ and nanostructured metal sulfide materials. Firstly, the crystal structures of metal sulfides are introduced. Secondly, the gas sensing mechanisms of different metal sulfides based on density functional theory analysis are summarised. Various gas-sensing concepts of metal sulfide-based devices, including chemiresistors, functionalized metal sulfides, Schottky junctions, heterojunctions, field-effect transistors, and optical and surface acoustic wave sensors, are compared and presented. It then discusses the extensive applications of metal sulfide-based sensors for different gas molecules, including volatile organic compounds (i.e., acetone, benzene, methane, formaldehyde, ethanol, and liquefied petroleum gas) and inorganic gas (i.e., $\mathrm{CO}_{2}, \mathrm{O}_{2}, \mathrm{NH}_{3}, \mathrm{H}_{2} \mathrm{~S}, \mathrm{SO}_{2}, \mathrm{NO}_{x}, \mathrm{CH}_{4}, \mathrm{H}_{2}$, and humidity). Finally, a strengths-weaknesses-opportunities-threats (SWOT) analysis is proposed for future development and commercialization in this field.
\end{abstract}

\section{Introduction}

Nanostructured materials have been considered promising candidates for gas sensing applications due to their large surface area, abundant surface-active sites, and high surface reactivity. ${ }^{1}$ They are primarily used for monitoring air quality, the environmental situation, and breath. Typically, atmospheric pollutants include nitrogen dioxide $\left(\mathrm{NO}_{2}\right)$, nitrogen monoxide (NO), ammonia $\left(\mathrm{NH}_{3}\right)$, hydrogen sulfide $\left(\mathrm{H}_{2} \mathrm{~S}\right)$, sulfur dioxide $\left(\mathrm{SO}_{2}\right)$, carbon monoxide $(\mathrm{CO})$, carbon dioxide $\left(\mathrm{CO}_{2}\right)$, methane $\left(\mathrm{CH}_{4}\right)$, and volatile organic compounds (VOCs). ${ }^{2}$ When these pollutants exceed the recommended exposure limits, they have negative effects on the environment and human health (Table 1). Therefore, the gas sensor needs to detect different gases simultaneously with high sensitivity and selectivity, a small size, low cost, and low power consumption $(<10 \mathrm{~mW}){ }^{3}$ In the aspect of breath analysis, different biomarkers from exhaled breath

${ }^{a}$ Department of Microelectronics, Faculty of Electrical Engineering, Mathematics \& Computer Science, Delft University of Technology, Delft 2628 CT, The Netherlands. E-mail: G.Q.Zhang@tudelft.nl

${ }^{b}$ School of Microelectronics, Southern University of Science and Technology, Shenzhen 518055, China

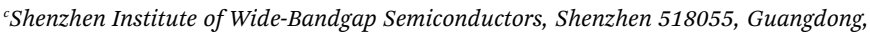
China

${ }^{d}$ Department of Mechanical Engineering, Lamar University, Texas 77710, USA. E-mail: xfan@lamar.edu need to be recognized accurately. ${ }^{4}$ Normally, human breath contains nitrogen $\left(\mathrm{N}_{2}\right)$, oxygen $\left(\mathrm{O}_{2}\right), \mathrm{CO}_{2}$, hydrogen $\left(\mathrm{H}_{2}\right)$, inert gases, and water vapour. Sometimes, it includes organic VOCs viz. acetone, ethanol, isoprene, ethane, methane, pentane, etc., and inorganic gases such as $\mathrm{NO}_{x}, \mathrm{NH}_{3}, \mathrm{CO}_{x}$, and $\mathrm{H}_{2} \mathrm{~S}$, see Fig. 1a. These excretory products diffuse into the inhaled air in the alveoli of the lungs and are then ejected in the form of exhaled air. Therefore, exhaled air carries different biomarkers, which can be used as fingerprints of metabolic products. This enables early diagnosis and prevention of respiratory diseases such as lung cancer, diseases of the kidneys, prostate, and bladder, and even Parkinson's disease, see Fig. 1b. ${ }^{5,6}$ However, the maximum permissible limits of biomarkers are mostly at the parts-per-billion (ppb) level, which requires a highly sensitive gas sensor with a low limit of detection (LOD).

Solid-state sensors such as metal oxide semiconductors (MOSs), ${ }^{9}$ carbon-based nanomaterials (CNMs), ${ }^{10-12}$ and metal sulfide semiconductors ${ }^{13}$ are used extensively in gas detection research. After Taguchi patented the first oxide-based gas sensor in 1962, various high sensitivity and low-cost gas sensors based on MOSs have been developed. ${ }^{14}$ Tungsten oxide $\left(\mathrm{WO}_{3}\right)$ nanotubes have been proved as a potential MOS for the detection of $\mathrm{NO}$ at the ppb level. ${ }^{15}$ Orthorhombic molybdenum trioxide $\left(\alpha-\mathrm{MoO}_{3}\right)$ nanoribbons can detect $\mathrm{NH}_{3}$ down to 280 ppt. ${ }^{16}$ Gas sensors based on Pt functionalized tin dioxide $\left(\mathrm{SnO}_{2}\right)^{17}$ or indium oxide $\left(\mathrm{In}_{2} \mathrm{O}_{3}\right)^{18}$ can detect the lowest acetone 
Table 1 The environmental and human health impacts of different air pollutants and their maximum permissible limits set by the European Union ${ }^{7,8}$

Gas Environmental and human health impact

\begin{tabular}{|c|c|c|}
\hline Maximu & rmissible limit & \\
\hline $\begin{array}{l}8 \text { hours } \\
(\mathrm{ppm})\end{array}$ & $\begin{array}{l}\text { Short-term } \\
(15 \text { min, ppm) }\end{array}$ & $\begin{array}{l}\text { Value of } \\
\text { interest } \\
(\mathrm{ppb})\end{array}$ \\
\hline
\end{tabular}

$\mathrm{NO}_{2}$ Indirect green house gas, acidification, eutrophication, cardiovascular mortality, asthma, lung 0.5 function

$\mathrm{NH}_{3}$ Toxic, $\mathrm{PM}_{2.5}$ precursor

$\mathrm{H}_{2} \mathrm{~S} \quad \mathrm{SO}_{2}$ precursor, toxic

$\mathrm{SO}_{2}$ Indirect green house gas, acidification, particulate matter, precursor, cardiovascular mortality 0.5

CO Indirect green house gas, toxic, asthma, cardiovascular disease, cardiac disease, psychiatric 20 admissions, etc.

$\mathrm{CO}_{2}$ Green house gas - climate change

$\mathrm{CH}_{4}$ Green house gas - climate change

0.5
20
5
0.5
20

5000
1000

1000
21

20000

5000

7.5

4000

100

$-$

$-$
400000

1800 concentration of $10 \mathrm{ppb}$. The $\mathrm{ZnSnO}_{3}$ gas sensor can detect $100 \mathrm{ppb}$ ethanol. ${ }^{19}$ Many MOS-based devices can detect $\mathrm{H}_{2} \mathrm{~S}$ at less than $1 \mathrm{ppm}$, such as copper oxide (CuO), $\mathrm{SnO}_{2}, \mathrm{In}_{2} \mathrm{O}_{3}$, zinc oxide $(\mathrm{ZnO})$, titanium oxide $\left(\mathrm{TiO}_{2}\right)$, and iron oxide $\left(\mathrm{Fe}_{2} \mathrm{O}_{3}\right){ }^{20}$ However, the operating temperature (OT) of MOS-based devices is usually high $\left(100-300{ }^{\circ} \mathrm{C}\right)$, which induces high power consumption and consequently hinders the gas-sensing applications. CNMs, such as graphene and its derivatives and carbon nanotubes (CNTs), were employed as chemical gas sensors owing to their outstanding characteristics of a mesoporous nature, a large specific surface area, and enhanced electron transport properties. ${ }^{21}$ Pristine reduced graphene oxide (rGO) can detect $\mathrm{NH}_{3}$ and $\mathrm{NO}_{x}$, and $\mathrm{rGO}$ with a functionally modified surface (such as $\mathrm{rGO} / \mathrm{ZnO}, \mathrm{rGO} / \mathrm{Pt}$, and $\mathrm{rGO} / \mathrm{Ni}$ ) are known to detect VOCs (such as acetone, phenol, and nitrobenzene). ${ }^{22-24}$ Rigoni et al. ${ }^{25}$ recently demonstrated an $\mathrm{NH}_{3}$ sensor comprising pristine SWCNTs that had a LOD of $3 \mathrm{ppb}$. The review of

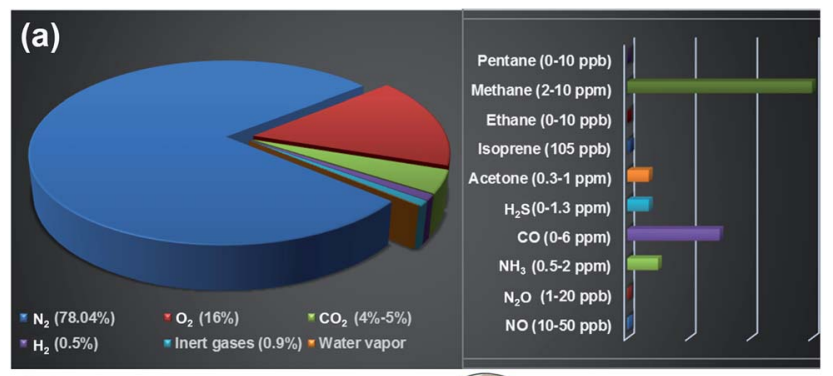

(b)

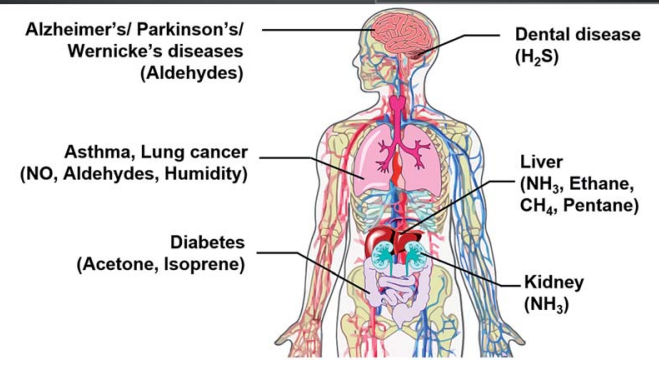

Fig. 1 (a) The gas contents of human breath and (b) the biomarkers of different diseases. graphene-based ${ }^{26}$ and CNT-based ${ }^{12}$ chemical sensors reported that $2 \mathrm{D} /$ nano-materials have great potential applications in gas detection and proposed several techniques to improve gassensing performance, which can be extended to other materials, for instance, metal sulfides.

Lots of metal sulfide-based sensors can work at room temperature and have lower power consumption, making them superior to MOS-based sensors. ${ }^{27}$ The sensing performances of metal sulfides are similar to those of CNM-based devices, except for their sizeable and tunable bandgaps, making such materials suitable for transistor applications, further inducing unique

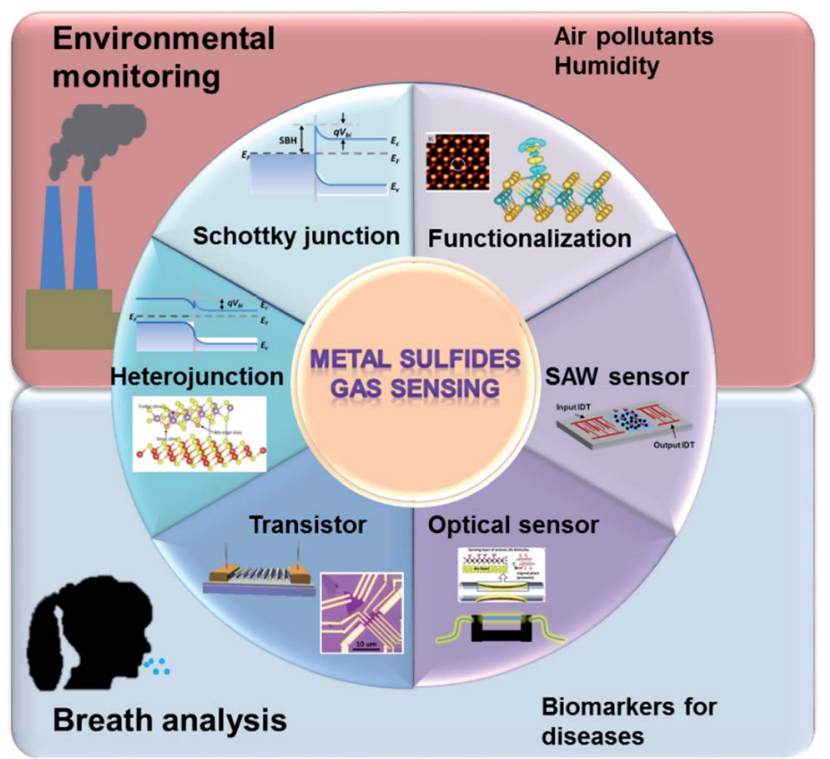

Fig. 2 Strategies of high-performance metal sulfide-based gas sensors and their applications. The heterojunction image is reprinted with permission from ref. 35 Copyright 2017, ACS Publishing. The functionalization images are reprinted with permission from ref. 36 . Copyright 2013, ACS Publishing and reprinted with permission from ref. 37. Copyright 2017, Elsevier. The transistor image is reprinted with permission from ref. 38. Copyright 2013, ACS Publishing. The optical sensor image is reprinted with permission from ref. 39. Copyright 2020, ACS Publishing. 


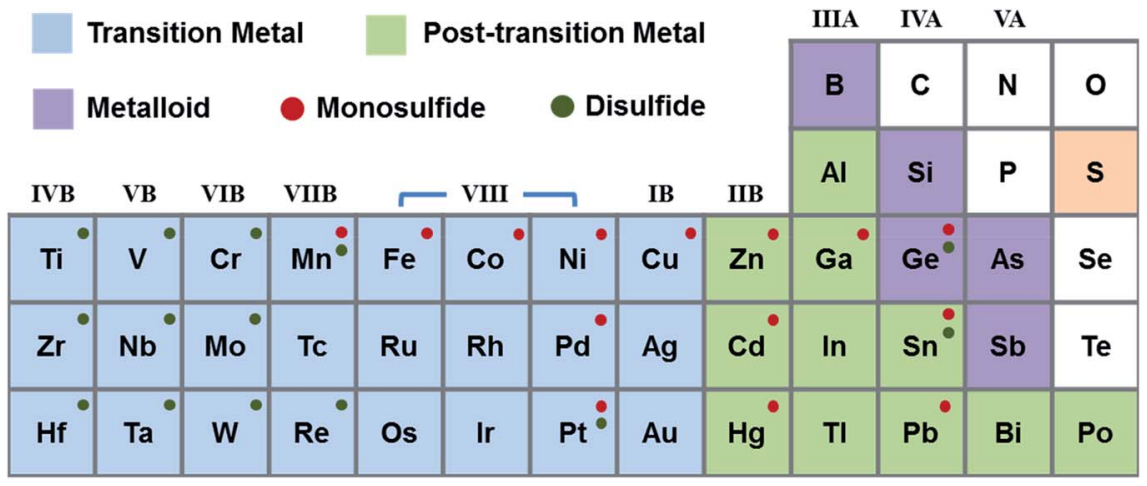

Fig. 3 Periodic table with symbols indicating metal sulfide.

sensing behaviours. ${ }^{28}$ They have the advantages of a shallow valence band, exposed active sites, and the quantum size effect. Typical metal sulfide semiconductors, such as molybdenum disulfide $\left(\mathrm{MoS}_{2}\right)$ and tungsten disulfide $\left(\mathrm{WS}_{2}\right)$, are layered metal disulfide materials, which consist of several S-metal-S layers attached via weak van der Waals (vdW) force. Sensor metal sulfide materials act as charge acceptors or donors. Because of the highspeed charge transfer and the high adsorption energy between it and gas molecules, metal disulfide has been widely used in gas sensing. The LOD of a $\mathrm{MoS}_{2} \mathrm{NO}_{2}$ gas sensor is $20 \mathrm{ppb.} .^{29}$ For posttransition metal sulfide, tin sulfide (SnS) and germanium sulfide (GeS) are semiconductors that belong to a family of layered group IV monosulfides and have similar puckered structures to black phosphorus (BP). ${ }^{30-32}$ Owing to its anisotropic crystal structure, SnS has been employed for the detection of VOCs and toxic gases, such as acetone, alcohol, and $\mathrm{NO}_{2} \cdot{ }^{33,34}$ Additionally, many advanced methods were proposed to improve their sensing properties, such as functionalizing metal sulfide (e.g., with defects or dopants), constructing heterojunctions (Schottky junctions and p-n, n-n, and p-p heterojunctions), and using transistors, see Fig. 2.

The present review will provide a comprehensive perspective on metal sulfide-based gas sensors, including the crystal structure, gas sensing mechanisms, applications, and perspectives. The paper is organized as follows: Section 2 describes the basic characteristics of metal sulfide nanomaterials. Section 3 discusses various gas sensing mechanisms of different metal sulfides through density functional theory (DFT). Section 4 summarises different sensing concepts of gas sensors based on metal sulfides. Section 5 lists the gas sensing applications of metal sulfide-based devices. Section 6 discusses the challenges and perspectives of metal sulfide sensors. This review is conceptually self-contained and intended to serve as an informational resource to newcomers and experienced researchers on metal sulfide-based sensors.

\section{Gas sensing mechanisms of metal sulfides}

Sulfide is an inorganic sulfur anion with the chemical formula $\mathrm{S}^{2-}$ or a compound containing one or more $\mathrm{S}^{2-}$ ions. ${ }^{40}$ Metal sulfide is a kind of combination of sulfur anions and metal/ semi-metal cations in the form of $\mathrm{M}_{x} \mathrm{~S}_{y}(x: y=1: 1,1: 2$, $2: 1,3: 4){ }^{41}$ As shown in Fig. 3, metal monosulfides mostly correspond to group VIII, IB, IIB, IIIA, and IVA metals. The elements from group IVB-VIIB and Sn can be used to form metal disulfides. ${ }^{42}$ Materials of the same composition with different crystal phases have different properties. $2 \mathrm{H}$ phase group VIB disulfides are usually semiconducting, while the corresponding $1 \mathrm{~T}, 1 \mathrm{~T}^{\prime}$, and $\mathrm{Td}$ phase crystals are metallic. Group IVA disulfides, such as $\mathrm{GeS}_{2}$ and $\mathrm{SnS}_{2}$, are often semiconductors. $\mathrm{MoS}_{2}, \mathrm{WS}_{2}$, and $\mathrm{SnS}_{2}$ are group VIB semiconductors, which have been used for transistors. Compared to other disulfides, group IVB disulfides exhibit high carrier mobility. Table 2 introduces the characteristics and applications of nanostructured metal sulfides. It is found that numerous metal sulfides possess several crystal phases, which can be controlled by altering the fabrication processes and external stimulations. ${ }^{41,43,44}$ The preparation strategies for metal sulfides primarily comprise "top-down" and "bottom-up" methods. The top-down approaches include sputtering, electrospinning, lithography, mechanical exfoliation (ME), and liquid phase exfoliation (LPE). Bottom-up strategies are chemical vapour deposition (CVD), atomic layer deposition (ALD), spray pyrolysis, pulsed laser deposition/ablation, thermal deposition, hydrothermal synthesis, solvothermal synthesis, and the self-assembly method. All these methods have been proposed to prepare large scale, high yield, and low-cost metal sulfides in the form of $0 \mathrm{D}, 1 \mathrm{D}, 2 \mathrm{D}$, and 3D structures. Chandrasekaran et $a l .{ }^{40}$ presented a comprehensive review on preparation technologies of metal sulfides; complementarily, in this review we primarily focus on gas sensing mechanisms and applications.

It is demonstrated that the gas molecules physically or chemically adsorb at the surface of the nanostructured materials through adsorption energy. The higher the adsorption energy the stronger the adsorption interaction between gas molecules and metal sulfides. First-principles simulation, that is DFT calculations using plane waves and pseudopotentials, has become an efficient method to evaluate the sensing performance of $2 \mathrm{D} /$ nano-materials. Because the behaviours of atoms during chemical bonding and the flow of electrons in materials can be calculated through DFT based on quantum 
Table 2 Characteristics and applications of nanostructured metal sulfides ${ }^{a}$

\begin{tabular}{|c|c|c|c|c|c|c|}
\hline & Crystal structure & Electric conductivity & Bandgap $[\mathrm{eV}]$ & Fabrication method & Application & Ref. \\
\hline $\operatorname{SnS}$ & Orthorhombic & p-type & Indirect 1.1 & PVD & $\begin{array}{l}\text { Photodetectors, gas } \\
\text { sensors }\end{array}$ & 45 \\
\hline GaS & Hexagonal & Semiconductor & Indirect 2.52 & LPE & $\begin{array}{l}\text { Hydrogen evolution } \\
\text { reaction }\end{array}$ & 46 \\
\hline GeS & Orthorhombic & p-type & $\begin{array}{l}\text { (Monolayer) } \\
\text { indirect } 2.34\end{array}$ & Vapour deposition & High electron mobility & 32 \\
\hline $\mathrm{ZnS}$ & Hexagonal & n-type & Direct 3.7 & Hydrothermal & $\begin{array}{l}\text { Gas sensors, optical } \\
\text { sensors }\end{array}$ & 47 \\
\hline CdS & Hexagonal & n-type & Direct 2.42 & Spray pyrolysis & Solar cells, gas sensors & 48 \\
\hline $\mathrm{CuS}$ & Hexagonal & p-type & Direct 2.5 & Deposition & Solar cells, gas sensors & 49 \\
\hline $\mathrm{PbS}$ & Hexagonal & n-type & Bulk 0.373 nm 1.30 & $\begin{array}{l}\text { Chemical bath } \\
\text { deposition }\end{array}$ & $\begin{array}{l}\text { Solar cells, photonics, } \\
\text { gas sensors }\end{array}$ & 50 and 51 \\
\hline $\mathrm{NiS}$ & Rhombohedral & p-type & 0.5 & $\begin{array}{l}\text { Solventless, thermal } \\
\text { decomposition }\end{array}$ & Photocatalysts & 52 \\
\hline $\mathrm{MoS}_{2}$ & $\begin{array}{l}2 \mathrm{H} \text { hexagonal } \\
1 \mathrm{~T}\end{array}$ & $\begin{array}{l}\text { (2H) semiconductor } \\
(1 \mathrm{~T}) \text { metal }\end{array}$ & $\begin{array}{l}\text { (Bulk) indirect } 1.29 \\
\text { (Monolayer) direct } 1.8\end{array}$ & CVD, ME & $\begin{array}{l}\text { FETs, photodetectors, } \\
\text { solar cells, photonics, } \\
\text { supercapacitors }\end{array}$ & 53 and 54 \\
\hline $\mathrm{WS}_{2}$ & $\begin{array}{l}2 \mathrm{H} \text { hexagonal } \\
1 \mathrm{~T}\end{array}$ & $\begin{array}{l}\text { (2H) n-type } \\
(1 \mathrm{~T}) \text { metal }\end{array}$ & $\begin{array}{l}\text { (Bulk) indirect } 1.3 \\
\text { (Monolayer) direct } 2.1\end{array}$ & CVD, ME & $\begin{array}{l}\text { FETs, photodetectors, } \\
\text { gas sensors }\end{array}$ & 55 \\
\hline $\mathrm{SnS}_{2}$ & 4H hexagonal & n-type & $\begin{array}{l}\text { (Bulk) indirect } 2.308 \\
\text { (Monolayer) } \\
\text { indirect } 2.033\end{array}$ & $\mathrm{CVD}, \mathrm{ME}$ & $\begin{array}{l}\text { FETs, photovoltaics, } \\
\text { photodetectors }\end{array}$ & 56 \\
\hline $\mathrm{ZrS}_{2}$ & $1 \mathrm{~T}$ rhombohedral & n-type & (Bulk) indirect 1.7 & CVD & Photoconductivity & 57 \\
\hline $\mathrm{HfS}_{2}$ & 1T rhombohedral & Semiconductor & Indirect 2.0 & $\mathrm{ME}$ & FETs, phototransistors & 58 \\
\hline $\mathrm{NbS}_{2}$ & $2 \mathrm{H}$ hexagonal & Metal & 0.73 & CVD & Superconductivity & 59 \\
\hline $\mathrm{TaS}_{2}$ & $\begin{array}{l}1 \mathrm{~T} \text { rhombohedral } \\
2 \mathrm{H} \text { hexagonal }\end{array}$ & Metal & 0.7 & CVD & $\begin{array}{l}\text { Photosensitivity, } \\
\text { superconductivity }\end{array}$ & 60 \\
\hline $\mathrm{TiS}_{3}$ & Monoclinic & n-type & Direct 1.13 & ME, CVT & $\begin{array}{l}\text { Photodetectors, gas } \\
\text { sensors }\end{array}$ & 61 and 62 \\
\hline $\mathrm{ZrS}_{3}$ & Monoclinic & n-type & Direct 2.56 & CVT & Photodetectors & 63 \\
\hline $\mathrm{HfS}_{3}$ & Monoclinic & Semiconductor & - & CVT & FETs, photodetectors & 64 \\
\hline $\mathrm{TaS}_{3}$ & Orthorhombic & Metal & - & - & FETs, gas sensors & 65 \\
\hline $\operatorname{In}_{2} S_{3}$ & Tetragonal & n-type & Direct 2.02 & CVD & $\begin{array}{l}\text { Photodetectors, gas } \\
\text { sensors }\end{array}$ & 66 \\
\hline
\end{tabular}

mechanics, it is much easier to understand the behaviour of systems at the atomic scale. This section discusses the major parameter calculated using DFT for evaluating sensing performance, the sensing mechanism of different metal sulfide materials, such as pristine, doped, defective, and heterojunction-based metal sulfides.

\subsection{Performance parameters based on DFT results}

First-principles calculations are performed to calculate the band structure, adsorption energy $\left(E_{\mathrm{a}}\right)$, charge transfer $(\Delta Q)$, bandgap $\left(E_{\mathrm{g}}\right)$, charge density difference (CDD), electron localization function (ELF), and density of states (DOS) of the gas molecule-metal sulfide system.

The $E_{\mathrm{a}}$ of gas molecules on a substrate can be calculated as,

$$
E_{\mathrm{a}}=E_{\text {bare system }}+E_{\text {gases }}-E_{\text {total system }}
$$

where $E_{\text {bare system }}, E_{\text {gases }}$, and $E_{\text {total system }}$ are the total energies of the optimized bare metal sulfide, isolated gas molecules, and metal sulfide + gas molecule system, respectively. A negative value of $E_{\mathrm{a}}$ indicates that the adsorption is exothermic. The higher the $E_{\mathrm{a}}$, the stronger the interaction between gas molecules and metal sulfides; $E_{\mathrm{a}}$ has a great influence on the sensitivity/response of the chemiresistive gas sensor. Usually, the selectivity of materials can be determined through the $E_{\text {a }}$ among different types of gases, because the higher the $E_{\mathrm{a}}$, the higher the probability of adsorption towards the specific gas. As shown in Fig. 4, the $E_{\mathrm{a}}$ of the $\mathrm{H}_{2} \mathrm{O} / \mathrm{SnS}$ system is relatively high $(-0.388 \mathrm{eV})$ among the four types of gases in air, which indicates that $\mathrm{SnS}$ has good sensitivity and specificity for the detection of $\mathrm{H}_{2} \mathrm{O}$ in air.

In addition to $E_{\mathrm{a}}$, the electron transport property changes should also be considered. Charge transfer $(\Delta Q)$ is the total charge in the adsorbed gas molecule. It is shown as charge difference after DFT calculation, which can be calculated as follows:

$$
\Delta Q=Q_{\text {total system }}-Q_{\text {bare system }}-Q_{\text {gases }}
$$

where $Q_{\text {total system }}, Q_{\text {bare system }}$, and $Q_{\text {gases }}$ are the total charge on metal sulfide + gases, metal sulfide, and gas molecules, respectively. The amount of charge transferred was calculated 


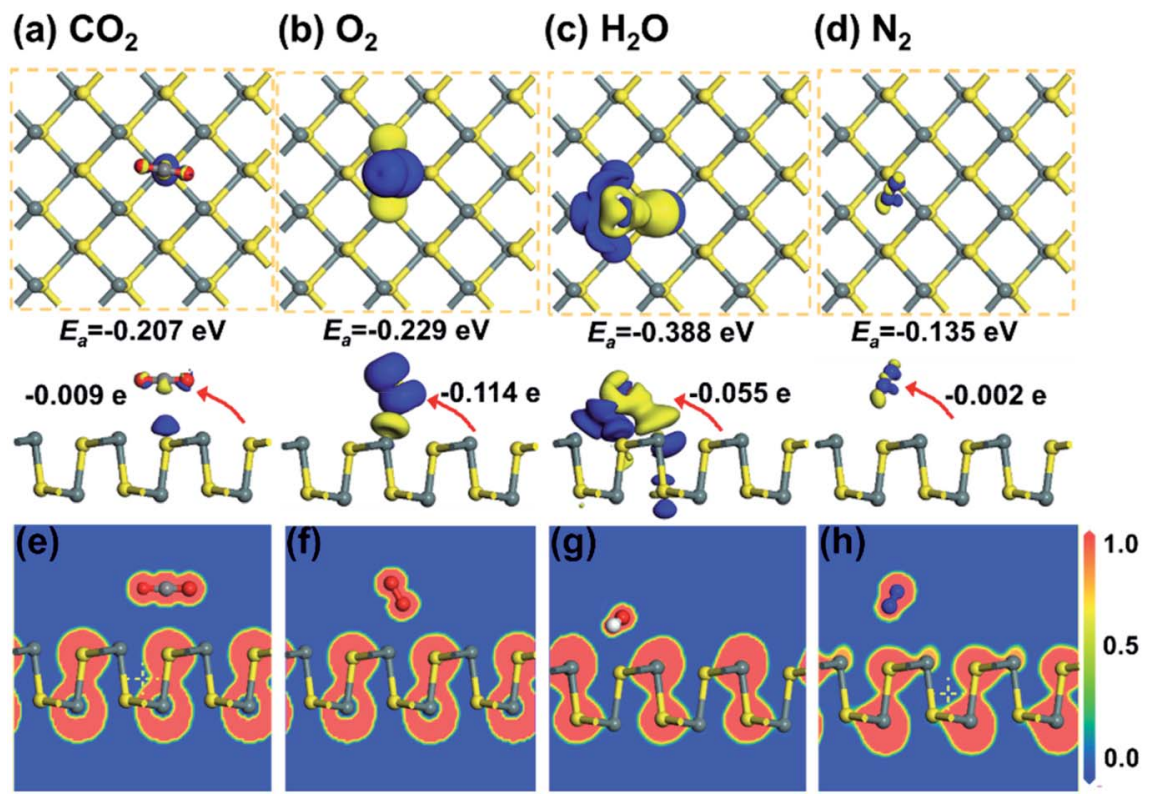

Fig. 4 The CDD for (a) $\mathrm{CO}_{2}$, (b) $\mathrm{O}_{2}$, (c) $\mathrm{H}_{2} \mathrm{O}$, and (d) $\mathrm{N}_{2}$ adsorbed on monolayer SnS. The isosurface is taken as 0.003 e $\AA^{-3}$. (e)-(h) show the corresponding ELF plots. Reprinted with permission from ref. 71. Copyright 2019, @ IOP Publishing. All rights reserved.

by Löwdin analysis. ${ }^{67}$ Some typical CDD images are shown in Fig. $4 \mathrm{a}-\mathrm{d}$. The blue region represents charge accumulation, while the yellow region shows charge depletion. These four types of gas molecule $\left(\mathrm{CO}_{2}, \mathrm{O}_{2}, \mathrm{H}_{2} \mathrm{O}\right.$, and $\left.\mathrm{N}_{2}\right)$ act as charge acceptors and receive electrons of $0.009 e, 0.114 e, 0.055 e$, and $0.002 e$ from SnS, respectively.

In quantum chemistry, ELF is a measure of the possibility of finding an electron in the neighborhood space of a reference electron at a given point and with the same spin. ${ }^{68}$ The ELF provides a method for mapping the electron pair probability in multielectronic systems and a description of electron delocalization in molecules and solids. ${ }^{69}$ It can be used to analyze the extent of spatial localization of the reference electron and classify the chemical bond for almost all classes of compounds. $^{70}$ The ELF plots are normalized and present as

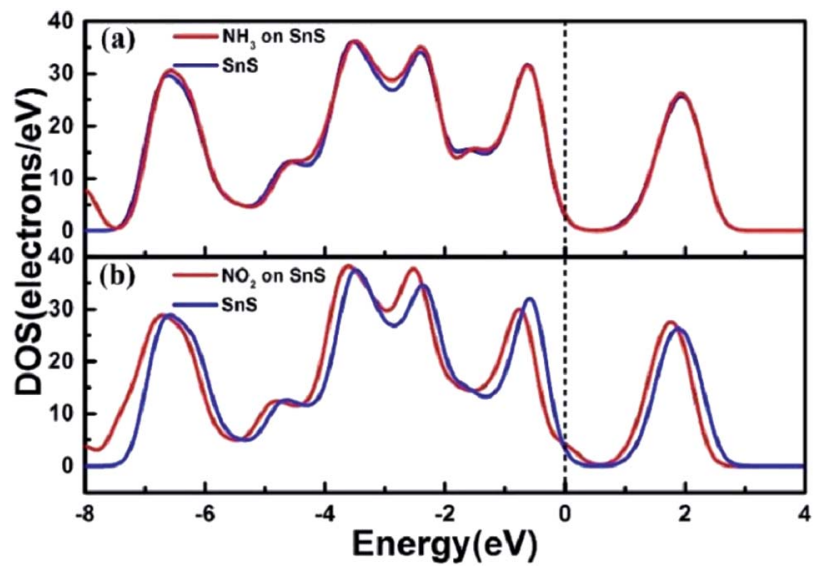

Fig. 5 The total DOS for (a) $\mathrm{NH}_{3}$ and (b) $\mathrm{NO}_{2}$ adsorbed on monolayer $\mathrm{SnS}$. The Fermi level is set as zero. Reprinted with permission from ref. 72. Copyright 2017, IEEE. a jellium-like homogeneous electron. The normalized values of $1.00,0.50$, and 0.00 refer to fully localized electrons, fully delocalized electrons, and very low charge density, respectively. Some typical ELF images are shown in Fig. 4e-h. It is found that there is no remarkable electron sharing between gas molecules and SnS, which indicates that the chemical bond is unformed.

The DOS of a system presents the features of the electronic structure, such as the bandgap in insulators and the width of the valence band. It helps to qualitatively analyze the effects of external stimulations on the electronic structure, such as molecules, pressure, mechanical strain, and electric field. Fig. 5a shows the total DOS of the adsorption system of SnS without and with $\mathrm{NH}_{3}$. The DOS of the SnS system changes slightly after adsorbing $\mathrm{NH}_{3}$ molecules, which is associated with the electronic level

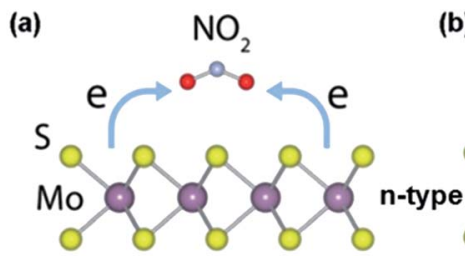

(b) $\quad \mathrm{NH}_{3}$ (c)

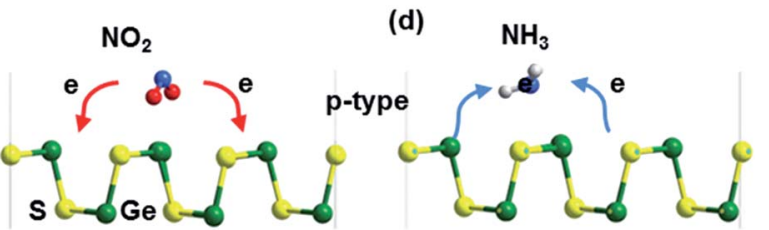

Fig. 6 Gas sensing mechanism of (a and b) $\mathrm{MoS}_{2}$ (n-type metal sulfide). Reprinted with permission from ref. 27. Copyright 2018, ACS Publishing. (c and d) GeS ( $p$-type metal sulfide) in the presence of $\mathrm{NO}_{2}$ and $\mathrm{NH}_{3}$ molecules. Reprinted with permission from ref. 77. Copyright 2018, The Royal Society of Chemistry. 


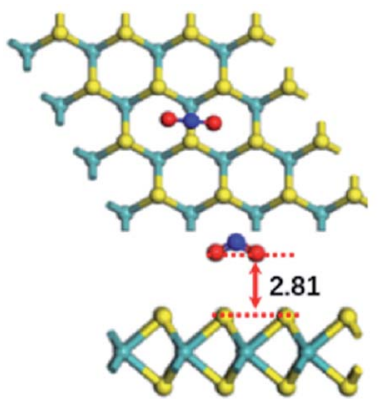

(a) $2 \mathrm{H}-\mathrm{MoS}_{2}$

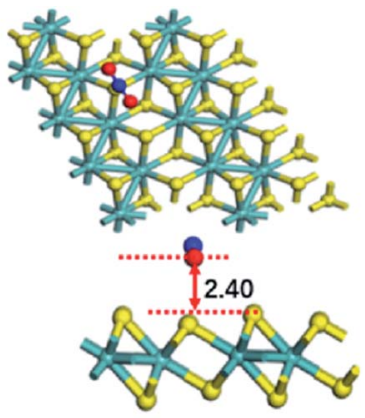

(b) $1 \mathrm{~T}^{\prime}-\mathrm{MoS}_{2}$
Adsorption Energies (eV) of Gas Molecules on Both 2H- and 1T'-MoS2 Monolayers

\begin{tabular}{ccccccc}
$\mathrm{MoS}_{2}$ & $\mathrm{CO}$ & $\mathrm{CO}_{2}$ & $\mathrm{NH}_{3}$ & $\mathrm{SO}_{2}$ & $\mathrm{NO}$ & $\mathrm{NO}_{2}$ \\
\hline $2 \mathrm{H}$ & -0.14 & -0.31 & -0.18 & -0.30 & -0.16 & -0.21 \\
$1 \mathrm{~T}^{\prime}$ & -0.15 & -0.22 & -0.22 & -0.35 & -0.47 & -0.25
\end{tabular}

Fig. 7 Top and side view of the most stable configurations of $\mathrm{NO}_{2}$ molecules adsorbed on (a) $2 \mathrm{H}-\mathrm{MoS}_{2}$ and (b) $1 \mathrm{~T}^{\prime}-\mathrm{MoS}_{2}$. The distance (A) between the molecule (the lowest atom) and the $\mathrm{MoS}_{2}$ sheets (the plane of the uppermost $S$ atoms) is labelled. The bottom table shows the $E_{a}$ of different gases on the $2 \mathrm{H}-\mathrm{MoS}_{2}$ and $1 \mathrm{~T}^{\prime}-\mathrm{MoS}_{2}$ monolayer. Reprinted with permission from ref. 79. Copyright 2019, ACS Publishing.

localized between $-4 \mathrm{eV}$ and $-2 \mathrm{eV}$ in the valence band. However, concerning the $\mathrm{NO}_{2} / \mathrm{SnS}$ system, there are obvious changes of the DOS on both sides near the Fermi level, which reveals the strong interaction between $\mathrm{NO}_{2}$ and $\mathrm{SnS}$ (Fig. 5b).

\subsection{Gas sensing mechanisms}

\subsubsection{Pristine metal sulfides}

$N$-type and p-type metal sulfides. When exposed to gases, the charge transfer reaction occurs between the sensing materials and the adsorbed gases, accompanied by different transfer directions and quantities of charges, which leads to different

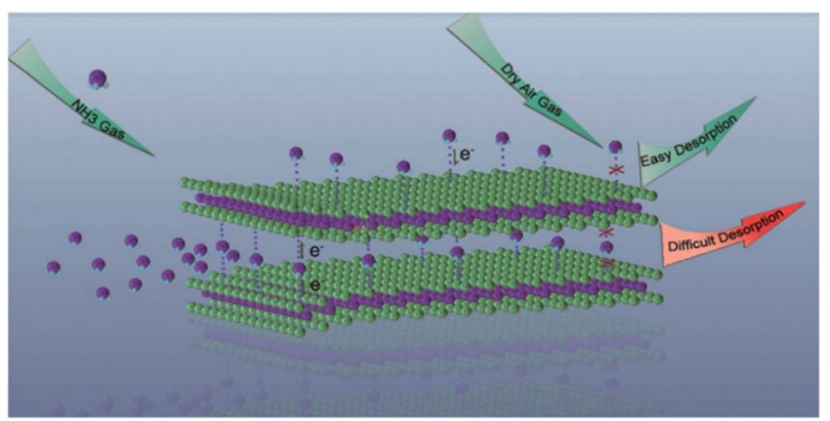

Fig. 9 The schematic of the interfacial interaction between the surface and interlayer of $\mathrm{WS}_{2}$ and $\mathrm{NH}_{3}$ molecules. Reprinted with permission from ref. 81. Copyright 2017, Elsevier.

changes in the material resistance. If the sensing materials are re-exposed to air, desorption of gas molecules occurs, causing the sensing material resistance to return to its initial state. ${ }^{73}$ As shown in Fig. 6, when n-type $\mathrm{MoS}_{2}$ is exposed to oxidizing gases such as $\mathrm{O}_{2}, \mathrm{H}_{2} \mathrm{O}, \mathrm{NO}, \mathrm{NO}_{2}$, and $\mathrm{CO}$, the electron charges transfer from $\mathrm{MoS}_{2}$ to the sensitive gases, leading to a decreased carrier density in $\mathrm{MoS}_{2}$. As a result, the resistance of n-type $\mathrm{MoS}_{2}$ increases. In contrast, reducing $\left(\mathrm{NH}_{3}\right)$ gas molecules adsorbed on $\mathrm{MoS}_{2}$ act as charge donors and transfer electrons to the $\mathrm{MoS}_{2}$ monolayer, increasing the electron carrier density of the n-type $\mathrm{MoS}_{2}$ monolayer and reducing its resistance. ${ }^{74}$ Among posttransition metal sulfides, GeS is a p-type semiconductor, where the electron-accepting gases act as charge donors to GeS and $\mathrm{NH}_{3}$ molecules trap electrons from GeS. Besides, lots of DFT calculations proved that gas molecules adsorb more strongly at the edge sites than at the basal plane of metal sulfides. $^{75,76}$

$2 \mathrm{H}$ and $1 T^{\prime}$ phase of metal sulfides. $2 \mathrm{H}$ phase group VIB metal disulfides are usually semiconducting, and the corresponding

\section{(a)}

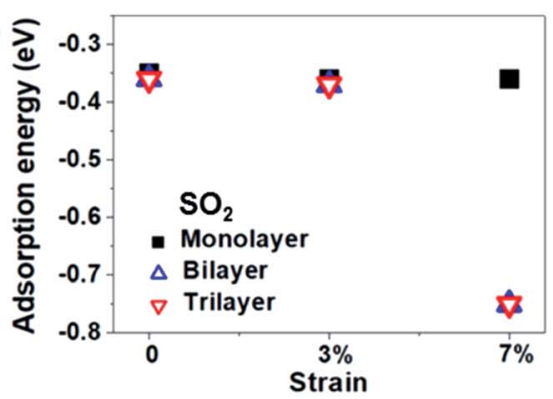

(c)

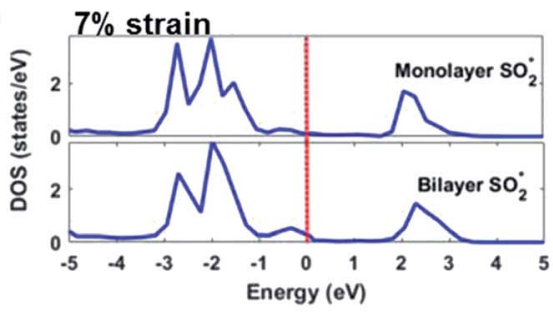

(b)

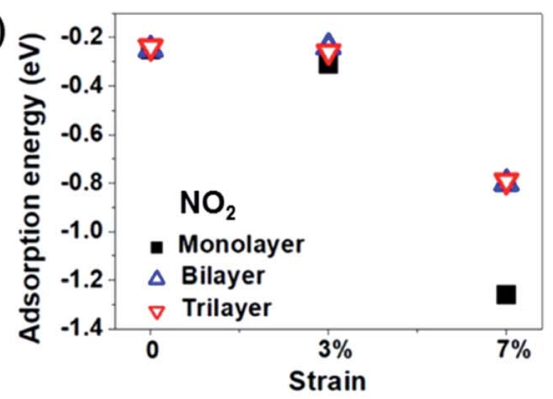

(d)

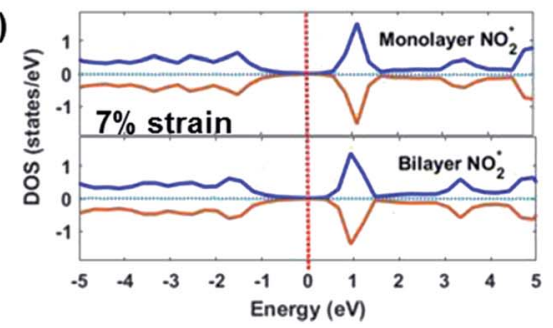

Fig. 8 Adsorption energies of (a) $\mathrm{SO}_{2}$ and (b) $\mathrm{NO}_{2}$ on $1 \mathrm{~T}^{\prime}-\mathrm{MoS}_{2}$ sheets with a different number of layers and different strains. Total DOS of $\mathrm{MoS} 2$ monolayer and bilayer systems at $7 \%$ strain adsorbed by (c) $\mathrm{SO}_{2}$ and (d) $\mathrm{NO}_{2}$. Reprinted with permission from ref. 79. Copyright 2019, ACS Publishing. 
$1 \mathrm{~T}, 1 \mathrm{~T}^{\prime}$, and $\mathrm{Td}$ phase crystals are metallic. Different phases of metal sulfides have different $E_{\mathrm{a}}$ of the gas molecules over the sensor's surface. Putungan et al. ${ }^{78}$ demonstrated that $1 \mathrm{~T}^{\prime}-\mathrm{MS}_{2}$ $(\mathrm{M}=\mathrm{Mo}, \mathrm{W})$ are more stable than their 1T phases, ideal candidates for hydrogen evolution reaction (HER) catalysts. Linghu et al. ${ }^{79}$ proved that the $\mathrm{H}$ adsorption strength on the basal plane of $1 \mathrm{~T}^{\prime}-\mathrm{MoS}_{2}$ is approximately $1.5 \mathrm{eV}$ higher than that of $2 \mathrm{H}-\mathrm{MoS}_{2}$ because the molecules are closer to the $1 \mathrm{~T}^{\prime}-\mathrm{MoS}_{2}$ surface, allowing closer and stronger interaction. Besides, the $1 \mathrm{~T}^{\prime}$ - $\mathrm{MoS}_{2}$-based sensors have higher $E_{\mathrm{a}}$ towards gas molecules (i.e., $\mathrm{CO}_{x}, \mathrm{NH}_{3}, \mathrm{SO}_{2}$, and $\mathrm{NO}_{x}$ ) than the sensors of $2 \mathrm{H}-\mathrm{MoS}_{2}$. The table in Fig. 7 reveals that $1 \mathrm{~T}^{\prime}-\mathrm{MoS}_{2}$ has high sensitivity and selectivity toward NO gas molecules. Tang et al. ${ }^{80}$ compared and analyzed the stability and band-gap state of the $2 \mathrm{H}$ phase and $1 \mathrm{~T}$ phase $\mathrm{MoS}_{2}$ by covalent functionalization with $\mathrm{H}, \mathrm{CH}_{3}, \mathrm{CF}_{3}$, $\mathrm{OCH}_{3}$, and $\mathrm{NH}_{2}$. The results showed that the chemical bonding is strong in the $1 \mathrm{~T}$ phase but very weak in the $2 \mathrm{H}$ phase, associated with the metallicity and partially filled Mo $4 \mathrm{~d}$ states of $1 \mathrm{~T}$ $\mathrm{MoS}_{2}$.

The effects of the number of layers. It is well known that the number of layers affects the electronic properties of $2 \mathrm{D}$ materials. Based on the experimental results, it is found that multilayer or few-layer $\mathrm{MoS}_{2}$ was more stable and showed better gas sensing performance than its monolayer counterpart. ${ }^{\mathbf{8 2} 83}$ Concerning the DFT analysis results, Linghu et al. ${ }^{79}$ investigated the adsorption behaviour of $\mathrm{SO}_{2}, \mathrm{NH}_{3}, \mathrm{NO}$, and $\mathrm{NO}_{2}$ on bilayered and trilayered $1 \mathrm{~T}^{\prime}-\mathrm{MoS}_{2}$ sheets, as shown in Fig. 8. The $1 \mathrm{~T}^{\prime}-\mathrm{MoS}_{2}$ sheets with different thickness show only an approximately $0.01 \mathrm{eV}$ change from the monolayer sheets without external mechanical strain. After applying $7 \%$ strain, the $E_{\mathrm{a}}$ of the trilayered system changes significantly compared to that of the monolayer systems. This is associated with the new hybridized states or the occupied states of the gases near the Fermi level. Furthermore, the number of layers influences the recovery time of the devices. Qin et $a{ }^{\mathbf{8 1}}$ found that the recovery time after detecting $\mathrm{NH}_{3}$ has an anti-linear relationship with the number of layers. According to their DFT calculation results, the $E_{\mathrm{a}}$ of the $\mathrm{NH}_{3}$ molecule intercalated into the interlayer of $\mathrm{WS}_{2}$ $(-0.356 \mathrm{eV})$ is higher than that of surface desorption $(-0.179$ $\mathrm{eV}$ ), as shown in Fig. 9. The ratio of intercalated $\mathrm{NH}_{3}$ to surfaceadsorbed $\mathrm{NH}_{3}$ becomes larger as the layer number increases. Therefore, the more the layers of $\mathrm{WS}_{2}$, the longer the recovery time that is needed.

2.2.2 Doped metal sulfides. Chemical doping is an efficient way to change the band structure, modify the electronic and transport properties, and enhance the gas sensing applications. Metal doping is the most common method used for metal sulfides. Fig. 10 shows that typically doped metal atoms (i.e., V, $\mathrm{Nb}$, and $\mathrm{Ta}$ ) replace the Mo atoms of metal sulfides. Table 3 lists the different types of metal dopants for monolayer $\mathrm{MoS}_{2}$, such

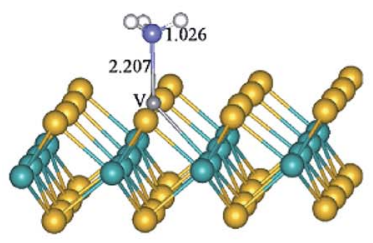

(a)

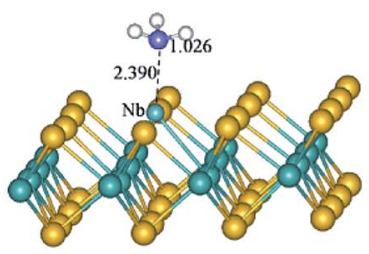

(d)

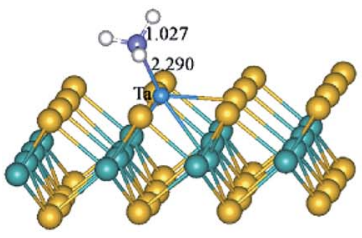

(g)

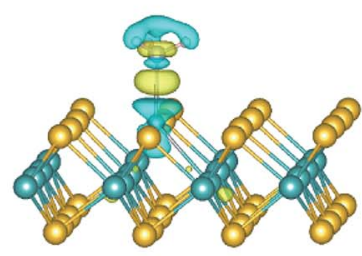

(b)

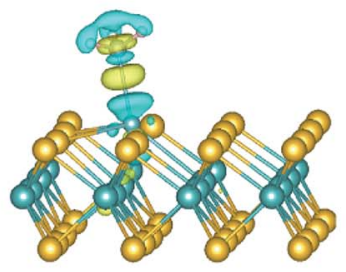

(e)

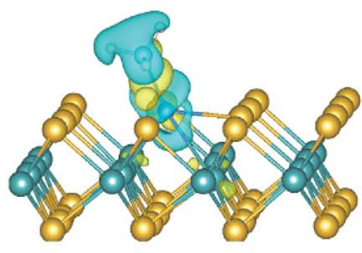

(h)

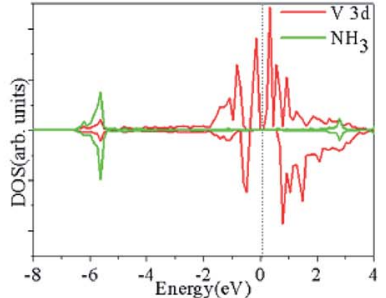

(c)

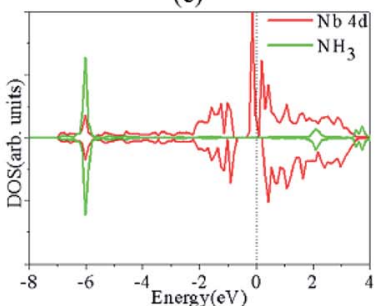

(f)

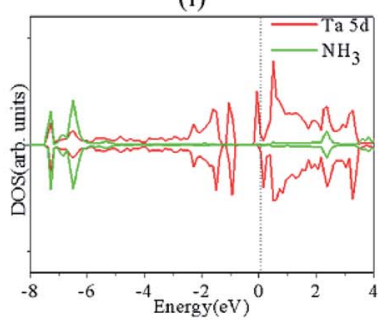

(i)

Fig. 10 The optimized structures, CDD, and corresponding spin-polarized DOS projected on $3 \mathrm{~d}$ states of $\mathrm{V}$ atoms, adsorbed gas molecules of $\mathrm{NH}_{3}$ adsorbed on the monolayer $\mathrm{MoS}_{2}$ with $\mathrm{V}(\mathrm{a}, \mathrm{b}$ and $\mathrm{c}), \mathrm{Nb}$ ( $\mathrm{d}$, e and f), and Ta ( $\mathrm{g}, \mathrm{h}$ and i) doped in the S-vacancy, respectively. The Mo, S, N, $\mathrm{H}, \mathrm{V}, \mathrm{Nb}$, and Ta atoms are denoted by dark green, yellow, purple, white, light grey, light green, and blue spheres, respectively. The yellow and cyan regions represent the positive (electron accumulation) and negative (electron depletion) values, respectively. The isosurface value is taken as 0.003 e $\AA^{-3}$. The vertical dashed line indicates the position of the Fermi level, taken as zero energy. Reprinted with permission from ref. 37. Copyright 2017, Elsevier. 
Table 3 Literature study on the $E_{\mathrm{a}}$ of doped metal sulfide nanomaterials with different gas molecules

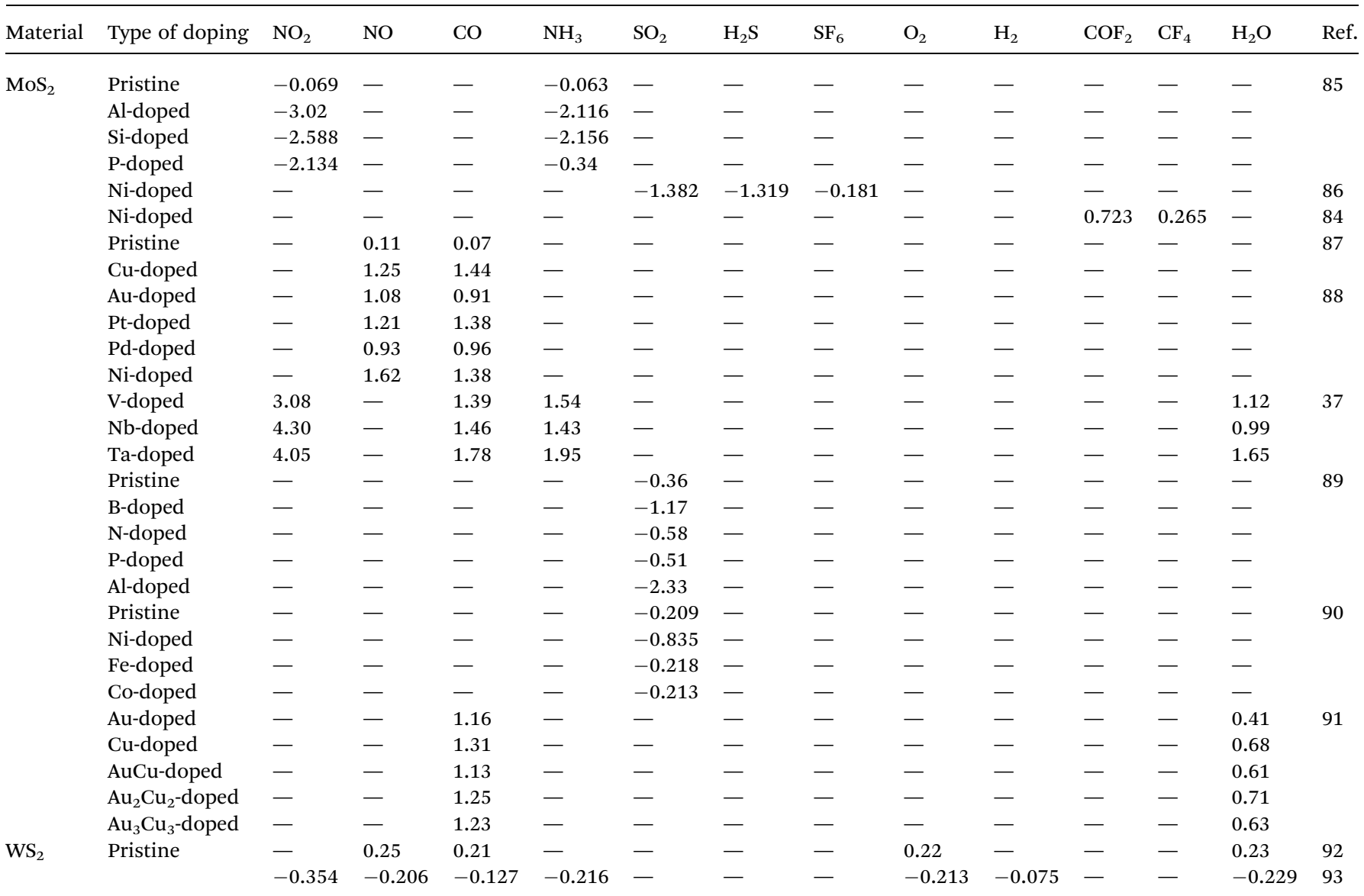

as $\mathrm{Al}, \mathrm{Si}, \mathrm{P}, \mathrm{Ni}, \mathrm{Cu}, \mathrm{Au}, \mathrm{Pt}, \mathrm{Pd}, \mathrm{V}, \mathrm{Nb}, \mathrm{Ta}, \mathrm{B}, \mathrm{N}, \mathrm{Fe}, \mathrm{Co}$, and $\mathrm{Au}_{x} \mathrm{Cu}_{y}$, and their $E_{\mathrm{a}}$ after adsorbing different gas molecules $\left(\mathrm{NO}_{x}, \mathrm{CO}\right.$, $\mathrm{NH}_{3}, \mathrm{SO}_{2}, \mathrm{H}_{2} \mathrm{~S}, \mathrm{SF}_{6}, \mathrm{O}_{2}, \mathrm{H}_{2}$, carbonyl fluoride $\left(\mathrm{COF}_{2}\right)$, cobalt tetrafluoride $\left(\mathrm{CF}_{4}\right)$, and $\left.\mathrm{H}_{2} \mathrm{O}\right)$. Based on the DFT results of all the metal-doped $\mathrm{MoS}_{2}$ listed in Table 3, Ta-doped $\mathrm{MoS}_{2}$ has the highest $E_{\mathrm{a}}$ of $4.30 \mathrm{eV}$ towards $\mathrm{NO}_{2}, 1.78 \mathrm{eV}$ towards $\mathrm{CO}$, and $1.65 \mathrm{eV}$ towards $\mathrm{H}_{2} \mathrm{O}$; Si-doped $\mathrm{MoS}_{2}$ shows a high $E_{\mathrm{a}}$ of $2.156 \mathrm{eV}$ to $\mathrm{NH}_{3} ; \mathrm{Al}$-doped $\mathrm{MoS}_{2}$ shows an $E_{\mathrm{a}}$ of 2.33 to $\mathrm{SO}_{2}$. Besides, $\mathrm{Li}$ et al. ${ }^{84}$ demonstrated that Ni-doped $\mathrm{MoS}_{2}$ has great potential for sensing applications in organic gas molecules, such as $\mathrm{COF}_{2}$ and $\mathrm{CF}_{4}$.

2.2.3 Defective metal sulfides. It is known that the $\mathrm{MoS}_{2}$ monolayer exhibits naturally formed vacancies, such as $\mathrm{S}$ vacancies $\left(\mathrm{V}_{\mathrm{S}}\right)$ and Mo vacancies $\left(\mathrm{V}_{\mathrm{Mo}}\right)$, which have significant impacts on the gas sensing performance. ${ }^{\mathbf{9 4}-97}$ Zhao et al. ${ }^{\mathbf{9 4}}$ investigated various defects in monolayer $\mathrm{MoS}_{2}$, including monosulfur vacancies $\left(\mathrm{V}_{\mathrm{S}}\right)$, disulfur vacancies $\left(\mathrm{V}_{\mathrm{S}_{2}}\right)$, Mo vacancies $\left(\mathrm{V}_{\mathrm{Mo}}\right)$, a vacancy complex of Mo with three $\left(\mathrm{V}_{\mathrm{MoS}_{3}}\right)$ or six $\left(\mathrm{V}_{\mathrm{MoS}_{6}}\right)$ nearby sulfur vacancies, antisite defects where a Mo atom is substituting a sulfur atom $\left(\mathrm{Mo}_{\mathrm{S}}\right)$ or an $\mathrm{S} 2$ column $\left(\mathrm{Mo}_{\mathrm{S} 2}\right)$, antisite defects where a sulfur atom $\left(\mathrm{S}_{\mathrm{Mo}}\right)$ or $\mathrm{S} 2$ column $\left(\mathrm{S} 2_{\mathrm{Mo}}\right)$ substitutes a Mo, and an external Mo (Mo-In). They found that four types of defect systems were stable after geometry optimizations, as shown in Fig. 11. These are monosulfur vacancies $\left(\mathrm{MoS}_{2}-\mathrm{V}_{\mathrm{S}}\right)$, disulfur vacancies $\left(\mathrm{MoS}_{2}-\mathrm{V}_{\mathrm{S}_{2}}\right)$, antisite defects $\left(\mathrm{MoS}_{2}-\mathrm{Mo}_{\mathrm{S}}\right)$, and external Mo atoms $\left(\mathrm{MoS}_{2}-\right.$ Mo). The corresponding $E_{\mathrm{a}}$ values after adsorbing $\mathrm{O}_{2}$ are $-1.822,-1.687,-3.293$, and $-2.545 \mathrm{eV}$ for $\mathrm{MoS}_{2}-\mathrm{V}_{\mathrm{S}}-\mathrm{O}_{2}, \mathrm{MoS}_{2}-$ $\mathrm{V}_{\mathrm{S}_{2}}-\mathrm{O}_{2}, \mathrm{MoS}_{2}-\mathrm{Mo}_{\mathrm{S}}-\mathrm{O}_{2}$, and $\mathrm{MoS}_{2}-\mathrm{Mo}-\mathrm{O}_{2}$, respectively. All of them are much stronger than that of pristine $\mathrm{MoS}_{2}(-0.01 \mathrm{eV})$.

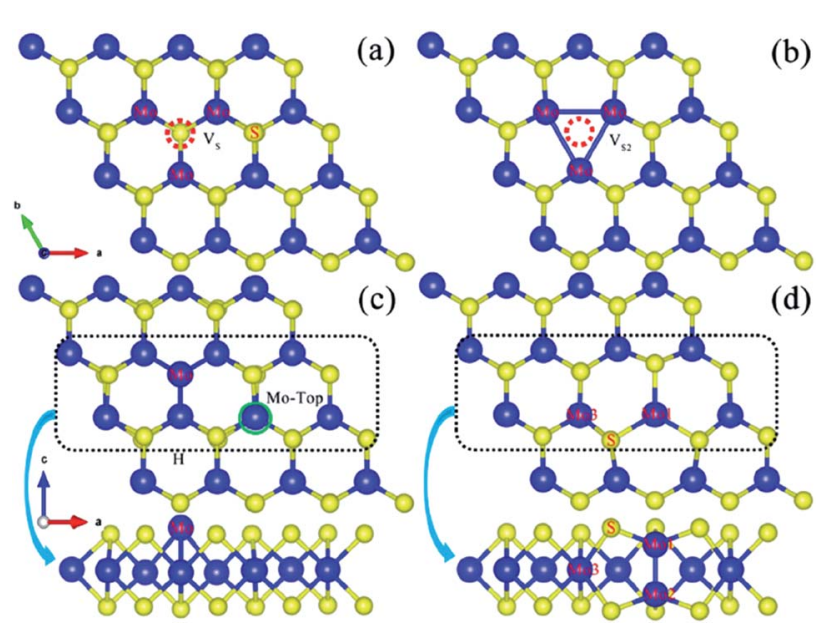

Fig. 11 Optimized geometric structure of the defect within a monolayer $\mathrm{MoS}_{2}$ : (a) monosulfur vacancy $\left(\mathrm{V}_{\mathrm{S}}\right)$, (b) disulfur vacancy $\left(\mathrm{V}_{\mathrm{S}_{2}}\right)$, (c) antisite $\mathrm{Mo}_{\mathrm{S}}$, and (d) an external Mo located on the top of the Mo lattice site. Reprinted with permission from ref. 94. Copyright 2017, Elsevier. 
(a)
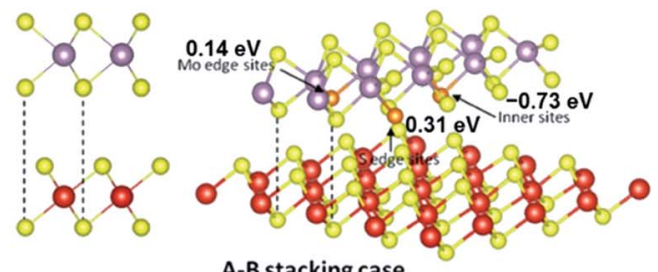

A-B stacking case

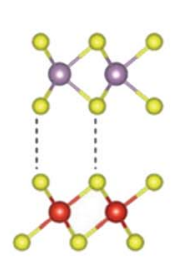

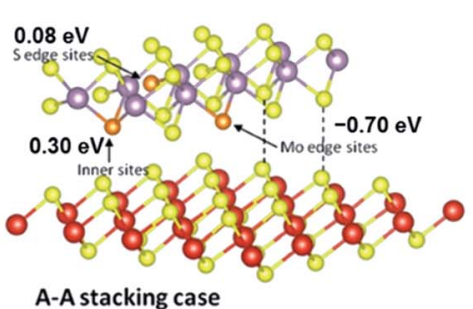

(b)

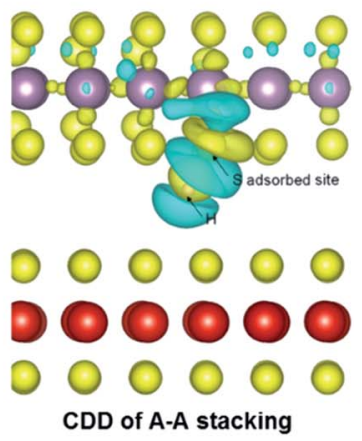

Fig. 12 (a) Two types of stacked bilayer structural models and their adsorption configurations. (b) CDD of the A-A stacking case (right) of the $\mathrm{VS}_{2}\left(\mathrm{aMoS}_{2}\right.$-edge nanosheet. The cyan and yellow regions represent the charge depletion and accumulation space, respectively. Reprinted with permission from ref. 35 Copyright 2017, ACS Publishing.

The CDD results reveal typical chemisorption of $\mathrm{O}_{2}$ on the defective surface, which is associated with the $\mathrm{O}-\mathrm{O}$ bond length extension in varying degrees.

2.2.4 Metal sulfide-based heterojunctions. Different stacking methods affect the $E_{\mathrm{a}}$ of the gas/substrate system. As shown in Fig. 12a, $\mathrm{MoS}_{2} / \mathrm{VS}_{2}$ heterojunctions with $\mathrm{A}-\mathrm{B}$ and $\mathrm{A}-\mathrm{A}$ stacking are built and used to investigate their hydrogen evolution ability. ${ }^{35}$ The Gibbs free energies of the inner sites and Mo and $S$ edge sites of the A-B and A-A stacking cases were also compared. The corresponding energies were calculated to be $-0.73,0.14$, and $0.31 \mathrm{eV}$ for the A-B stacking cases and -0.70 , 0.08 , and $0.30 \mathrm{eV}$ for the A-A stacking cases. The difference of energies in these two stacking cases is associated with the bandgap barrier from $\mathrm{VS}_{2}$ to $\mathrm{MoS}_{2}$, which induces different internal charge transfer. The CDD image in Fig. 12b further proves the charge transfer between the adjacent $\mathrm{H}$ atoms and the $\mathrm{S}$ atom. There is still a lack of DFT simulation results of the gas molecule/heterojunction system for metal sulfides. Lots of experimental results are analyzed based on bandgap theory, which will be described in the next section.

\section{Various sensing concepts of metal sulfide-based devices}

Based on the gas sensing mechanism, metal sulfide-based devices can be classified into chemiresistors, Schottky junctions, heterojunctions, field-effect transistors (FETs), and optical and surface acoustic wave (SAW) gas sensors. In this section, we introduce the performance parameters as well as the sensing concepts of these devices.

\subsection{Performance parameters}

Typically, the criteria of an efficient gas sensor consist of high sensitivity and selectivity, fast response and recovery time, longterm stability, and low power consumption. Here, a set of parameters is defined to evaluate and compare the performance of different sensors, including response, sensitivity, selectivity, LOD, dynamic range, response and recovery time, and stability.

3.1.1 Response. The response is defined as the change in measured current $(I)$, resistance $(R)$, capacitance $(C)$, conductance $(G=I / V)$, light power $(P)$, effective refractive index (RI), and resonant frequency $(f)$ for a given gas concentration unit concerning the signal in the absence of analyte molecules. It is defined as:

$$
\left(X_{\text {gas }}-X_{0}\right) / X_{0}=\Delta X / X_{0}
$$

where $X=I, R, C, G, P$, RI, or $f, X_{\text {gas }}$ is the sensor's signal after adsorbing the analyte gas, and $X_{0}$ is the baseline signal (no analyte gas). Different concentrations of the analyte gas could induce different responses. This review uses response in percentage $($ response $\%)=$ response $\times 100 \%$ to present the change of the testing signal.

3.1.2 Sensitivity. Sensitivity is defined as the capability to discriminate small differences in concentration or mass of the analyte. In other words, the sensitivity of the sensor is the slope of the calibration graph, which represents the variation in the sensor response per unit concentration of the target gas. In other words, sensitivity $(S)=$ response/concentration. Thus, a higher sensitivity indicates a higher efficiency of the sensor.

3.1.3 Selectivity. Selectivity refers to the strong adsorption of target gases in the mixed gas, while being insensitive to other gases. The selectivity factor/coefficient $(K)$ of the 'target gas' to another gas is defined as:

$$
K=S_{1} / S_{2}
$$

where $S_{1}$ and $S_{2}$ are the sensitivities of the sensor to a target gas and another gas, respectively.

$L O D$ is a key figure of merit in chemical sensing, used as an indicator of the minimum concentration of a detectable analyte. ${ }^{98}$ Traditionally, LOD formulas, according to the International Union of Pure and Applied Chemistry (IUPAC), are based 
on the use of linear regression models. ${ }^{98}$ When the signal is three times greater than the noise, the theoretical LOD can be calculated from the slope of the linear region of the response curve, namely "Sensitivity $(S)$ " and the root-mean-square (RMS) deviation at the baseline,

$$
\mathrm{LOD}=3 \times \mathrm{RMS}_{\text {noise }} / S
$$

where $\mathrm{RMS}_{\text {noise }}$ is the noise level in the absence of the analyte gas. Concerning the LOD in non-linear gas sensors, including metal oxide sensors, gas FETs, or thermoelectric sensors, Burgués et al. ${ }^{99}$ proposed a methodology to estimate LOD through linearized calibration models.

operating temperature (OT) is the temperature that corresponds to maximum sensitivity.

3.1.4 Response and recovery time. The response time $\left(\tau_{\mathrm{s}}\right)$ and recovery time $\left(\tau_{\mathrm{r}}\right)$ are defined as the time required for reaching $90 \%$ of the final response and the time taken to recover $90 \%$ of the original value of the device. They are mostly used as an index of the speed of response, which is highly dependent on the types of gases, the device structure, and the exposure time.

Stability is defined as the ability of a sensor to provide consistent and reproducible results for a specified period. This parameter becomes highly important when sensors are exposed to hazardous, corrosive, or high-temperature atmospheres.

Usually, an ideal gas sensor would possess high sensitivity, selectivity and stability, low LOD, and short recovery and response times. But its final application depends on the requirements of the specified environment or working conditions. Moreover, all the parameters could be affected by other factors, including the sensing materials, substrate, environmental factors (temperature, humidity, and pressure), and testing setup (volume, shape, and gas flow rate).

\subsection{Chemiresistor gas sensors}

Typically, different types of metal sulfides, such as nanoflakes (NFKs), nanosheets (NSs), nanowires (NWs), nanorods (NRs), nanoflowers (NFWs), or nanotubes (NTs), are synthesized or transferred on a substrate (i.e., sapphire, $\mathrm{Si}$, and $\mathrm{SiC}$ ) to form a chemiresistor sensor, as shown in Fig. 13. The electrodes can be pre-made on the substrate or evaporated on the top of metal sulfides after the transfer process.

As mentioned in Section 2.2, the basic sensing principle is metal sulfides act as charge acceptors or donors. Their shallow valence band, small effective mass, and diverse structures enable a quantum size effect and promising applications in gas

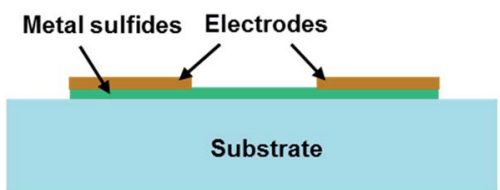

Fig. 13 Schematic of the structure of a metal sulfide-based chemiresistor gas sensor. sensing. The typical direct narrow bandgap IV-VI compound semiconductors, such as $\mathrm{SnS}, \mathrm{PbS}$, and $\mathrm{GeS}$, have similar puckered structures to black phosphorus. ${ }^{30,31}$ They have been employed for the detection of toxic $\left(\mathrm{NO}_{2}, \mathrm{NH}_{3}\right.$, and $\left.\mathrm{H}_{2} \mathrm{~S}\right)$ and organic (e.g., acetone and ethanol) gas molecules. The response and recovery time is fast (5-36 s). ${ }^{\mathbf{3 3 1 0 0 , 1 0 1}}$ The II-VI compound semiconductors mostly have a direct wide bandgap, including CdS and ZnS. They have high response and selectivity to VOCs, including isopropanol, methanol, ethanol, acetone, and methylbenzene. However, their OTs are relatively high (200-300 $\left.{ }^{\circ} \mathrm{C}\right) .{ }^{\mathbf{1 0 2 , 1 0 3}}$ Other metal monosulfide-based gas sensors, such as CuS and NiS, also have potential applications in $\mathrm{H}_{2}$ and $\mathrm{SO}_{2}$ gas sensing. ${ }^{\text {104-106}}$ According to Kim's research, 75\% of publications up to 2017 were focused on $\mathrm{MoS}_{2}$ followed by $\mathrm{WS}_{2}$ (14\%) and $\mathrm{SnS}_{2}(9 \%) .^{13}$ The predominance of $\mathrm{MoS}_{2}$ over other metal disulfides is because this material is the easiest to synthesize and the most stable among transition metal sulfides. Most transition metal sulfides are composed of metal atoms sandwiched between two layers of hexagonally close-packed sulfur (S) atoms; the adjacent S layers are connected by the weak van der Waals forces. They have a larger electronegativity, potentially increasing the number of gas adsorption sites. Thus various transition metal sulfides, including $\mathrm{NbS}_{2}, \mathrm{ReS}_{2}, \mathrm{TaS}_{2}$, and $\mathrm{VS}_{2}$, were used for gas sensing in $\mathrm{NO}_{x}, \mathrm{NH}_{3}, \mathrm{O}_{2}$, and ethanol.

Functionalization is a versatile method for the modulation of the electronic and chemical properties of metal sulfides. As discussed in Section 2.2, doping and defect substitution are the most commonly used tools in functionalization, which can change the electronic structure, modify chemical reactivity, and affect the sensing performance. ${ }^{108}$ Fig. 14 shows a hydrogen sensor with few-layered Pd-doped $\mathrm{MoS}_{2}$ and various point defects in CVD-MoS ${ }_{2}{ }^{36,107}$ Qin et al. ${ }^{109}$ demonstrated an enhanced $\mathrm{NH}_{3}$ sensor based on $2 \mathrm{D} \mathrm{SnS} \mathrm{S}_{2}$ with sulfur vacancies. It showed a fast response time of $16 \mathrm{~s}$ toward $500 \mathrm{ppm} \mathrm{NH}_{3}$. The enhanced sensitivity is associated with the high $E_{\mathrm{a}}$ of the defective system of $2 \mathrm{D} \mathrm{SnS}_{2}$. However, most of the gas-sensing behaviours of functionalized metal sulfides were analyzed through DFT calculations. There are a lack of experimental reports on the influence of defects on the metal sulfide-based devices' gas-sensing performance.

\subsection{Schottky junction}

Typically, a metal-semiconductor (M-S) junction is a type of heterostructure where a metal is in close contact with a semiconductor material. The rectifying $\mathrm{M}-\mathrm{S}$ junction is called a Schottky junction, while the non-rectifying junction forms an ohmic contact. Recently, researchers reported that a Schottky or an ohmic contact can also be formed between an atomic CNM and a semiconductor, depending on their electron affinity values. ${ }^{8}$ Fig. 15a shows a typical Schottky junction, in which the electrons flow from the conduction band to the semiconductor layer until they reach equilibrium. This forms a Schottky barrier (SB) of the built-in potential barrier $\left(V_{\mathrm{bi}}\right)$ in the contact layer and hinders further charge transport. ${ }^{\mathbf{1 1 0}}$ The Schottky barrier height $(\mathrm{SBH})$ from the metal side remains unchanged, while the bias 

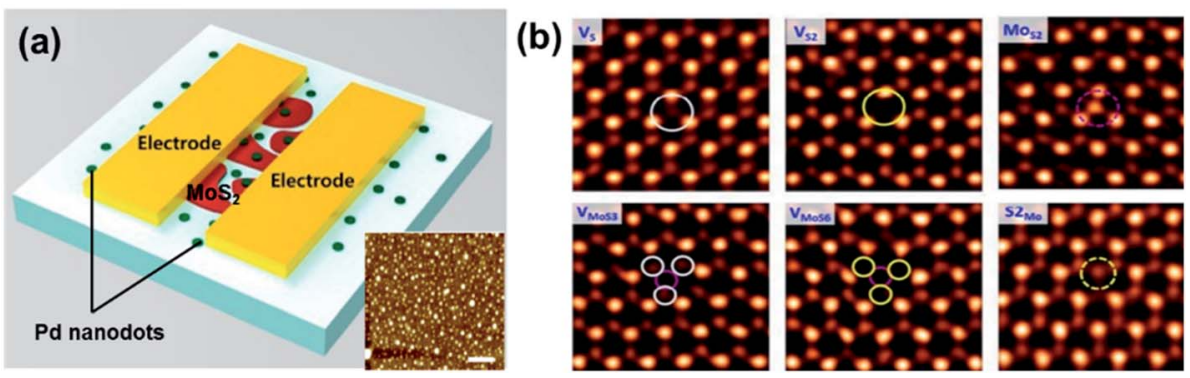

Fig. 14 (a) Schematic of a Pd-doped $\mathrm{MoS}_{2}$-based sensor. The inset image shows the AFM image of Pd on a $\mathrm{SiO}_{2}$ substrate. The scale bars indicate a distance of $400 \mathrm{~nm}$. Reprinted with permission from ref. 107. Copyright 2017, Elsevier. (b) Image analysis for intrinsic point defects in ML MoS 2 . Reprinted with permission from ref. 36. Copyright 2013, ACS Publishing.

across the junction could change according to the work function of the semiconductor $\left(\varphi_{\mathrm{s}}\right)$. As shown in Fig. $15 \mathrm{~b}(\mathrm{i}-\mathrm{v})$, the $\mathrm{SBH}$ was controlled using different metals $(\mathrm{Au}, \mathrm{Ag}$, and $\mathrm{Al})$ as the materials of electrodes. The adsorbed gas molecules, i.e., $\mathrm{CO}_{x}$, are a kind of dopant for the semiconductor, which could modify the doping level of materials and modulate the $\varphi_{\mathrm{s}}$ in turn (see Fig. $15 \mathrm{~b}$ (iv and v)). ${ }^{111}$ The SB is determined from the difference between $\varphi_{\mathrm{m}}$ and $\varphi_{\mathrm{s}}$, strongly influenced by the gas molecules. Therefore, the SBH is easily varied owing to the change of the gas concentration. Fig. 15 b(ii) shows that the response to $\mathrm{CO}$ gas is improved in devices after using the Ag electrode due to the increase in SBH, which means that the Schottky contact sensor could improve the sensitivity because the modulations of the $\varphi_{\mathrm{B} 0}$ and barrier width in the Schottky junction by gas molecules are concentrated in the tiny area of contact between the metal and metal sulfides and the Schottky diode-based sensor can detect ultralow levels. ${ }^{112,113}$ Besides, the sensing performances of vdW vertical heterojunctions of CNMs and metal sulfides are not only associated with the SBH modulation mechanism but also with the abundant adsorption sites on the CNMs' surfaces. This enables a significant enhancement of the device sensitivity toward the ppb level of $\mathrm{NO}_{2}$ gas exposure reaching $4.9 \% / \mathrm{ppb}(4900 \% / \mathrm{ppm}) .{ }^{114}$

\subsection{Heterojunction based gas sensors}

Heterojunctions based on metal sulfide can be easily constructed and present superior electric and photoelectric properties compared to pristine metal sulfide owing to the abundant adsorption sites and unique interface state at the contact interface. ${ }^{115}$ According to the type of semiconductors, 2D heterojunctions can be classified as $\mathrm{p}-\mathrm{n}, \mathrm{n}-\mathrm{n}$, and $\mathrm{p}-\mathrm{p}$ junctions.

3.4.1 $p-n$ junction. The band alignment of a $p-n$ heterojunction is shown in Fig. 16a; electrons and holes flow in opposite directions until equilibrium is achieved, forming a thick space-charge region that further narrows the electrical transport channels. Mostly, in $\mathrm{p}-\mathrm{n}$ heterojunction gas sensors,
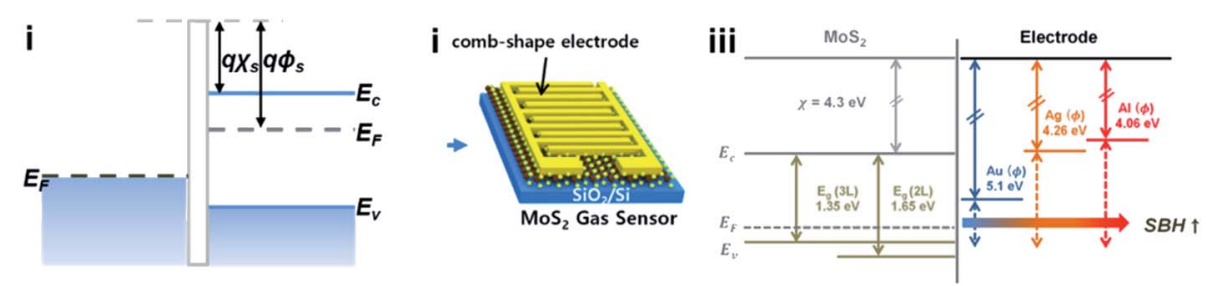

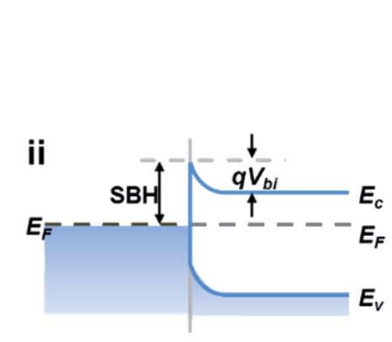

(a)
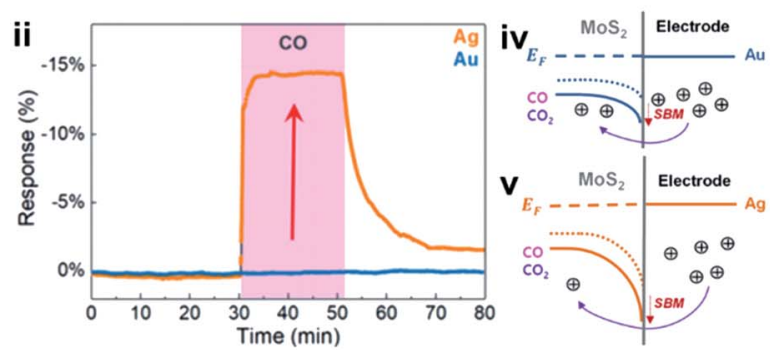

(b)

Fig. 15 Band alignment of (a) the Schottky junction. $E_{\mathrm{C}}, E_{\mathrm{F}}$, and $E_{\mathrm{v}}$ are the conduction band edge, Fermi level, and valence band edge of the semiconductor, respectively. $\varphi_{\mathrm{m}}, \varphi_{\mathrm{s}}$, and $\chi_{\mathrm{s}}$ are the metal work function (measured in volts), the semiconductor work function, and electron affinity, respectively. $\varphi_{\mathrm{BO}}, V_{\mathrm{bi}}$, and $x_{\mathrm{n}}$ are the barrier height, built-in potential barrier, and depletion width, respectively. Other symbols have their

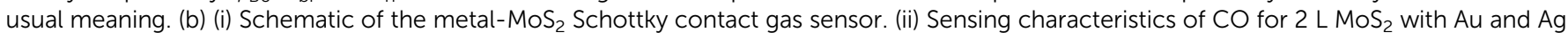
electrodes. (iii) Band diagram of $\mathrm{MoS}_{2}$ with metal electrodes. Band alignment of (iv) the Au/MoS 2 gas sensor and (v) Ag/MoS 2 gas sensor before and after $\mathrm{CO}$ and $\mathrm{CO}_{2}$ exposure. Reprinted with permission from ref. 111. Copyright 2019, ACS Publishing. 

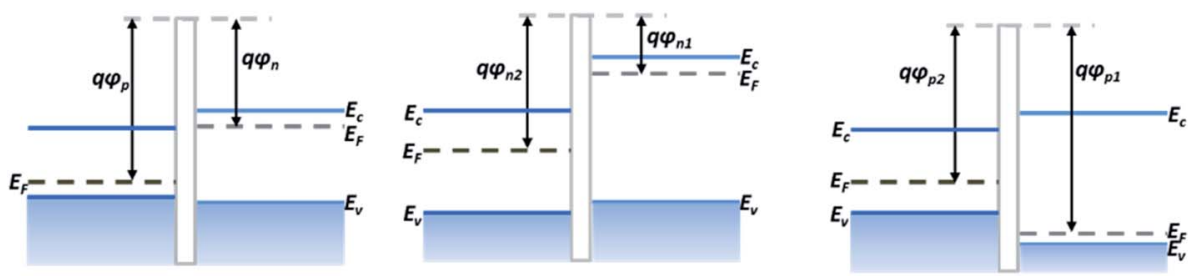

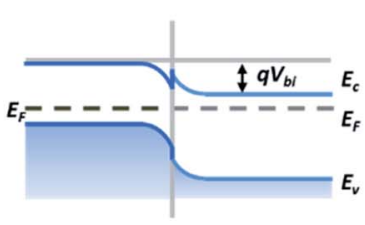

(a)

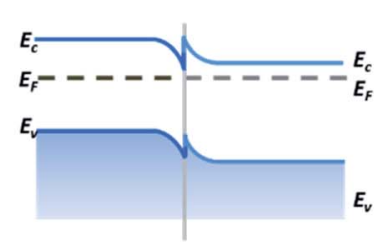

(b)

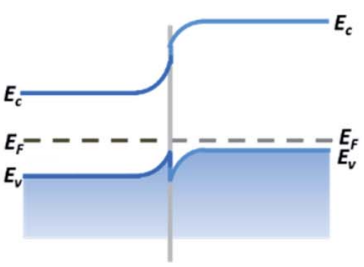

(c)

Fig. 16 Band alignment of (a) $\mathrm{p}-\mathrm{n}$ junctions, (b) $\mathrm{n}-\mathrm{n}$ junctions, and (c) $\mathrm{p}-\mathrm{p}$ junctions. $E_{\mathrm{c}}, E_{\mathrm{F}}$, and $E_{\mathrm{v}}$ are the conduction band edge, Fermi level, and valence band edge of the semiconductor, respectively. $\varphi_{\mathrm{p}}, \varphi_{\mathrm{n}}$, and $V_{\mathrm{bi}}$ are the $\mathrm{p}$-type semiconductor work function, the n-type semiconductor work function, and the built-in potential barrier, respectively. ${ }^{116}$

the sensing performances are determined by the difference in the areal coverage of the two dissimilar materials as well as the interfacial bonds. ${ }^{\mathbf{4 1 , 1 1 7}}$ With a higher areal coverage of the material, more electrons flow through the material, and so the charge transfer between gas molecules and the material is stronger than in the case of the material with lower areal coverage. Higher area materials dominate the sensing response of the $\mathrm{p}-\mathrm{n}$ heterojunction. Concerning the interfacial states of a $\mathrm{p}-\mathrm{n}$ junction, there are many dangling bonds and voids in the interface owing to a random connection between two different crystals. ${ }^{118}$ Since dangling bonds could trap the electron in the conduction path, the charge transfer is impeded, requiring additional energy to drive the electrons across the electrondepletion layer (EDL). Therefore, it is recommended to keep the interface state at a low density, for instance, by adopting lattice-matched materials or enhancing the crystal quality of the materials. Through the hydrothermal method, $\mathrm{MoS}_{2} / \mathrm{SnO}_{2} \mathrm{p}-\mathrm{n}$ heterojunctions have been fabricated and used for ethanol, trimethylamine (TMA), and $\mathrm{NO}_{2}$ gas sensing. ${ }^{119-121}$ They exhibited high sensitivity, lower OT, excellent sensing selectivity, and outstanding long-term stability. However, there are still a lack of quantitative experimental and theoretical analyses of the effects of areal coverage and dangling bonds on the gas sensing performances.

3.4.2 n-n or $\mathbf{p}-\mathbf{p}$ junction. Recently, various $n-n$ and $p-p$ heterostructures have been proposed to improve the gassensing performances. Most of the $n-n$ and $p-p$ junction gas sensors are based on metal oxide nanomaterials, such as $\mathrm{SnO}_{2} /$ $\mathrm{TiO}_{2},{ }^{122} \mathrm{SnO}_{2} / \mathrm{ZnO},{ }^{123} \mathrm{SnO}_{2} / \mathrm{Sn}_{3} \mathrm{O}_{4},{ }^{124} \mathrm{TiO}_{2} / \mathrm{ZnO},{ }^{125} \mathrm{CaO} / \mathrm{ZnO},{ }^{126}$ $\mathrm{ZnO} / \mathrm{In}_{2} \mathrm{O}_{3}{ }^{127}$ and $\mathrm{CuO} / \mathrm{rGO},{ }^{128}$ whose enhanced performances are attributed to the heterocontact of the two semiconductor surfaces. For metal sulfide-based $n-n$ and $\mathrm{p}-\mathrm{p}$ heterojunctions, Zhang et al. ${ }^{129}$ optimized the $\mathrm{NH}_{3}$ sensing behaviour by using $\mathrm{SnS}_{2} / \mathrm{ZnS}$ hierarchical NFWs. The gas sensors based on metal sulfide $n-n$ junctions benefiting from metal oxide hybrids, such as $\mathrm{CdS} / \mathrm{CeO}_{2},{ }^{130} \mathrm{CdS} / \mathrm{ZnO},{ }^{131} \mathrm{ZnS} / \mathrm{ZnO},{ }^{132}$ and $\mathrm{ZnS} / \mathrm{CuO},{ }^{133}$ have been employed for the detection of VOC toxic gases. The electrons flow across the heterojunction from the higher Fermi level to the lower one, which induces band bending and EDL formation at the interface. This improves the transfer efficiency of the interfacial charge and increases the adsorption of oxygen species. An EDL and electron-accumulation layer (EAL) are formed at n-n (Fig. 16b) and p-p (Fig. 16c) heterointerfaces. The adsorbed gases on the surface could further influence the width of the EDL/EAL by extracting/giving electrons from/to the conduction band of the semiconductors. Therefore, the conductivity of the device could be altered with the type and the concentration of analytes (gas molecules). Moreover, the interface states of $n-n$ or $p-p$ heterojunctions need further experimental and theoretical analysis.

\subsection{FET gas sensors}

FET gas sensors have attracted much research interest because of their sensitive detection and miniaturization. ${ }^{\mathbf{1 3 4 , 1 3 5}}$ Fig. 17 shows a typical FET gas sensor consisting of a sensing semiconductor as a channel material, a back gate layer, a dielectric layer, and source and drain electrodes on the two ends of the channel material. The conductance of the channel can be modulated by applying different bias voltages on the gate electrode through a thin dielectric layer. ${ }^{8}$ The channel materials could be pristine or functionalized metal sulfides and metal sulfide-based heterojunctions. Similarly to the chemiresistor gas sensor, gas detection can be realized by measuring the change of the current between the source and drain $\left(I_{\mathrm{ds}}\right)$ before and after exposure to target gases. The primary difference is that the gate voltage could alter the channel's charge carrier concentration by modulating the electric field across the dielectric layer. Consequently, the charge transfer between channel and target gases could be modified in the form of 
(a)

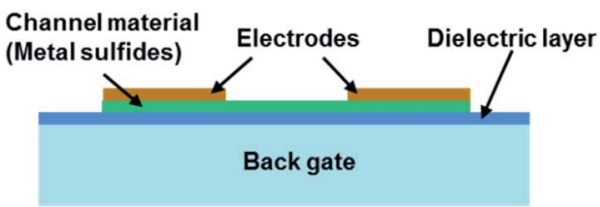

(b)

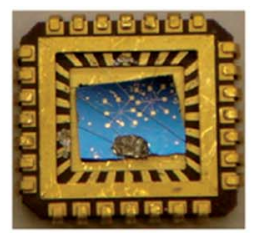

(c)

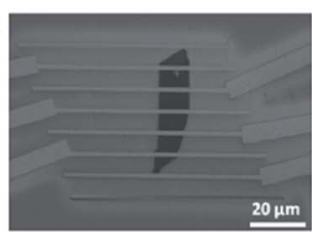

Fig. 17 (a) Schematic of an FET gas sensor. (b) Optical image of the $\mathrm{MOS}_{2}$ transistor sensor on a chip. (c) SEM image of a two-layer MoS 2 transistor. Reprinted with permission from ref. 83. Copyright 2013, ACS Publishing.

changes in the $I_{\mathrm{ds}}$. Traditionally, FET sensors could be back-gate FETs and top-gate FETs; however, most FET gas sensors are back-gate FETs because the channel materials can directly come into contact with target gases. This type of sensing device has been used to detect many types of gases, such as $\mathrm{CO}, \mathrm{NO}, \mathrm{NH}_{3}$, $\mathrm{NO}_{2}, \mathrm{SO}_{2}, \mathrm{H}_{2}$, and VOCs. However, most FET gas sensors are still not satisfactory due to their device instability and limited large-scale production even though they exhibit fast response and high selectivity. ${ }^{136}$

\subsection{Optical gas sensors}

Optical gas sensors monitor the optical properties of different gas species at defined optical wavelengths. They can be used as an optical "fingerprint" for any gas species because different types of gases have a specific distribution of optical absorption/ emission with the wavelength. Besides, different changes in optical properties of sensors can reflect different gas concentrations. Metal sulfides have strong photoluminescence, a wide range of photoresponsivity, high carrier mobility, and high sensitivity to humidity variation. ${ }^{\mathbf{4 4 0}}$ Fibre-optic sensors are attractive due to their low cost, light weight, and anti-corrosion properties. ${ }^{137}$ Therefore, taking advantage of the superior properties of both metal sulfides and optical fibres was considered. Most of metal sulfide-based optical gas sensors are fibre-optic devices. The $\mathrm{MoS}_{2}$-coated side polished fibre (SPF) sensor has a high response, and the $\mathrm{MoS}_{2}$-coated etched singlemode fibre (ESMF) has a fast response time, enabling the fibreoptic sensor to monitor different breathing patterns of human beings. ${ }^{138}$ As shown in Fig. 18, the normalized response (NR) of the $2 \mathrm{H}-\mathrm{MoS}_{2} / \mathrm{Au}$ coated optical fibre device was calculated from the change of the transmission light power, and the sensitivity was determined using $S=\Delta \mathrm{NR} / \Delta \mathrm{RH}$, where $\Delta \mathrm{NR}$ is the relative variation in the transmitted light intensity for the sensor and $\Delta \mathrm{RH}$ is the change of relative humidity, respectively. ${ }^{39}$

\subsection{SAW gas sensors}

The SAW sensor is based on the microelectromechanical system (MEMS), which converts an input electrical signal into a SAW, i.e., a mechanical wave. ${ }^{139}$ Fig. 19 shows a typical SAW gas sensor structure, whose SAW delay line between the input and output interdigital-transducer (IDT) is covered by a thin membrane that can selectively adsorb the gas to be detected. Any change in phase, frequency, amplitude, or time-delay induced by gas adsorption or desorption of the membrane, might further affect the wave. Then it is converted into an electrical signal and received by the output end. In particular, the phase velocities can be detected with high accuracy. In this case, SnS colloidal quantum dots (CQDs) were used as the sensing layer and fabricated on the ST-cut quartz substrate. ${ }^{\mathbf{1 4 0}}$ The sensor exhibited high selectivity and efficiency for the detection of $\mathrm{NO}_{2}$ gas with low concentration at room temperature. Moreover, this is an efficient approach to diagnose diseases from exhaled breath by coating SAW sensors with various polymers to identify specific breath biomarkers.

\section{Metal sulfide-based devices for gas sensing applications}

\subsection{VOCs}

VOCs primarily come from the exhaust gases generated by transportation, fuel combustion, and come from cooking, furniture, decorative materials, or much simpler breathing. ${ }^{\mathbf{1 4 1}}$
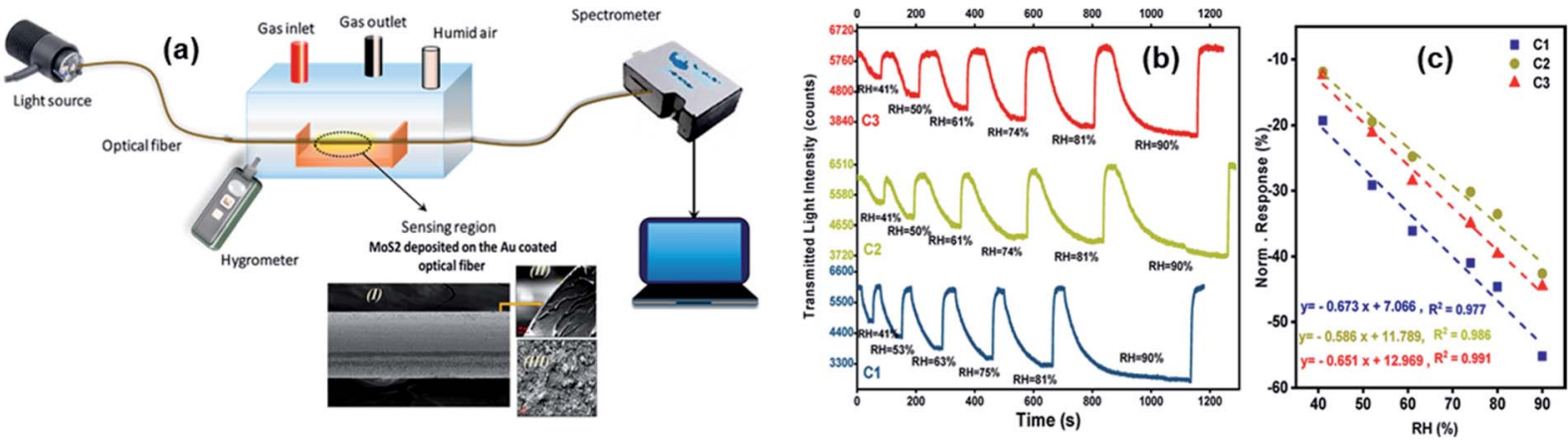

Fig. 18 (a) Schematic diagram of the gas sensing transmittance setup on the basis of an optical fiber coated with thin layers of anionic MoS ${ }_{2}$ and $\mathrm{Au}$. The inset image shows the cross-sectional FE-SEM images of the anionic $2 \mathrm{H}-\mathrm{MoS}_{2} /$ Au coated optical fibre. (b) Dynamic and (c) sensitivity responses of the optical fiber sensors modified with different samples. Reprinted with permission from ref. 39. Copyright 2020, ACS Publishing. 
(a)

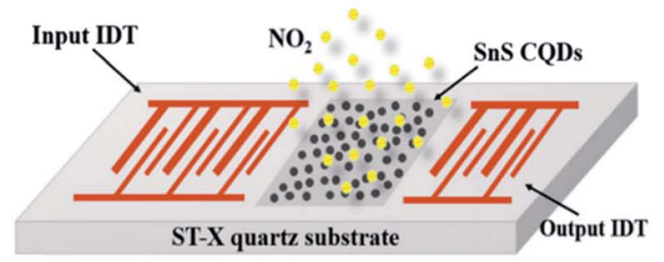

(b)

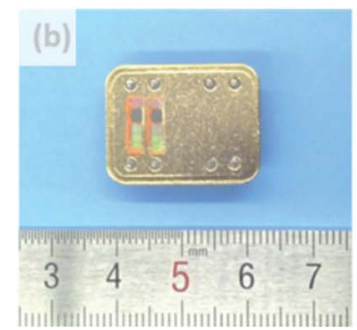

(c)

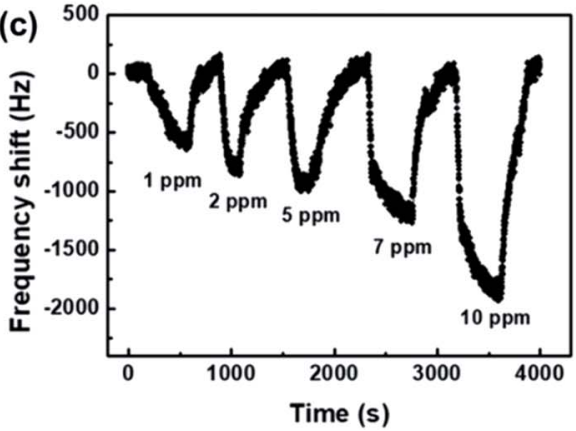

(d)

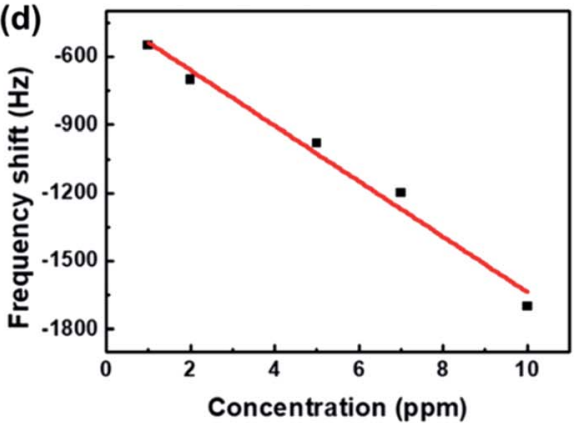

Fig. 19 (a) The schematic and (b) a photograph of the SAW sensor based on SnS CQDs. (c) The response curves of the SAW sensor to different $\mathrm{NO}_{2}$ concentrations. (d) The dependence of the response on $\mathrm{NO}_{2}$ concentration. Reprinted with permission from ref. 140. Copyright 2019, Elsevier.

Since the concentration of VOCs an indoor ambient environment is much higher than that outdoors (up to 10 times), the level of VOCs is used as one of the indicators for evaluating the air quality in indoor ambient. ${ }^{98}$ When people are exposed to a certain concentration of VOCs, they face a higher risk of suffering from headaches, nausea, and even organ damage. From a medical perspective, exhaled breath contains VOCs of alcohols, hydrocarbons, ketones, aldehydes, esters, nitriles, and aromatic compounds, ${ }^{142,143}$ which can be used as biomarkers of the diagnosis of diseases according to Fig. 1. The gas-sensing performance of metal sulfide-based devices towards different VOCs is summarised in Tables 4-6.

4.1.1 Acetone. Acetone is one of the common metabolites of the human body and is ordinarily present in the breath, blood, and urine. Increased acetone in the breath can be found in untreated patients with diabetes mellitus. ${ }^{14,145}$ Typically, the acetone concentration for diabetic patients is higher than 1.71 parts per million by volume (ppmv), whereas that for healthy people ranges from 0.3 to 0.9 ppmv. ${ }^{146}$ The detection and analysis of acetone in the breath can be a potential method for the diagnosis of diabetes. Besides, acetone may also be associated with lung cancer. ${ }^{142}$ To achieve high sensitivity, various shapes of metal sulfides were used. The SnS NFK-based gas sensor showed excellent stability and reproducibility at $100{ }^{\circ} \mathrm{C}$ for the detection of acetone from 5 to $50 \mathrm{ppm}$ and a rapid response of $3 \mathrm{~s}^{34}$ Wang et al. ${ }^{103}$ fabricated a single-crystal $\mathrm{ZnS}$ NW-based gas sensor through the thermal-evaporation-growth method, which showed high sensing selectivity towards acetone and ethanol. Giberti et al. ${ }^{147}$ obtained $\mathrm{SnS}_{2}$ NRs as a precipitate in aqueous solution and deposited them as functional materials on an alumina substrate for acetone, acetaldehyde, and $\mathrm{H}_{2} \mathrm{~S}$ gas sensing. The sensor showed excellent selectivity to acetone at $1 \mathrm{ppm}$ under both dry and wet conditions at an OT of $300{ }^{\circ} \mathrm{C}$. To decrease the OT, $\mathrm{SnS}_{2} / \mathrm{SnO}_{2}$ heterojunctions were employed for the detection of acetone, and they showed a response $\%$ of $107 \%$ and fast recovery $(80 \mathrm{~s})$ at $80{ }^{\circ} \mathrm{C} .{ }^{148}$ However, the LOD could not meet the limit of acetone concentration in the exhaled breath $(0.9 \mathrm{ppm})$, which shows that the LOD of metal sulfide-based gas sensors needs to be improved further.

4.1.2 Benzene. Benzene gas is volatile and highly toxic; even a small amount of benzene can cause vital harm to our body. ${ }^{149}$ The maximum permitted exposure limit in the atmosphere regulated by the World Health Organization (WHO) is $5 \mathrm{ppb}\left(16.25 \mu \mathrm{g} \mathrm{m} \mathrm{m}^{-3}\right) \cdot{ }^{150}$ However, benzene is commonly used as a solvent in petrochemical and pharmaceutical goods, which has terrible carcinogenic effects on the people working there. It is necessary to detect-trace benzene in the environment, which has led to the development of inexpensive sensors for benzene detection. The conventional methods are based on cataluminescence, chromatography, and spectroscopy. ${ }^{149,151,152}$ Recently, semiconductor sensors were explored. For metal sulfide-based devices, Zhang et al. ${ }^{153}$ synthesized and used Pddecorated $\mathrm{TiO}_{2} / \mathrm{MoS}_{2}$ ternary nanocomposites in the benzene sensor. Compared to pristine $\mathrm{MoS}_{2}$ and $\mathrm{TiO}_{2}$ sensors, this sensor has a higher response $\%$ of $64 \%$ for $50 \mathrm{ppm}$ benzene, wider linearity ranging from 0.1 to $100 \mathrm{ppm}$, shorter response and recovery times (13 s/10 s), and better selectivity and stability. Moreover, this group employed $\mathrm{WS}_{2} \mathrm{NFWs/ZnO} \mathrm{hollow}$ spheres to detect benzene, which showed a faster response and recovery time of $8 \mathrm{~s} / 6 \mathrm{~s}$ at room temperature. ${ }^{154}$ To extend the application area, Baek et al. ${ }^{155}$ demonstrated a flexible and transparent benzene sensor using cobalt-metalloporphyrin (CoMPP)-functionalized few-layer $\mathrm{MoS}_{2}$ as the sensing material. 
Table 4 Literature study on the gas-sensing performance of metal sulfide-based VOC gas sensors ${ }^{a}$

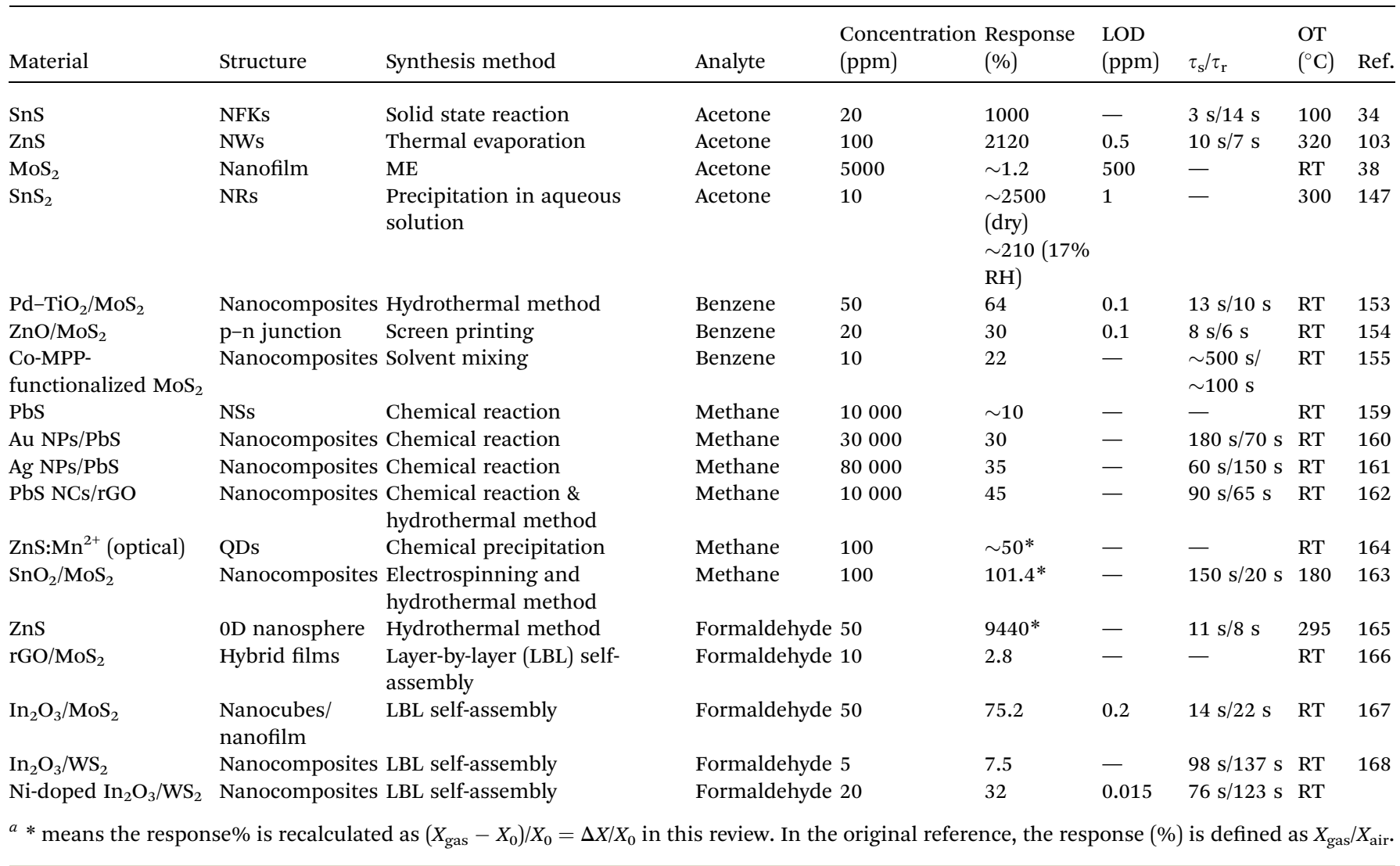

The device has a higher response $\%$ of over $250 \%$ compared to pristine $\mathrm{MoS}_{2}$ and a low LOD of $10 \mathrm{ppm}$ at room temperature.

4.1.3 Methane. Methane $\left(\mathrm{CH}_{4}\right)$ is widely present in industrial and residential areas and emitted into the atmosphere from natural wetlands, rice paddies, domestic ruminants, landfills, and biomass burning. ${ }^{156}$ It is a potent greenhouse gas, whose explosive limit concentration was reported to be more than $4.7 \%$ mixed with air. ${ }^{157}$ Traditionally, exhaled air from normal human breath doesn't have methane, except in people who are overweight and people who have irritable bowel syndrome, inflammatory bowel diseases, or anorexia. ${ }^{158}$ Taking advantage of the nanostructures, metal sulfide nanocrystals (NCs) and quantum dots (QDs) have been used in $\mathrm{CH}_{4}$ sensors. Sheikhi et al. proposed a series of PbS-based chemiresistor sensors for the detection of $\mathrm{CH}_{4}$, including intrinsic $\mathrm{PbS} \mathrm{NCs},{ }^{159}$ $\mathrm{Au}$ nanoparticle (NP) decorated $\mathrm{PbS},{ }^{160} \mathrm{Ag}$ NP decorated PbS, ${ }^{\mathbf{1 6 1}}$ and $\mathrm{PbS}$ NCs/rGO hybrids. ${ }^{\mathbf{1 6 2}}$ The PbS NCs/rGO nanocomposite sensor has shown a good response\% (45\%) at the lower explosive limit of $\mathrm{CH}_{4}$ with fast response and recovery time (90 s/65 s). Wang et al. employed hierarchical nanocomposites of $\mathrm{MoS}_{2}$ NFWs anchored on $\mathrm{SnO}_{2}$ nanofibers for $\mathrm{CH}_{4}$ sensing. As shown in Fig. 20, this n-n junction-based sensor showed a high

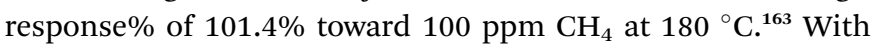
respect to optical gas sensors, Sergeev et al. ${ }^{\mathbf{1 6 4}}$ synthesized manganese-doped zinc sulfide ( $\mathrm{ZnS}: \mathrm{Mn}^{2+}$ ) QDs and found that the $\mathrm{ZnS}: \mathrm{Mn}^{2+}$ emission spectrum is changed significantly under exposure to $\mathrm{CH}_{4}$ in the concentration range from $100 \mathrm{ppm}$ to
2000 ppm. QDs in this luminescent sensor act as adsorption centres for achieving higher light transmittance and further improving the signal stability in the visible region. The response refers to the photoinduced electron transfer from QDs to $\mathrm{CH}_{4}$, which induces QD luminescence quenching and a decrease in the luminescence lifetime.

4.1.4 Formaldehyde. Formaldehyde (HCHO) is a colorless toxic gas with a pungent smell and can cause serious harm to the central nervous system and immune system of human beings. Because formaldehyde is a chemical used in the production of solvents, adhesives, and bonding agents, it is usually released from pressed-wood products, wallpapers, paints, and foam insulation in homes, offices, and the urban environment. According to the Occupational Safety and Health Standards, the time-weighted average limit of formaldehyde is $0.75 \mathrm{ppm}$, the short-term exposure limit is $2 \mathrm{ppm}$ and the immediately dangerous to life or health limit is $20 \mathrm{ppm} .{ }^{169} \mathrm{In}$ the view of healthcare, HCHO could act as a biomarker of multiple diseases, especially lung cancer. ${ }^{150}$

Hussain et al. ${ }^{165}$ successfully prepared 0D ZnS nanospheres via a low-temperature hydrothermal synthesis method. The gas sensor showed a high response $\%$ of $9540 \%$ and high selectivity towards formaldehyde compared to other gases (ethanol, ammonia, acetone, methanol, and $\mathrm{NO}_{2}$ ) at an OT of $295^{\circ} \mathrm{C}$. The enhanced gas-sensing performances can be attributed to the presence of more active sites because of the large exposed surface area and small size of $\mathrm{ZnS}$ nanospheres. Li et al. ${ }^{\mathbf{1 6 6}}$ 
(a)

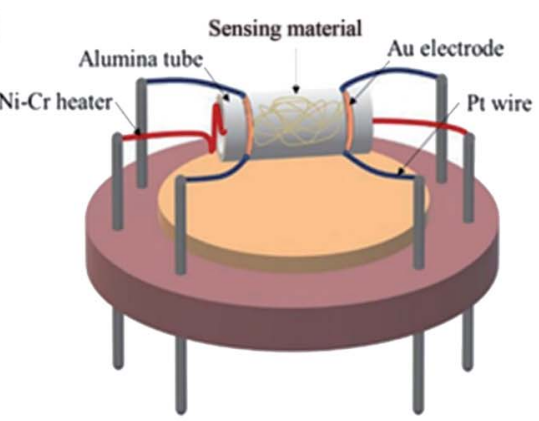

(b)

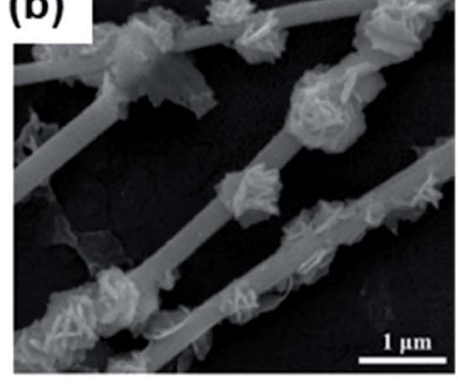

(c)

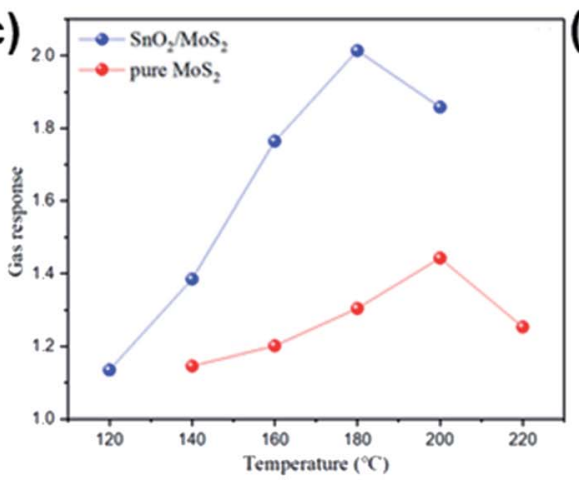

(d)

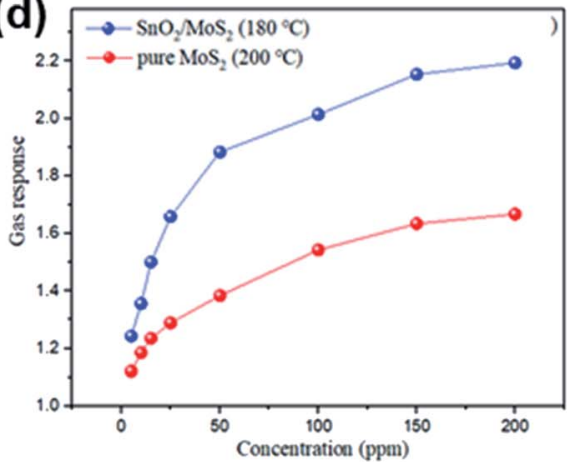

Fig. 20 (a) Schematic structure of a $\mathrm{SnO}_{2} / \mathrm{MoS}_{2}$ gas sensor. (b) SEM results of $\mathrm{SnO}_{2} / \mathrm{MoS}_{2}$ samples. (c) Gas response of sensor devices to $100 \mathrm{ppm} \mathrm{CH} 4$ under different operating temperatures. (d) Gas response of two sensors to $\mathrm{CH}_{4}$ with various concentrations. Reprinted with permission from ref. 163. Copyright 2019, Elsevier.

fabricated gas sensors based on $\mathrm{rGO} / \mathrm{MoS}_{2}$ hybrid films, which yielded flexible devices for formaldehyde detection at room temperature. The mechanisms for enhanced sensing performance of the $\mathrm{rGO} / \mathrm{MoS}_{2}$ hybrid films could be summarized as follows: in the hybrid film, $\mathrm{MoS}_{2}$ nanosheets acted as the formaldehyde adsorbent and electron acceptor, mediating a two-stage electron transfer from formaldehyde and finally to rGO, which served as a conducting network and exhibited a ptype response. As shown in Fig. 21, Zhang et al. demonstrated some room temperature formaldehyde sensors based on a LBL self-assembled $\operatorname{In}_{2} \mathrm{O}_{3}$ nanocubes/flower-like $\mathrm{MoS}_{2}$ nanofilm, ${ }^{167}$ and Ni-doped $\mathrm{In}_{2} \mathrm{O}_{3} / \mathrm{WS}_{2}$ nanocomposite. ${ }^{168}$ They exhibited a low LOD of $15 \mathrm{ppb}$, good selectivity, repeatability, fast detection rate, and a fair logarithmic function toward formaldehyde concentration. The dramatically enhanced sensing performance of the Ni- $\mathrm{In}_{2} \mathrm{O}_{3} / \mathrm{WS}_{2}$ sensor can be attributed to the $\mathrm{Ni}$ ion doping and synergistic interfacial incorporation of the $\mathrm{In}_{2} \mathrm{O}_{3} / \mathrm{WS}_{2}$ heterojunction.

4.1.5 Ethanol. Volatile alcohols such as ethanol are often found in the chemical, medical, pharmaceutical, and food industries. They can induce nasal and mucous membrane inflammation, respiration disruption, eyesight disturbance, nerve disease, lung irritation, and even death after long-term exposure to even a low alcohol vapour concentration. On the other hand, because ethanol is a kind of flammable gas, it is essential to monitor its real-time concentration in workplaces. Moreover, ethanol is one of the typical biomarkers for lung cancer. Thus it requires developing a high-performance gas sensor for the detection of low concentration ethanol.
Many pristine metal sulfides, such as SnS NFKs, ${ }^{34}$ CdS thin films, ${ }^{171}$ hollow sphere $\mathrm{CuS},{ }^{172}$ and $\beta$ - $\operatorname{In}_{2} \mathrm{~S}_{3}$ thin films, ${ }^{173}$ were proposed for the detection of ethanol. At an OT of $300{ }^{\circ} \mathrm{C}$, the CdS films show a high response $\%$ of $6300 \%$ and strong selectivity to alcohols in mixtures where aldehydes and other interferents are present. Their response and recovery time are speedy; however, their OTs are higher than $200{ }^{\circ} \mathrm{C}$. Therefore, heterostructures of metal sulfides with metal oxides are introduced to enhance the sensing capability for alcohol detection. Both metal oxides and metal sulfide would have the same Fermi energy level at the interface, which results in a staggered band offset and a built-in internal electric field. When using the heterogeneous structure in a sensor, the electron generated from the adsorption reaction can easily move across the interface and transfer to the conductive band. In the context of metal sulfide/metal oxide heterostructures prepared through hydrothermal methods, $\mathrm{MoS}_{2} / \mathrm{SnO}_{2}{ }^{119} \mathrm{MoS}_{2} / \mathrm{ZnO},{ }^{174}$ and $\mathrm{MoS}_{2} / \mathrm{TiO}_{2}$ (ref. 175) are three typical heterostructures. Among them, the $\mathrm{MoS}_{2} / \mathrm{SnO}_{2}$ sensor showed an ultra-high response $\%$ of $11900 \%$ toward $200 \mathrm{ppm}$ ethanol. All of them have fast response and recovery time $(\sim 20 \mathrm{~s})$; ; however, their OTs are higher than $150{ }^{\circ} \mathrm{C}$. Thus a room-temperature ethanol sensor based on $\mathrm{n}$ type $\alpha-\mathrm{Fe}_{2} \mathrm{O}_{3}$ hollow microspheres on $\mathrm{MoS}_{2}$ NSs prepared by the LBL self-assembly method was proposed and is shown in Fig. 22. ${ }^{170}$ The $\alpha-\mathrm{Fe}_{2} \mathrm{O}_{3} / \mathrm{MoS}_{2}$ sensor has a low LOD of $1 \mathrm{ppm}$ with high response, as well as a short response/recovery time of $6 \mathrm{~s} / 5 \mathrm{~s}$, which is shorter than those of $\alpha-\mathrm{Fe}_{2} \mathrm{O}_{3}$ or $\mathrm{MoS}_{2}$ devices. The enhancement performance of the $\alpha-\mathrm{Fe}_{2} \mathrm{O}_{3} / \mathrm{MoS}_{2}$ was attributed to the increased active sites for gas molecule 
(a)

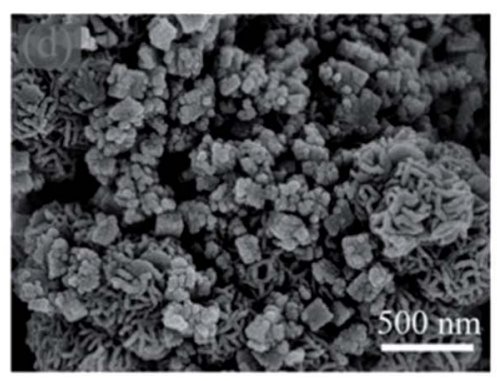

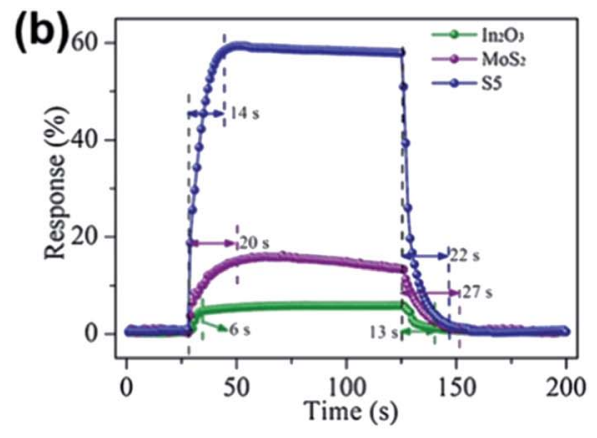

(c)

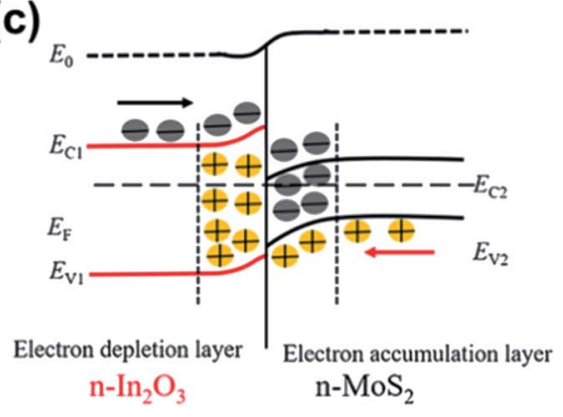

Fig. 21 (a) SEM images of $\ln _{2} \mathrm{O}_{3}$ nanocubes/flower-like $\mathrm{MoS}_{2}$ hybrids. (b) The response and recovery characteristics of $I n_{2} \mathrm{O}_{3}, \mathrm{MoS}_{2}$ and $I \mathrm{n}_{2} \mathrm{O}_{3} /$ $\mathrm{MoS}_{2}$ (S5) film sensors exposed to $50 \mathrm{ppm} \mathrm{HCHO}$ gas. (c) The energy band diagram for the $n-n$ junction of the $\mathrm{In}_{2} \mathrm{O}_{3} / \mathrm{MoS}_{2}$ film. Reprinted with permission from ref. 167. Copyright 2018, Elsevier.

adsorption, defects, or oxygen vacancies, when $\alpha-\mathrm{Fe}_{2} \mathrm{O}_{3}$ into $\mathrm{MoS}_{2}$ nanosheets. Besides, Li et al. ${ }^{\mathbf{1 3 0}}$ modified CdS NWs with $\mathrm{CeO}_{2}$ NPs and found that the $5 \mathrm{wt} \% \mathrm{CeO}_{2} / \mathrm{CdS} \mathrm{n}-\mathrm{n}$ heterostructures exhibited a much higher response \% toward $100 \mathrm{ppm}$ ethanol ( $\sim 5100 \%)$, which was 2.6 times larger than that of pure
CdS. The gas sensing properties of different metal sulfide-based ethanol sensors are listed in Table 5.

4.1.6 Liquefied petroleum gas (LPG). LPG is primarily composed of propane or butane and is widely used as fuels in vehicles, cooking, and heating appliances. LPG is potentially
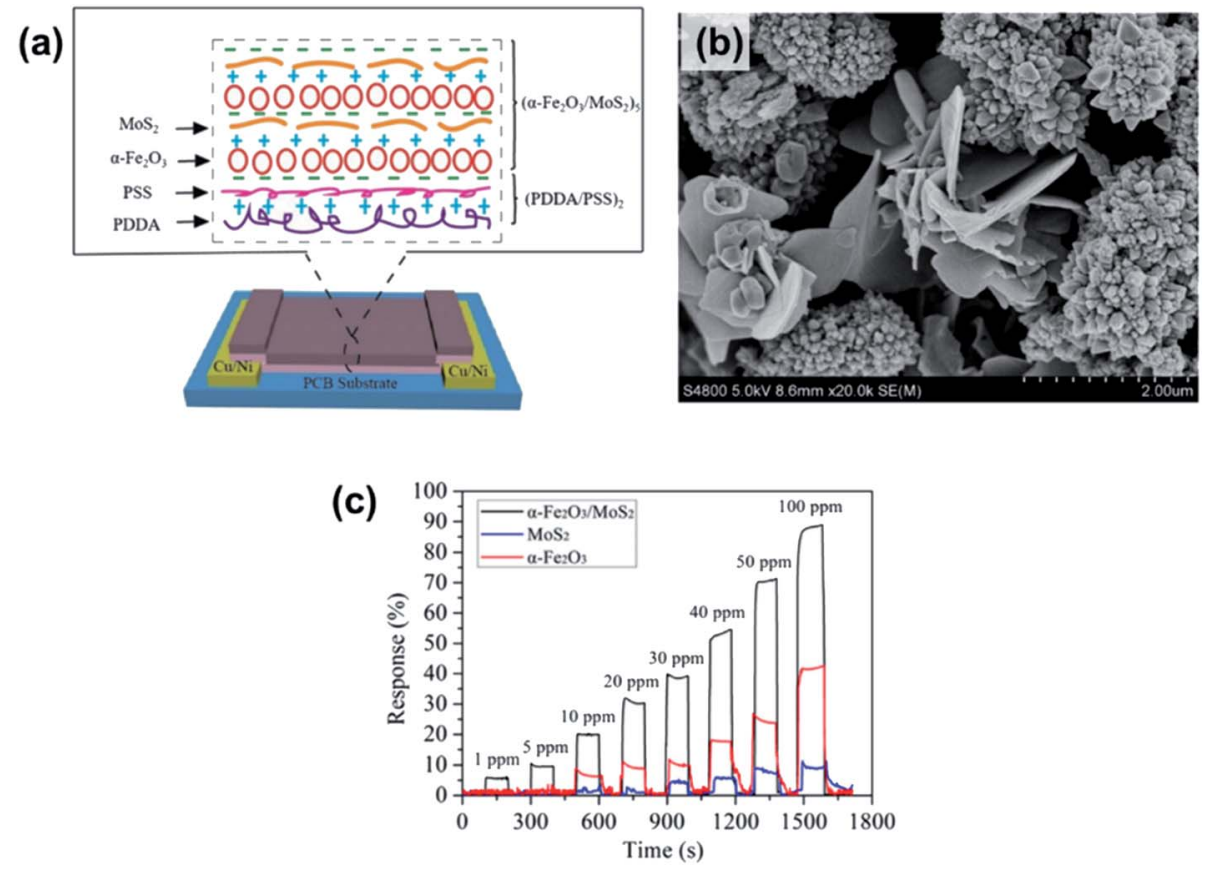

Fig. 22 (a) Schematic of an $\alpha-\mathrm{Fe}_{2} \mathrm{O}_{3} / \mathrm{MoS}_{2}$ gas sensor. (b) SEM image of the $\alpha-\mathrm{Fe}_{2} \mathrm{O}_{3} / \mathrm{MoS}_{2}$ nanocomposite. (c) Time-dependent response of the $\alpha-\mathrm{Fe}_{2} \mathrm{O}_{3} / \mathrm{MoS}_{2}, \alpha-\mathrm{Fe}_{2} \mathrm{O}_{3}$, and $\mathrm{MoS}_{2}$ film sensors towards various ethanol gas concentrations. Reprinted with permission from ref. 170 . Copyright 2018, Elsevier. 
Table 5 Gas sensing properties of metal sulfide-based sensors for ethanol

\begin{tabular}{|c|c|c|c|c|c|c|c|c|}
\hline Material & Structure & Synthesis method & Concentration & Response (\%) & LOD (ppm) & $\tau_{\mathrm{s}} / \tau_{\mathrm{r}}$ & OT $\left({ }^{\circ} \mathrm{C}\right)$ & Ref. \\
\hline $\mathrm{SnS}$ & NFKs & Solid state reaction & $10 \mathrm{ppm}$ & 130 & - & $2 \mathrm{~s} / 9 \mathrm{~s}$ & 200 & 34 \\
\hline CdS & Thin film & Screen printing & 5 ppm & 6300 & - & $\sim 400 \mathrm{~s} / \sim 400 \mathrm{~s}$ & 300 & 171 \\
\hline CuS & Hollow spheres & $\begin{array}{l}\text { Surfactant micelle-template inducing } \\
\text { reaction }\end{array}$ & $800 \mathrm{ppm}$ & $1300 *$ & - & $15 \mathrm{~s} / 15 \mathrm{~s}$ & 210 & 172 \\
\hline$\beta-\operatorname{In}_{2} S_{3}$ & Thin film & Spray pyrolysis & $500 \mathrm{ppm}$ & $70 *$ & - & $150 \mathrm{~s} / 155 \mathrm{~s}$ & 350 & 173 \\
\hline $\mathrm{MoS}_{2} / \mathrm{SnO}_{2}$ & Nanocomposites & Hydrothermal method & $200 \mathrm{ppm}$ & $11900^{*}$ & - & $\sim 20 \mathrm{~s} / \sim 20 \mathrm{~s}$ & 280 & 119 \\
\hline $\mathrm{MoS}_{2} / \mathrm{ZnO}$ & Nanocomposites & Hydrothermal method & $50 \mathrm{ppm}$ & $4180^{*}$ & - & $\sim 20 \mathrm{~s} / \sim 20 \mathrm{~s}$ & 260 & 174 \\
\hline $\begin{array}{l}0 \mathrm{D}-\mathrm{MoS}_{2} / \\
\mathrm{TiO}_{2}\end{array}$ & $\mathrm{p}-\mathrm{n}$ heterojunction & Hydrothermal method & $100 \mathrm{ppm}$ & $1320^{*}$ & - & $\sim 20 \mathrm{~s} / \sim 15 \mathrm{~s}$ & 150 & 175 \\
\hline$\alpha-\mathrm{Fe}_{2} \mathrm{O}_{3} / \mathrm{MoS}_{2}$ & Nanocomposite & LBL self-assembly & $100 \mathrm{ppm}$ & 88.9 & 1 & $6 \mathrm{~s} / 5 \mathrm{~s}$ & RT & 170 \\
\hline $\mathrm{CdS} / \mathrm{CeO}_{2}$ & NWs & Solvothermal method & $100 \mathrm{ppm}$ & $5100 *$ & - & $12 \mathrm{~s} / 3 \mathrm{~s}$ & 161 & 130 \\
\hline
\end{tabular}

dangerous because it may cause suffocation or even an explosion when it leaks accidentally. Various types of heterojunctions were found to achieve a high gas response due to their nm-level crystalline size and the specific surface area. Patil et al. ${ }^{\mathbf{1 7 6}}$ reported an LPG sensor based on $p$-polyaniline/n-PbS heterojunctions, which showed a maximum response up to $70 \%$ at 0.06 vol\% LPG at room temperature. As shown in Fig. 23, Ladhe et al. successfully proposed an $\mathrm{n}-\mathrm{Bi}_{2} \mathrm{~S}_{3} / \mathrm{p}-\mathrm{PbS}^{177}$ heterojunction for room temperature LPG sensors, which showed $\sim 70 \%$ response towards $1000 \mathrm{ppm}$ LPG with fast response and recovery time. Moreover, $\mathrm{n}-\mathrm{Bi}_{2} \mathrm{~S}_{3} / \mathrm{p}-\mathrm{CuSCN},{ }^{178} \mathrm{n}-\mathrm{CdO} / \mathrm{p}-\mathrm{PbS},{ }^{179} \mathrm{n}$ $\mathrm{CdS} / \mathrm{p}-\mathrm{PbS},{ }^{180} \mathrm{CdS} / \mathrm{SnO}_{2},{ }^{181} \mathrm{n}$-CdS/p-polyaniline, ${ }^{182}$ and $\mathrm{ZnS} /$ polyacrylamide $^{\mathbf{1 8 3}}$ demonstrated potential application in LPG detection. It is found that the alignment of energy bands at the interface of these heterojunctions shows the importance of gas sensing owing to the changes in barrier height of junction after exposure to the LPG gas environment.

\subsection{Inorganic gases}

Inorganic gases are essential for environment detection and as biomarkers in medical monitoring. The primary gases of interest are $\mathrm{NH}_{3}, \mathrm{NO}, \mathrm{NO}_{2}, \mathrm{CO}_{2}, \mathrm{O}_{2}, \mathrm{H}_{2} \mathrm{~S}, \mathrm{SO}_{2}, \mathrm{H}_{2}$, and humidity. This section will discuss metal sulfide-based devices for the detection of various inorganic gases.

4.2.1 $\mathrm{NH}_{3}$. High concentrations of $\mathrm{NH}_{3}$ could severely irritate the nose and throat of human beings and $1000 \mathrm{ppm}$ vapours can cause pulmonary edema. Low concentrations of
$\mathrm{NH}_{3}$ also could hurt the skin, eyes, and respiratory system after prolonged exposure. ${ }^{\mathbf{1 8 4}}$ Thus, the maximum permissible limit of $\mathrm{NH}_{3}$ is 20 ppm for 8 hours. ${ }^{7}$ Besides, $\mathrm{NH}_{3}$ is present in the breath samples of healthy people and patients with renal disease. According to reports, the exhaled $\mathrm{NH}_{3}$ concentration for healthy people ranges from 0.43 to $1.80 \mathrm{ppm}$, while that for end-stage renal disease patients ranges from 0.82 to 14.70 ppm. ${ }^{185}$ Liu et al. ${ }^{186}$ first presented high-performance room temperature chemical sensors based on Schottkycontact CVD $\mathrm{MoS}_{2}$. The devices showed a response\% of $20 \%$ toward $20 \mathrm{ppb}$ of $\mathrm{NO}_{2}$ and $40 \%$ toward $1 \mathrm{ppm}$ of $\mathrm{NH}_{3}$. The $\mathrm{WS}_{2}$ NFK-based gas sensor showed p-type sensing behaviour and excellent response $\%$ of $\sim 1500 \%$ towards $5 \mathrm{ppm} \mathrm{NH}_{3}$ at room temperature. ${ }^{187}$ Xiong et al. ${ }^{188}$ fabricated an $\mathrm{NH}_{3}$ sensor based on $\mathrm{SnS}_{2}$ NFWs via a solvothermal process. The sensors exhibited a high response $\%$ of $640 \%$, short response/recovery time of 40.6 $\mathrm{s} / 624 \mathrm{~s}$ and a low LOD of $0.5 \mathrm{ppm} \mathrm{NH}_{3}$. Late et al. ${ }^{83}$ compared and analyzed the gas sensing behaviours of single-layer (SL) and multilayer (ML) $\mathrm{MoS}_{2}$ transistor-based sensors towards $\mathrm{NO}_{2}$, $\mathrm{NH}_{3}$, and humidity, see Fig. 17. They found that the SL-MoS sensor was unstable; the $5 \mathrm{~L}-\mathrm{MoS}_{2}$ sensor showed a stronger response to a bias voltage, and the gas sensing response was enhanced after applying gate voltage. Moreover, phototransistor gas sensors of $\mathrm{WS}_{2}$ (ref. 189) and $\mathrm{ReS}_{2}$ (ref. 190) were employed for $\mathrm{NH}_{3}$ gas detection, whose response and recovery times were fast.

Table 6 Gas sensing properties of metal sulfide-based sensors for LPG gases

\begin{tabular}{|c|c|c|c|c|c|c|c|}
\hline Material & Synthesis method & $\begin{array}{l}\text { Concentration } \\
\text { (ppm) }\end{array}$ & Response (\%) & LOD (ppm) & $\tau_{\mathrm{s}} / \tau_{\mathrm{r}}$ & $\mathrm{OT}\left({ }^{\circ} \mathrm{C}\right)$ & Ref. \\
\hline$p$-Polyaniline/n-PbS & $\begin{array}{l}\text { Chemical bath deposition and } \\
\text { electrodeposition }\end{array}$ & 780 & 70 & - & $125 \mathrm{~s} / 200 \mathrm{~s}$ & RT & 176 \\
\hline $\mathrm{n}-\mathrm{Bi}_{2} \mathrm{~S}_{3} / \mathrm{p}-\mathrm{CuSCN}$ & Chemical deposition & 1370 & 70 & - & $180 \mathrm{~s} / 142 \mathrm{~s}$ & RT & 178 \\
\hline$n-\mathrm{Bi}_{2} \mathrm{~S}_{3} / \mathrm{p}-\mathrm{PbS}$ & $\begin{array}{l}\text { Successive ionic layer adsorption and } \\
\text { reaction (SILAR) }\end{array}$ & 1000 & 72 & - & $300 \mathrm{~s} / 170 \mathrm{~s}$ & RT & 177 \\
\hline n-CdO/p-PbS & SILAR & 1176 & 51.1 & - & $150 \mathrm{~s} / 134 \mathrm{~s}$ & RT & 179 \\
\hline n-CdS/p-PbS & SILAR & 1200 & 60 & - & $120 \mathrm{~s} / 105 \mathrm{~s}$ & RT & 180 \\
\hline $\mathrm{CdS} / \mathrm{SnO}_{2}$ & Screen printing & 5000 & 7000 & - & $40 \mathrm{~s} / 110 \mathrm{~s}$ & 200 & 181 \\
\hline $\mathrm{n}$-CdS $/ p$-polyaniline & Electrodeposition & 1040 & 80 & - & $105 \mathrm{~s} / 165 \mathrm{~s}$ & RT & 182 \\
\hline $\mathrm{ZnS} /$ polyacrylamide & Thermal frontal polymerization & 5 vol $\%$ & 62 & - & $180 \mathrm{~s} / 480 \mathrm{~s}$ & RT & 183 \\
\hline $\mathrm{PbS} /$ polyacrylamide & & & 285 & - & $120 \mathrm{~s} / 300 \mathrm{~s}$ & & \\
\hline
\end{tabular}



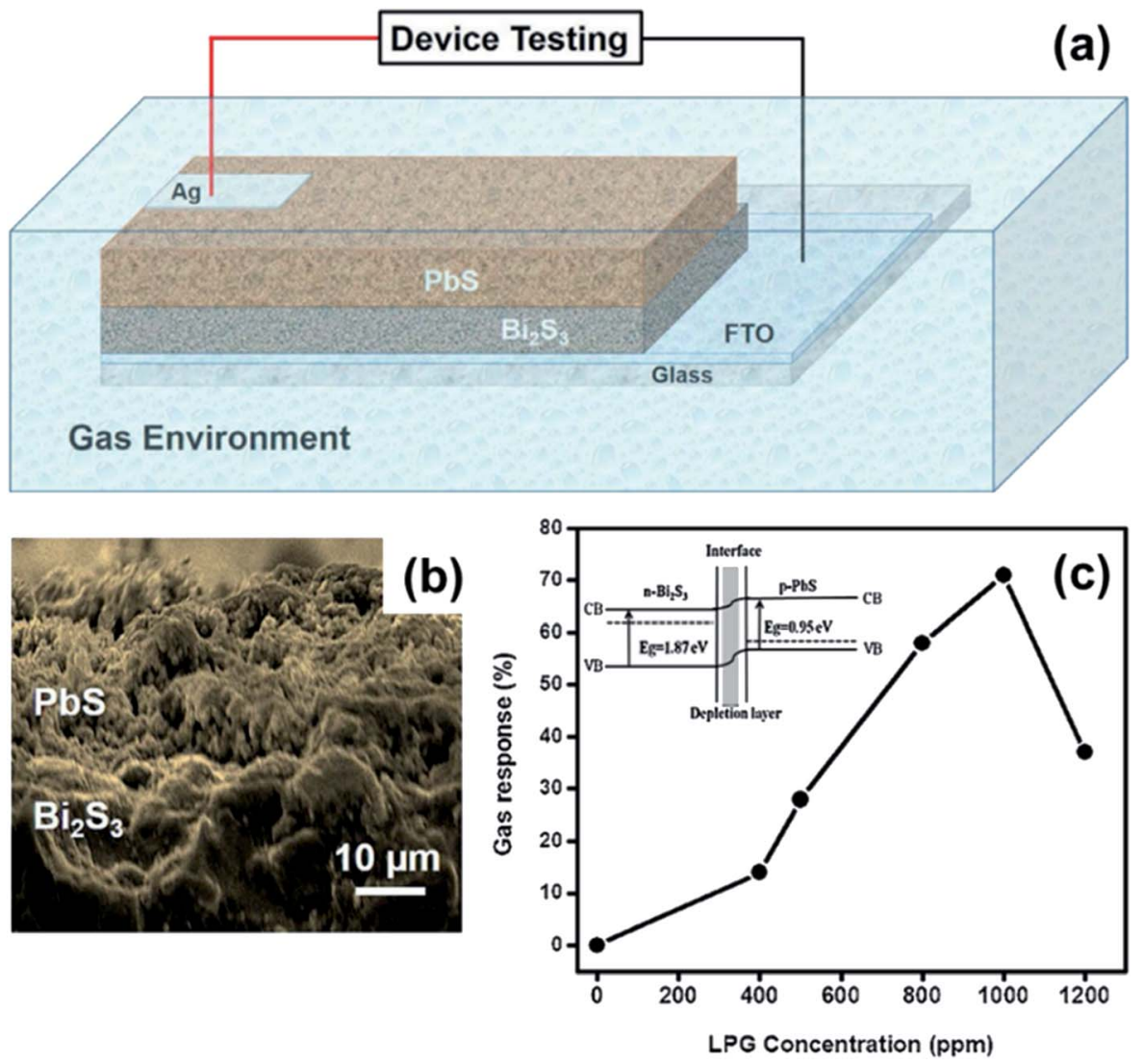

Fig. 23 (a) Schematic representation of the $n-B_{2} S_{3} / p-P b S$ heterojunction device. (b) SEM image of the $n-B_{2} S_{3} / p-P b S$ heterojunction. (c) The plot of variation in gas response (\%) vs. LPG concentration (ppm) of the $n-\mathrm{Bi}_{2} \mathrm{~S}_{3} / \mathrm{p}-\mathrm{PbS}$ heterojunction. The inset shows the band diagram of the $\mathrm{n}-\mathrm{Bi}_{2} \mathrm{~S}_{3} / \mathrm{p}-\mathrm{PbS}$ heterojunction. Reprinted with permission from ref. 177. Copyright 2017, Elsevier.

Benefitting from the interfacial Coulomb scattering and strong charge transfer, heterojunction-based devices have been used as $\mathrm{NH}_{3}$ gas sensors. Zhang et al. ${ }^{191}$ prepared $\mathrm{MoS}_{2} / \mathrm{ZnO}$ nanocomposites comprising ZnO NRs and $\mathrm{MoS}_{2}$ NSs, which could detect down to $12 \mathrm{ppb} \mathrm{NH}_{3}$. Response/recovery times of $10 \mathrm{~s} / 11 \mathrm{~s}$ were observed towards $50 \mathrm{ppm} \mathrm{NH}_{3}$ at room temperature. The first $\mathrm{MoS}_{2} / \mathrm{Co}_{3} \mathrm{O}_{4}$ nanocomposite $\mathrm{NH}_{3}$ sensor was demonstrated by Sun et al., which showed a high response of $10.3 \%$ towards $100 \mathrm{ppb} \mathrm{NH}_{3}$ with a response and recovery time of $98 \mathrm{~s} / 100 \mathrm{~s}$ at room temperature, see Fig. 24a. ${ }^{192}$ Moreover, an ultrahigh performance $\mathrm{NH}_{3}$ sensor based on a nanoporous $\mathrm{MoS}_{2} / \mathrm{VS}_{2}$ heteroarchitecture was successfully fabricated. As shown in Fig. 24b, the gas-sensing performance investigated using a quartz crystal microbalance (QCM) reveals that $\mathrm{MoS}_{2} /$ (a)

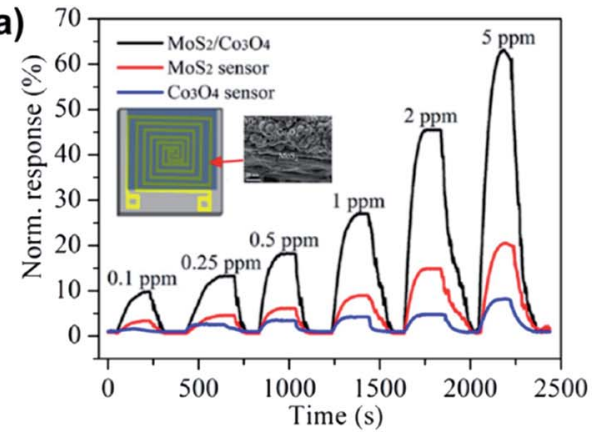

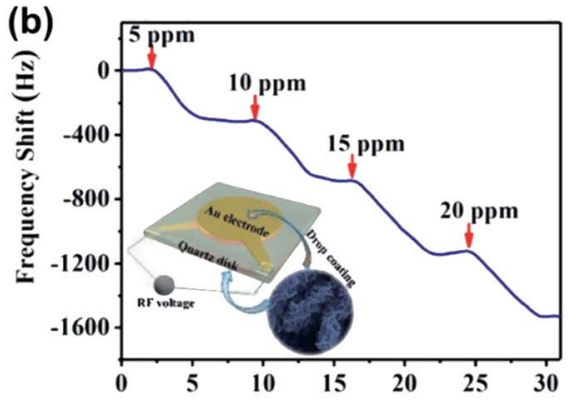

Fig. 24 (a) Normalized response of the $\mathrm{MoS}_{2} / \mathrm{CO}_{3} \mathrm{O}_{4} \mathrm{MoS}_{2}$, and $\mathrm{CO}_{3} \mathrm{O}_{4}$ film sensors toward various $\mathrm{NH}_{3}$ concentrations (inset: the schematic of the $\mathrm{MoS}_{2} / \mathrm{CO}_{3} \mathrm{O}_{4}$ gas sensor and SEM image of $\mathrm{MoS}_{2} / \mathrm{CO}_{3} \mathrm{O}_{4}$ ). Reprinted with permission from ref. 192. Copyright 2017, ACS Publishing. (b) The mass-normalized time-dependent frequency shifts of $\mathrm{NH}_{3}$ adsorption on the $\mathrm{MoS}_{2} / \mathrm{VS}_{2}$ heterostructure at $40{ }^{\circ} \mathrm{C}$ (inset: illustration of the $\mathrm{QCM}$ experimental sensor prepared via drop-coating of the $\mathrm{MoS}_{2} / \mathrm{VS}_{2}$ heterostructure onto the Au electrode). Reprinted with permission from ref. 193. Copyright 2019, Wiley-VCH Verlag GmbH \& Co. KGaA, Weinheim. 
$\mathrm{VS}_{2}$ exhibits a high adsorption uptake of $\Delta f=344.5 \mathrm{~Hz}$ toward 5 ppm $\mathrm{NH}_{3}$, which is much better than that of previously reported QCM $\mathrm{NH}_{3}$ sensors. ${ }^{193}$ Other $\mathrm{p}-\mathrm{n}$ heterojunction gas sensors, for instance, $2 \mathrm{D} \mathrm{WS}_{2}$ NSs decorated with $\mathrm{TiO}_{2}$ QDs, were proved to have a high response to $\mathrm{NH}_{3}$ gas at room temperature. ${ }^{194} \mathrm{Xu}$ et al. ${ }^{117}$ and Leonardi et al. ${ }^{195}$ synthesized $\mathrm{SnO}_{2}-\mathrm{SnS}_{2} \mathrm{p}-\mathrm{n}$ heterojunctions by the oxidation of $\mathrm{SnS}_{2}$ at high annealing temperature. The devices exhibited fast response time (11 s) at room temperature, much faster than that of other $\mathrm{NH}_{3}$ sensors. For other heterojunction gas sensors, Pr-SnS ${ }_{2} /$ $\mathrm{ZnS},{ }^{129} \mathrm{PbS} / \mathrm{TiO}_{2},{ }^{196}$ and $\mathrm{PbS} / \mathrm{NaS}_{2}$ (ref. 197) were proposed as sensing materials for $\mathrm{NH}_{3}$ detection. $\mathrm{Pr}-\mathrm{SnS}_{2} / \mathrm{ZnS}$ showed a high response $\%$ of $1303 \%$ and fast response/recovery time of $6 \mathrm{~s} / 13 \mathrm{~s}$ towards $50 \mathrm{ppm} \mathrm{NH}_{3}$ at an OT of $160{ }^{\circ} \mathrm{C}$, and $\mathrm{PbS} / \mathrm{NaS}_{2}$ had a high response $\%$ of $30000 \%$ when exposed to $8.08 \% \mathrm{NH}_{3}$ at room temperature. The gas-sensing performances of various metal sulfide-based $\mathrm{NH}_{3}$ gas sensors are listed in Table 7 . It was found that the sensor based on metal oxide/metal sulfide heterojunctions exhibits higher response\% and lower LOD.

4.2.2 $\mathrm{NO}_{2}$ and NO. $\mathrm{NO}_{2}$ is one of the most abundant air pollutants and is primarily emitted by fossil fuel burning, road traffic, indoor combustion, ${ }^{201}$ and biomass burning. ${ }^{202}$ It induces acid rain and photochemical smog. High concentrations of $\mathrm{NO}_{2}$ can irritate the human respiratory system. Long exposures to low $\mathrm{NO}_{2}$ concentrations also cause the development of asthma and respiratory symptoms. NO in exhaled breath is associated with inflammation of the air path, such as asthma and bronchiectasis. It is a typical biomarker for chronic obstructive pulmonary disease and nasal polyposis. ${ }^{203}$ The recommended concentration of NO for healthy people is below $25 \mathrm{ppb}$; when it is higher than $50 \mathrm{ppb}$, it is perhaps a sign of airway inflammation. ${ }^{204}$ Notably, $\mathrm{NO}$ is easily oxidized to $\mathrm{NO}_{2}$, indicating that it is challenging to detect NO directly using semiconductor gas sensors. Sometimes, the concentration of $\mathrm{NO}$ is usually reflected indirectly by detecting $\mathrm{NO}_{2}$. Li et al. ${ }^{\mathbf{2 2}}$ proposed a $\mathrm{MoS}_{2}$ FET NO sensor and compared and analyzed the sensors with monolayer, bilayer, trilayer, and quadrilayer $\mathrm{MoS}_{2}$. The response of the monolayer sensor is rapid and dramatic but unstable. In contrast, the multilayer sensors are stable and show sensitive responses down to a LOD of $0.8 \mathrm{ppm}$ NO. $\mathrm{TaS}_{2}$ NSs exfoliated by electrochemical lithium intercalation have been employed for the detection of NO and showed a high response $\%$ of $6000 \%$ towards 500 ppm NO and exhibited a sub-ppm LOD. ${ }^{60} \mathrm{~A} \mathrm{TaS}_{3}$ nanofibre NO gas sensor exhibited a high sensitivity of $4.48^{\circ} \mu \mathrm{M}^{-1}$ and a low LOD of $0.48 \mathrm{ppb}$, well under the allowed value set by the WHO, see Fig. $25 .^{65}$ The different types of $\mathrm{NO}$ and $\mathrm{NO}_{2}$ gas sensors based on metal sulfides are summarised in Table 8.

Wang et al. ${ }^{33}$ proposed a $\mathrm{NO}_{2}$ gas sensor using large-sized SnS thin crystals, which present a high response\% of $20 \%$ towards $\mathrm{NO}_{2}$ at a $100 \mathrm{ppb}$ concentration, as well as superior selectivity, low LOD ( $\ll 100 \mathrm{ppb}$ ), and reversibility at room temperature. Benefitting from a large excitation Bohr radius (18 $\mathrm{nm}$ ), $\mathrm{PbS}$ thin films were synthesized and applied in $\mathrm{NO}_{2}$ detection, and they exhibited a response $\%$ of $35 \%$ for $50 \mathrm{ppm}$ $\mathrm{NO}_{2}$ at $150{ }^{\circ} \mathrm{C}$ with a rapid response time of $6 \mathrm{s.}^{207}$ Recently, Sonker et al. ${ }^{205}$ used a sol-gel method for fabricating CdS NPs, which can detect $20 \mathrm{ppm} \mathrm{NO}_{2}$ gas with a response\% of $17300 \%$

Table 7 Literature study on the gas-sensing performance of metal sulfide-based $\mathrm{NH}_{3}$ gas sensors

\begin{tabular}{|c|c|c|c|c|c|c|c|c|}
\hline Material & Structure & Synthesis method & Concentration & $\begin{array}{l}\text { Response } \\
(\%)\end{array}$ & $\begin{array}{l}\text { LOD } \\
(\mathrm{ppm})\end{array}$ & $\tau_{\mathrm{s}} / \tau_{\mathrm{r}}$ & $\begin{array}{l}\text { OT } \\
\left({ }^{\circ} \mathrm{C}\right)\end{array}$ & Ref. \\
\hline $\begin{array}{l}\mathrm{MoS}_{2} \text { (green } \\
\text { illumination) }\end{array}$ & Transistor & $\mathrm{ME}$ & $1000 \mathrm{ppm}$ & 86 & - & $\sim 800 \mathrm{~s} / 1500 \mathrm{~s}$ & RT & 83 \\
\hline \multirow[t]{2}{*}{$\mathrm{WS}_{2}$} & NFKs & Ball milling & 5 ppm & $\sim 1400^{*}$ & - & $\sim 120 \mathrm{~s} / \sim 150 \mathrm{~s}$ & RT & 187 \\
\hline & Phototransistor & $\mathrm{ME}$ & - & - & - & $2.6 \mathrm{~s} / 56 \mathrm{~s}$ & RT & 189 \\
\hline $\operatorname{ReS}_{2}$ & Phototransistor & $\mathrm{ME}$ & - & - & - & $\sim 70 \mathrm{~ms} / \sim 70 \mathrm{~ms}$ & RT & 190 \\
\hline \multirow[t]{3}{*}{$\mathrm{SnS}_{2}$} & $\begin{array}{l}2 \mathrm{D} \mathrm{SnS}_{2} \text { with sulfur } \\
\text { vacancies }\end{array}$ & $\begin{array}{l}\text { Chemical } \\
\text { exfoliation }\end{array}$ & $500 \mathrm{ppm}$ & 420 & - & $16 \mathrm{~s} / 450 \mathrm{~s}$ & RT & 109 \\
\hline & NFWs & $\begin{array}{l}\text { Solvothermal } \\
\text { method }\end{array}$ & $100 \mathrm{ppm}$ & $640 *$ & 0.5 & $40.6 \mathrm{~s} / 624 \mathrm{~s}$ & 200 & 188 \\
\hline & NFWs & $\begin{array}{l}\text { Hydrothermal } \\
\text { method }\end{array}$ & 5 ppm & 21.6 & - & $40-50 \mathrm{~s} / 100-120 \mathrm{~s}$ & RT & 198 \\
\hline Graphene/MoS 2 & Heterostructure & $\begin{array}{l}\text { ME-MoS } \\
\text { CVD-graphene }\end{array}$ & $100 \mathrm{ppm}$ & 6 & - & $\mathrm{NA} / 30 \mathrm{~min}$ & 150 & 199 \\
\hline $\mathrm{MoS}_{2} / \mathrm{ZnO}$ & Nanocomposites & LBL self-assembly & $50 \mathrm{ppm}$ & 46.2 & 0.012 & $10 \mathrm{~s} / 11 \mathrm{~s}$ & RT & 191 \\
\hline $\mathrm{MoS}_{2} / \mathrm{CuO}$ & Nanoworms & Sputtering & $100 \mathrm{ppm}$ & 47 & 5 & $17 \mathrm{~s} / 26 \mathrm{~s}$ & RT & 200 \\
\hline $\mathrm{MoS}_{2} / \mathrm{Co}_{3} \mathrm{O}_{4}$ & Nanocomposites & LBL self-assembly & $0.1 \mathrm{ppm}$ & 10.3 & 0.1 & $98 \mathrm{~s} / 100 \mathrm{~s}$ & RT & 192 \\
\hline $\mathrm{MoS}_{2} / \mathrm{VS}_{2}$ & Heterostructure, QCM & $\begin{array}{l}\text { Hydrothermal } \\
\text { method }\end{array}$ & 5 ppm & $\begin{array}{l}\Delta f=344.5 \\
\mathrm{~Hz}\end{array}$ & - & - & 40 & 193 \\
\hline $\mathrm{WS}_{2} / \mathrm{TiO}_{2}$ & Nanocomposites & Mixture solution & $500 \mathrm{ppm}$ & 56.69 & 20 & $\begin{array}{l}200 \mathrm{~s} / 174.43 \pm \\
13.75 \mathrm{~s}\end{array}$ & RT & 194 \\
\hline \multirow[t]{2}{*}{$\mathrm{SnS}_{2} / \mathrm{SnO}_{2}$} & NFKs & Annealing & 50 ppm & $40^{*}$ & - & $\sim 60 \mathrm{~s} / \sim 300 \mathrm{~s}$ & 130 & 195 \\
\hline & Hybrids & Oxidation & $10 \mathrm{ppm}$ & $16^{*}$ & - & $11 \mathrm{~s} / \mathrm{NA}$ & $\mathrm{RT}$ & 117 \\
\hline $\operatorname{Pr}-\mathrm{SnS}_{2} / \mathrm{ZnS}$ & NFWs & $\begin{array}{l}\text { Hydrothermal } \\
\text { method }\end{array}$ & $50 \mathrm{ppm}$ & $1303^{*}$ & - & $6 \mathrm{~s} / 13 \mathrm{~s}$ & 160 & 129 \\
\hline $\mathrm{PbS}$ QDs$/ \mathrm{TiO}_{2}$ & NTs & SILAR & $100 \mathrm{ppm}$ & $1649 *$ & 2 & $\sim 10 \mathrm{~s} / \sim 10 \mathrm{~s}$ & RT & 196 \\
\hline $\mathrm{PbS} / \mathrm{NaS}_{2}$ & NPs & - & $8.08 \%$ & $30000 *$ & - & $46 \mathrm{~s} / 67 \mathrm{~s}$ & RT & 197 \\
\hline
\end{tabular}


(a)

at $70{ }^{\circ} \mathrm{C}$. Donarelli et al. ${ }^{29}$ found that $\mathrm{LPE}-\mathrm{MoS}_{2}$ NFKs after annealing in air at $150{ }^{\circ} \mathrm{C}$ and $250{ }^{\circ} \mathrm{C}$ can show a p-type and ntype conductivity, respectively. The p-type $\mathrm{MoS}_{2}$ showed 15\% response towards $1 \mathrm{ppm}$ with fast response/recovery time $(11 \mathrm{~s} /$ $22 \mathrm{~s}$ ), while the n-type $\mathrm{MoS}_{2}$ exhibited a higher response\% of $480 \%$ and a lower LOD of $20 \mathrm{ppb}$. Xu et al. ${ }^{208}$ synthesized ultrathin $\mathrm{WS}_{2}$ NSs through a hydrothermal and calcination process, which showed a high response of $9.3 \%$ after exposure to 0.1 ppm $\mathrm{NO}_{2}$ gas at room temperature. Ko et al. ${ }^{211}$ proved that the $\mathrm{WS}_{2}$ gas sensor showed dramatically improved response $(667 \%)$ and recovery upon $\mathrm{NO}_{2}$ exposure after functionalization with AgNWs. Another $\mathrm{WS}_{2} / \mathrm{WO}_{3}$-based gas sensor showed an excellent LOD of $40 \mathrm{ppb}$ in dry air for $\mathrm{NO}_{2}$ at an OT of $150{ }^{\circ} \mathrm{C}^{215}$ $2 \mathrm{D} \mathrm{SnS}_{2}$-based gas sensors presented a high response\% of $3533 \%$ toward 10 ppm $\mathrm{NO}_{2}$ and showed highly selective and reversible $\mathrm{NO}_{2}$ sensing. ${ }^{210}$ Kim et al. ${ }^{59}$ fabricated a room temperature $\mathrm{NO}_{2}$ sensor using $2 \mathrm{D} \mathrm{NbS}_{2}$, which showed a response\% of $2832 \%$ toward 10 ppm $\mathrm{NO}_{2}$ and a low LOD of $241.02 \mathrm{ppb}$.

For metal-metal sulfide Schottky junctions, Liu et al. ${ }^{\mathbf{1 8 6}}$ observed a considerable $\mathrm{SB}$ in the $\mathrm{Ti} / \mathrm{Au}$ electrodes and at the CVD-MoS 2 contact interface, which showed a conductance change of 2-3 orders of magnitude upon exposure to sub-ppb level concentrations of $\mathrm{NO}_{2}$ and $\mathrm{NH}_{3}$. Besides, vdW vertical Schottky junctions of graphene and semiconductors have attracted considerable attention as emerging transducers for gas sensors. Tabata et al. ${ }^{212}$ deeply analyzed the $\mathrm{NO}_{2}$ gas-sensing performance of a graphene/ $\mathrm{MoS}_{2}$-based gas sensor, where the SBH was modulated by bias- and gate-voltage. The device exhibited an ultra-high response\% of $160000 \%$ after $10 \mathrm{~min}$ exposure to $\mathrm{NO}_{2}$. To know the difference between the Schottky junction of metal-metal sulfides and graphene-metal sulfides, (b)

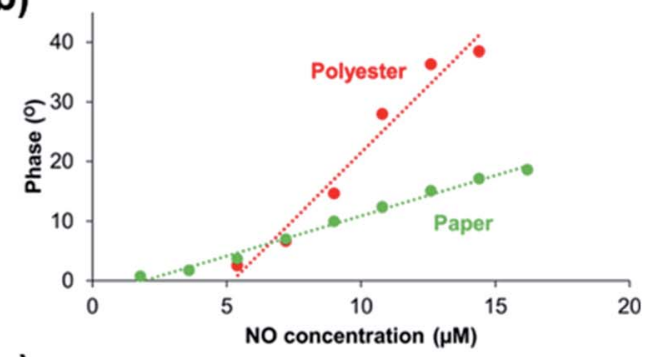

(c)

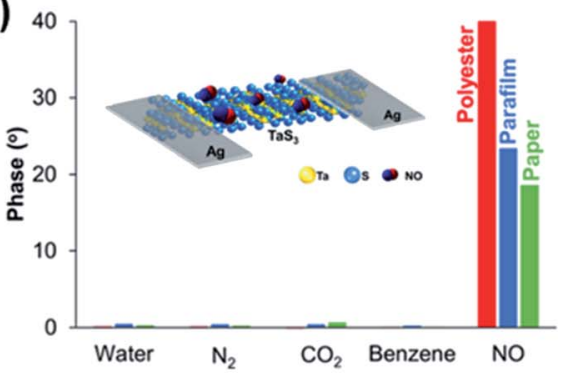

Pham et al. ${ }^{\mathbf{1 1 4}}$ compared and analyzed the gas-sensing performances of CVD $\mathrm{MoS}_{2}$ with Au metal electrodes ( $\left.\mathrm{Au}-\mathrm{MoS}_{2}-\mathrm{Au}\right)$, graphene electrodes ( $\left.\mathrm{Gr}-\mathrm{MoS}_{2}-\mathrm{Gr}\right)$, and graphene/Au electrodes $\left(\mathrm{Au} / \mathrm{Gr}-\mathrm{MoS}_{2}-\mathrm{Gr} / \mathrm{Au}\right)$. The resulting $\mathrm{Au} / \mathrm{Gr}-\mathrm{MoS}_{2}-\mathrm{Gr} / \mathrm{Au}$ gas sensor under red light illumination showed a significant enhancement of the device response\% toward $150 \mathrm{ppb}$ of $\mathrm{NO}_{2}$ gas reaching $500 \%$ (see Fig. 26). The excellent performance could be attributed to the encapsulation of graphene electrodes with the $\mathrm{Au}$ layer affecting the work function of graphene, resulting in an increasing $\mathrm{SBH}$. Furthermore, $\mathrm{Au} / \mathrm{Gr}$ electrodes could hinder the negative effects of the modulation of the work function induced by the doped graphene with $\mathrm{NO}_{2}$ molecules.

For heterojunction-based devices, $\mathrm{MoS}_{2} / \mathrm{SnO}_{2} \mathrm{p}-\mathrm{n}$ heterojunctions were constructed and used for ethanol, TMA, and $\mathrm{NO}_{2}$ gas sensing. ${ }^{119-121}$ They exhibited high sensitivity, lower OT, excellent sensing selectivity, and outstanding long-term stability. Shao et al. ${ }^{\mathbf{2 1 4}}$ fabricated $\mathrm{rGO}-\mathrm{MoS}_{2}-\mathrm{CdS}$ nanocomposite films via solvothermal treatment and analyzed the sensing performance. The results showed a largely enhanced sensor response of $27.4 \%$ toward $0.2 \mathrm{ppm} \mathrm{NO}_{2}$, approximately 7 times higher than the value for the rGO- $\mathrm{MoS}_{2}$ based gas sensor. Moreover, $\mathrm{a} \mathrm{SnO}_{2}-\mathrm{SnS}_{2} \mathrm{p}-\mathrm{n}$ heterojunction was employed in the $\mathrm{NO}_{2}$ gas sensor. ${ }^{117,148}$

A FET gas sensor was used for $\mathrm{NO}_{2}$ gas sensing because the conductance of the channel can be modulated by applying different bias voltages on the gate electrode. Late et al. ${ }^{83}$ analyzed the $\mathrm{NO}_{2}$ sensing behaviours of the $\mathrm{MoS}_{2}$ transistor, Fig. 17. The response was enhanced after applying gate bias. Similarly, $\mathrm{WS}_{2}$ (ref. 189) and $\mathrm{ReS}_{2}$ (ref. 190) FETs were employed to detect different gases, such as $\mathrm{O}_{2}, \mathrm{NH}_{3}$, and $\mathrm{NO}_{2}$. As mentioned in Section 3.5, the strong electron transfer between the FET channel materials and the gas molecule could alter the 
carrier concentration of the channel, modulate the mobility, further affect semiconductor work function, and finally change the current of the FET. ${ }^{221,222}$ Based on this mechanism, our group analyzed a $\mathrm{WS}_{2} / \mathrm{IGZO} \mathrm{p}-\mathrm{n}$ junction-based gas sensor in chemiresistor and transistor mode, respectively. ${ }^{217}$ It was found that the transistor shows an ultra-high response after exposure to $\mathrm{NO}_{2}$, with a response\% of $499400 \%$ for $300 \mathrm{ppm}$, which is $\sim 27$ times higher than that in chemiresistor mode (see Fig. 27ac). One special case reported by Tabata et $a .^{212}$ is the graphene/ $\mathrm{MoS}_{2}$ heterojunction (GMH) sensor. As shown in Fig. 27d-f, the device had a high response $\%$ to $\mathrm{NO}_{2}$ of $160000 \%$ at a $0 \mathrm{~V}$ backgate voltage $\left(V_{\mathrm{BG}}\right)$; however, when $V_{\mathrm{BG}}=40 \mathrm{~V}$, the response $\%$ decreased to $600 \%$. They found that the drain current was primarily determined by the $\mathrm{SBH}$ at the counter Schottky diode of the $\mathrm{MoS}_{2} / \mathrm{Ti}$ contact, and the $\mathrm{NO}_{2}$-induced modulation in the $\mathrm{SBH}$ at the GMH was not reflected in the sensor response. Last but not least, the SAW $\mathrm{NO}_{2}$ sensor uses SnS CQDs as the sensing layer and is fabricated on a quartz substrate. ${ }^{\mathbf{1 4 0}}$ The sensor could detect a low concentration of $\mathrm{NO}_{2}$ gas at room temperature with a good efficiency and selectivity (see Fig. 19).

4.2.3 $\mathrm{CO}_{2}$ and $\mathrm{O}_{2}$. $\mathrm{CO}_{2}$ is the fourth most abundant component of dry air. Tests have shown that $5 \% \mathrm{CO}_{2}$ is not harmful to humans if sufficient oxygen is present, but once the $\mathrm{O}_{2}$ concentration is less than $17 \%$, even $4 \% \mathrm{CO}_{2}$ can cause severe poisoning. Considering that the ambient concentration of $\mathrm{CO}_{2}$ is approximately $0.03 \%$, the required LOD for $\mathrm{CO}_{2}$

Table 8 Literature study on the $\mathrm{NO}_{x}$ sensing performance of metal sulfide-based devices

\begin{tabular}{|c|c|c|c|c|c|c|c|c|c|}
\hline Material & Structure & Synthesis method & Analyt & $\begin{array}{l}\text { Concentration } \\
(\mathrm{ppm})\end{array}$ & Response (\%) & LOD & $\tau_{\mathrm{s}} / \tau_{\mathrm{r}}$ & $\mathrm{OT}\left({ }^{\circ} \mathrm{C}\right)$ & Ref. \\
\hline SnS & Thin crystal & Solvothermal method & $\mathrm{NO}_{2}$ & 0.1 & 20 & - & $\mathrm{NA} / 5 \mathrm{~s}$ & RT & 33 \\
\hline \multirow[t]{2}{*}{ CdS } & Thin film & Chemical route & $\mathrm{NO}_{2}$ & 20 & 17300 & - & $331 \mathrm{~s} / 207 \mathrm{~s}$ & 70 & 205 \\
\hline & Thin film & Chemical bath deposition & $\mathrm{NO}_{2}$ & 200 & 61 & - & $50 \mathrm{~s} / \mathrm{NA}$ & RT & 206 \\
\hline \multirow[t]{2}{*}{$\mathrm{PbS}$} & Thin film & Chemical bath deposition & $\mathrm{NO}_{2}$ & 100 & 74 & - & $20 \mathrm{~s} / 36 \mathrm{~s}$ & 38 & 100 \\
\hline & Thin film & SILAR & $\mathrm{NO}_{2}$ & 50 & 35 & - & $6 \mathrm{~s} / 97 \mathrm{~s}$ & 150 & 207 \\
\hline $\mathrm{TaS}_{2}$ & NSs & $\begin{array}{l}\text { Electrochemical lithium- } \\
\text { intercalation }\end{array}$ & NO & 5 & 60 & - & - & RT & 60 \\
\hline $\mathrm{TaS}_{3}$ & Nanofibres & Vapour-phase growth & NO & - & $\begin{array}{l}\text { Sensitivity } 4.48^{\circ} \\
\mu \mathrm{M}^{-1}\end{array}$ & $\begin{array}{l}0.48 \\
\mathrm{ppb}\end{array}$ & - & RT & 65 \\
\hline \multirow[t]{3}{*}{$\mathrm{MoS}_{2}$} & Transistor & ME & NO & 2 & 80 & $0.8 \mathrm{ppm}$ & - & RT & 82 \\
\hline & Transistor & $\mathrm{ME}$ & $\mathrm{NO}_{2}$ & 1000 & 1372 & - & $\begin{array}{l}\sim 800 \mathrm{~s} / 1500 \\
\mathrm{~s}\end{array}$ & $\begin{array}{l}\text { RT (green } \\
\text { light) }\end{array}$ & 83 \\
\hline & NFKs & LPE & $\mathrm{NO}_{2}$ & 1 & $\begin{array}{l}15 \text { (p-type) } \\
480 \text { (n-type) }\end{array}$ & $20 \mathrm{ppb}$ & $\begin{array}{l}11 \mathrm{~s} / 22 \mathrm{~s} \\
41 \mathrm{~s} / 39 \mathrm{~s}\end{array}$ & 200 & 29 \\
\hline $\mathrm{WS}_{2}$ & NSs & $\begin{array}{l}\text { Hydrothermal method \& } \\
\text { calcination }\end{array}$ & $\mathrm{NO}_{2}$ & 0.1 & 9.3 & $100 \mathrm{ppb}$ & $\begin{array}{l}5 \mathrm{~min} / 25 \\
\min \end{array}$ & RT & 208 \\
\hline $\mathrm{SnS}_{2}$ & $\begin{array}{l}2 \mathrm{D} \\
2 \mathrm{D} \text { flakes }\end{array}$ & $\begin{array}{l}\text { Ball milling } \\
\text { Solvothermal method }\end{array}$ & $\begin{array}{l}\mathrm{NO}_{2} \\
\mathrm{NO}_{2}\end{array}$ & $\begin{array}{l}10 \\
10\end{array}$ & $\begin{array}{l}2000 \\
3533^{*}\end{array}$ & - & $\begin{array}{l}6 / 40 \mathrm{~s} \\
\sim 170 \mathrm{~s} / \sim 140 \\
\mathrm{~s}\end{array}$ & $\begin{array}{l}250 \\
120\end{array}$ & $\begin{array}{l}209 \\
210\end{array}$ \\
\hline $\mathrm{NbS}_{2}$ & NSs & CVD & $\mathrm{NO}_{2}$ & 10 & 2832 & $\begin{array}{l}241.02 \\
\mathrm{ppb}\end{array}$ & $\begin{array}{l}3000 \mathrm{~s} / 9000 \\
\mathrm{~s}\end{array}$ & RT & 59 \\
\hline Ag NWs-WS 2 & NSs & ALD & $\mathrm{NO}_{2}$ & 500 & 667 & - & $\begin{array}{l}5 \mathrm{~min} / 10 \\
\min \end{array}$ & RT & 211 \\
\hline $\mathrm{Al} / \mathrm{MoS}_{2}$ & Schottky contact & CVD & $\mathrm{NO}_{2}$ & 10 & 60 & - & $\begin{array}{l}\sim 5 \min / \sim 20 \\
\min \end{array}$ & RT & 111 \\
\hline $\begin{array}{l}\mathrm{Au} / \mathrm{Gr}-\mathrm{MoS}_{2}- \\
\mathrm{Gr} / \mathrm{Au}\end{array}$ & Schottky contact & CVD & $\mathrm{NO}_{2}$ & 0.15 & $500^{*}$ & $0.1 \mathrm{ppb}$ & $\begin{array}{l}\sim 1000 \mathrm{~s} / \\
\sim 700 \mathrm{~s}\end{array}$ & $\begin{array}{l}\text { RT (red } \\
\text { light) }\end{array}$ & 114 \\
\hline $\mathrm{Gr}-\mathrm{MoS}_{2}$ & Schottky contact & $\mathrm{ME}$ & $\mathrm{NO}_{2}$ & 1 & 160000 & - & - & RT & 212 \\
\hline $\mathrm{MoS}_{2} / \mathrm{SnO}_{2}$ & Heterostructures & Chemical methods & $\mathrm{NO}_{2}$ & 5 & $1770 *$ & - & $74 \mathrm{~s} / \mathrm{NA}$ & RT & 121 \\
\hline $\mathrm{MoS}_{2} / \mathrm{ZnO}$ & NWs & Hydrothermal method \& CVD & $\mathrm{NO}_{2}$ & 50 & 31.2 & $0.2 \mathrm{ppm}$ & $\begin{array}{l}60 \mathrm{~min} / 65 \\
\min \end{array}$ & 200 & 213 \\
\hline $\begin{array}{l}\text { rGO--MoS } 2_{2}^{-} \\
\mathrm{CdS}\end{array}$ & Nanocomposite & Hydrothermal method & $\mathrm{NO}_{2}$ & 0.2 & 27.4 & - & $25 \mathrm{~s} / 34 \mathrm{~s}$ & 75 & 214 \\
\hline $\mathrm{WS}_{2} / \mathrm{WO}_{3}$ & Nanocomposites & Oxidation & $\mathrm{NO}_{2}$ & 0.4 & $100^{*}$ & $400 \mathrm{ppb}$ & - & 150 & 215 \\
\hline $\mathrm{WS}_{2} / \mathrm{ZnS}$ & Heterostructures & ${\mathrm{LPE}-W S_{2}}_{2}$ chemical method & $\mathrm{NO}_{2}$ & 5 & $3150 *$ & $10 \mathrm{ppb}$ & $4 \mathrm{~s} / \sim 400 \mathrm{~s}$ & RT & 216 \\
\hline $\mathrm{WS}_{2} / \mathrm{IGZO}$ & Heterojunction & CVD, sputtering & $\mathrm{NO}_{2}$ & $\begin{array}{l}5 \\
300\end{array}$ & $\begin{array}{l}6820 \\
499400\end{array}$ & $26 \mathrm{ppb}$ & - & RT & 217 \\
\hline $\mathrm{SnS}_{2} / \mathrm{SnO}_{2}$ & Nanocomposites & Oxidation & $\mathrm{NO}_{2}$ & 8 & $430^{*}$ & $1 \mathrm{ppm}$ & $159 \mathrm{~s} / 297 \mathrm{~s}$ & 80 & 148 \\
\hline $\mathrm{SnS}_{2} / \mathrm{SiO}_{2}$ & Nanograins & CVD & $\mathrm{NO}_{2}$ & 10 & 701 & $\begin{array}{l}408.9 \\
\mathrm{ppb}\end{array}$ & $\begin{array}{l}272.8 \mathrm{~s} / \\
3800.4 \mathrm{~s}\end{array}$ & RT & 218 \\
\hline $\mathrm{SnS}_{2} / \mathrm{rGO}$ & Heterojunction & Hydrothermal method & $\mathrm{NO}_{2}$ & 8 & 49.8 & $8.7 \mathrm{ppb}$ & NA/76 s & RT & 219 \\
\hline $\begin{array}{l}\text { PbS QDs/ } \\
\mathrm{MoS}_{2}\end{array}$ & Nanocomposites & $\begin{array}{l}\text { Hydrothermal method \& } \\
\text { chemical precipitation }\end{array}$ & $\mathrm{NO}_{2}$ & 100 & $\sim 23$ & - & $30 \mathrm{~s} / 235 \mathrm{~s}$ & RT & 220 \\
\hline $\mathrm{ZnS} / \mathrm{CuO}$ & NWs & $\begin{array}{l}\text { Thermal evaporation \& } \\
\text { solvothermal method }\end{array}$ & $\mathrm{NO}_{2}$ & 5 & $955^{*}$ & - & $45 \mathrm{~s} / 170 \mathrm{~s}$ & $\begin{array}{l}\text { RT (UV } \\
\text { light) }\end{array}$ & 133 \\
\hline
\end{tabular}


(a)
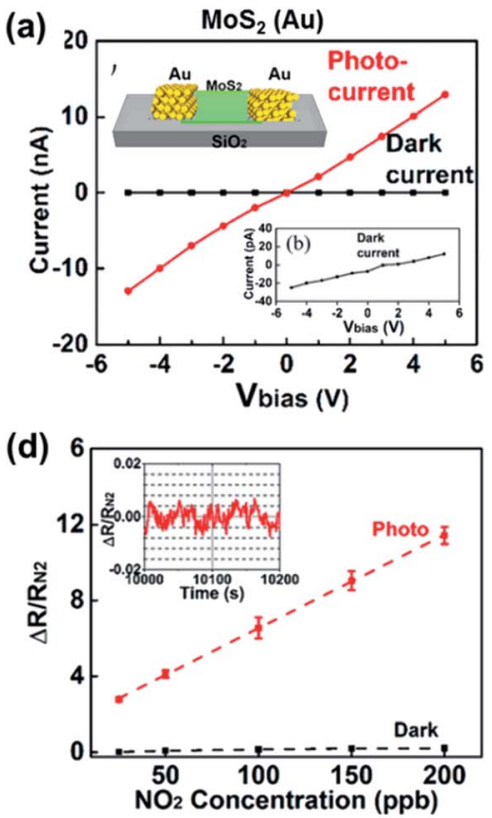

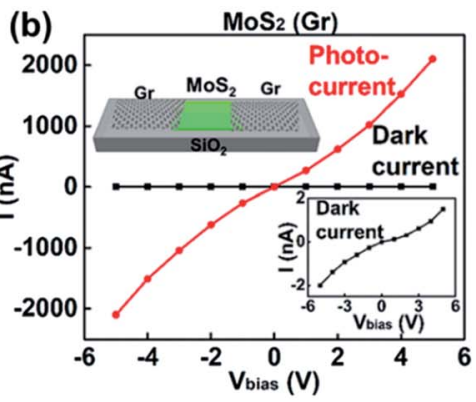

(e)

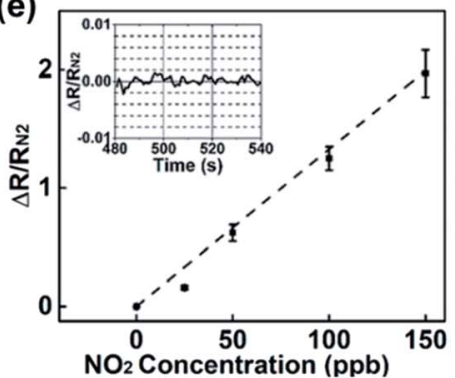

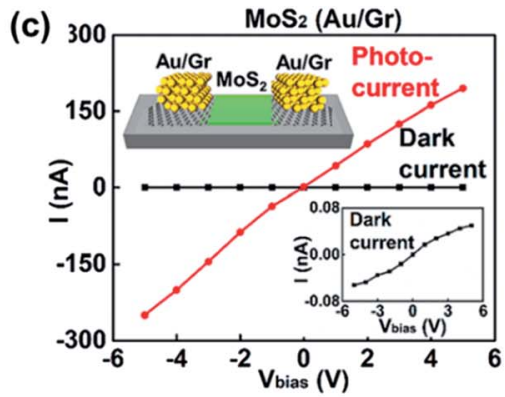

(f)

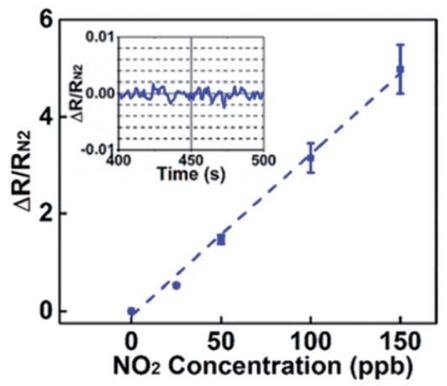

Fig. $26 I-V$ curves under red LED illumination (red line) and in the dark (black line) of (a) Au-MoS $2-A u$, (b) Gr-MoS $2-G r$, and (c) Au/Gr-MoS $2-$ $\mathrm{Gr} / \mathrm{Au}$ devices. The insets show the corresponding schematics of the devices and expanded $I-V$ curves in the dark. (d-f) Dependence of the normalized amplitude of the resistance change of (d) $\mathrm{Au}-\mathrm{MoS}_{2}-\mathrm{Au}$, (e) $\mathrm{Gr}-\mathrm{MoS}_{2}-\mathrm{Gr}$, and (f) $\mathrm{Au} / \mathrm{Gr}-\mathrm{MoS} \mathrm{S}_{2}-\mathrm{Gr} / \mathrm{Au}$ devices on the concentration of $\mathrm{NO}_{2}$ gas. The inset image shows a temporal trace of the experimentally recorded noise of $\Delta R / R_{\mathrm{N}_{2}}$. All data were collected under a dc bias of 5 V. Reprinted with permission from ref. 114. Copyright 2019, ACS Publishing.

sensors could be at the ppm-level. Because $\mathrm{CO}_{2}$ is a kind of nonpolar gas owing to its linear and symmetrical structure, the adsorption energy between $\mathrm{CO}_{2}$ and the surface of metal sulfides is low. To this end, a new optical $\mathrm{CO}_{2}$ sensor based on the colorimetric change of the $\mathrm{pH}$ indicator $\alpha$-naphtholphthalein with the internal reference fluorescent CIS/ZnS QDs was developed. ${ }^{223,224}$ The experimental result reveals that the new optical $\mathrm{CO}_{2}$ sensor has a response $\%$ of $\left(I_{100}-I_{0}\right) / I_{0} \times 100 \%=$ $1240 \%$. Similarly, Chu et al. ${ }^{225}$ developed a CdSe/ZnS QD based optical fibre $\mathrm{CO}_{2}$ sensor, which showed a high response $\%$ of $\left(R_{0}\right.$ $-R) / R \times 100 \%=84 \%$ and exhibited a uniquely linear response to $\mathrm{CO}_{2}$ concentrations in the range of $0-100 \%$. The gas testing setup of the fibre-optic $\mathrm{CO}_{2}$ sensor is shown in Fig. 28, and this testing method can quantitively measure the $\mathrm{CO}_{2}$ concentration; however, it cannot detect changes of the fluorescence spectra in real-time.

$\mathrm{O}_{2}$ is a major component of air and greatly affects metal corrosion protection, fuel combustion, and food storage. It is

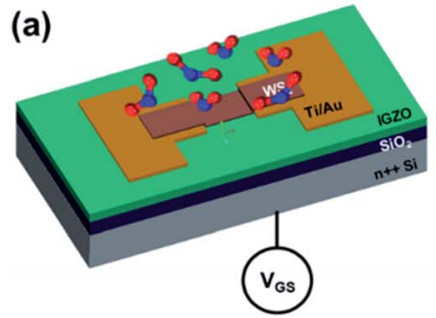

(d)

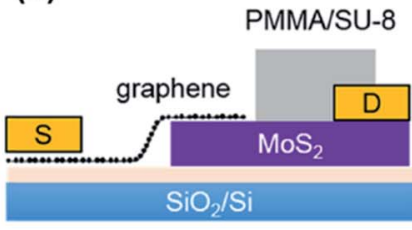

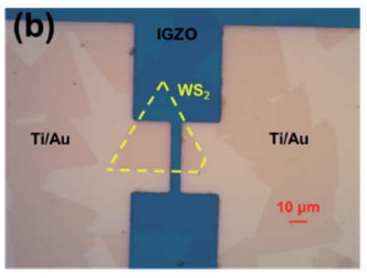
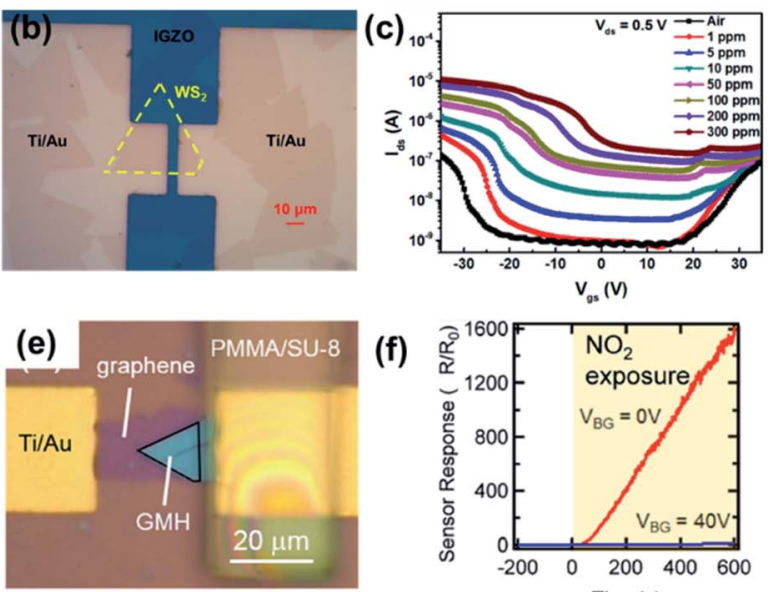

Fig. 27 (a) Schematic diagram and (b) optical image of the $\mathrm{WS}_{2} / \mathrm{IGZO}$ transistor. (c) Transfer curves of the $\mathrm{WS}_{2} / \mathrm{IGZO}$ transistor under different $\mathrm{NO}_{2}$ concentrations. Reprinted with permission from ref. 217. Copyright 2019, ACS Publishing. (d) Schematic diagram and (e) optical image of the graphene/MoS 2 heterojunction (GMH) device with a gas barrier layer. (f) Time-dependent sensor responses of GMH under different gate voltages $\left(V_{\mathrm{BG}}=0\right.$ and $\left.40 \mathrm{~V}\right)$. Reprinted with permission from ref. 212. Copyright 2019, ACS Publishing. 
(a)
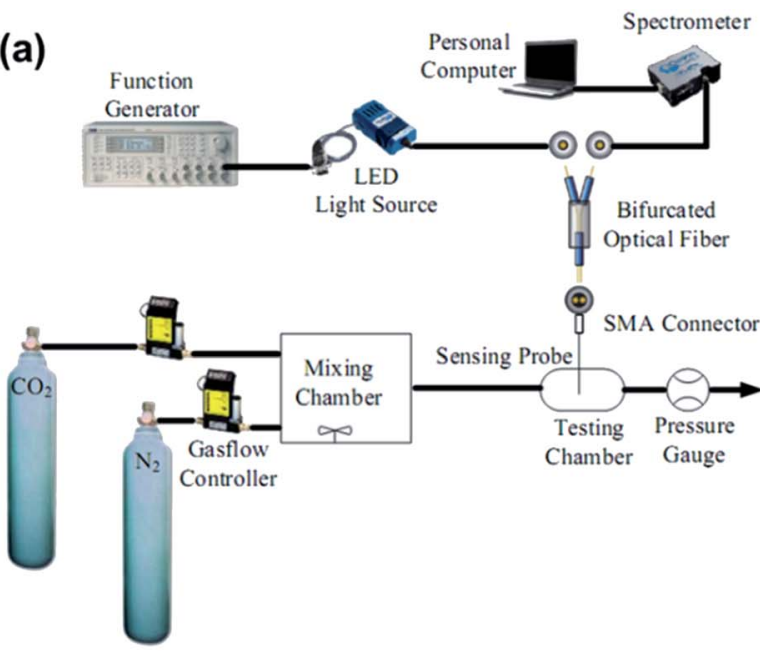

(b)

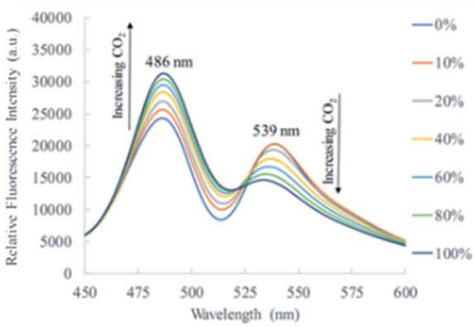

(c)

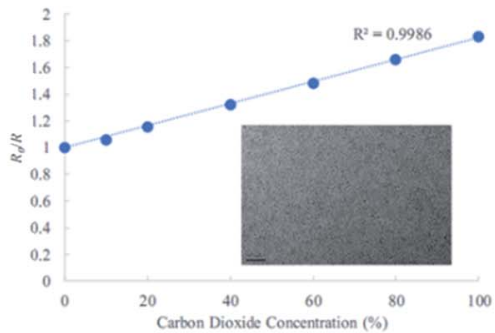

Fig. 28 (a) Experimental setup for the ratiometric optical fibre $\mathrm{CO}_{2}$ sensing. (b) Fluorescence spectra of the ratiometric optical fibre sensor under different $\mathrm{CO}_{2}$ concentrations. (c) Calibration curve of the ratiometric optical fibre $\mathrm{CO}_{2}$ sensor at $0-100 \%$ concentration. Reprinted with permission from ref. 225. Copyright 2019, SPIE publishing.

essential to monitor the $\mathrm{O}_{2}$ content in industrial production and medical care. Metal sulfide nanomaterials for $\mathrm{O}_{2}$ sensing have not been extensively studied. Kim et al. ${ }^{226}$ prepared $\mathrm{MoS}_{2}$ NP-based gas sensors through LPE methods and investigated their $\mathrm{O}_{2}$ sensing behaviour, which showed a high response $\%$ of $769 \%$ towards a $2 \%$ concentration of $\mathrm{O}_{2}$ and a low LOD at the ppb level. Li et al. ${ }^{227}$ proposed a $2 \mathrm{D} \mathrm{SnS}_{2}$-based sensor, which provided high and reversible responses to $\mathrm{O}_{2}$ pulses in the range of 0 to $20 \%$ volume in the dark at $150{ }^{\circ} \mathrm{C}$. They applied UV irradiation for improving the $\mathrm{O}_{2}$ sensing performance. Karami et al. ${ }^{228}$ synthesized $\mathrm{SnS}-\mathrm{SnO}_{2}$ nanocomposites and used them as $\mathrm{O}_{2}$ gas-sensing agents, which showed a high dynamic range, high sensitivity to $\mathrm{O}_{2}$, fast response time, and low memory effect without any interference from the other gases $\left(\mathrm{OT}=128{ }^{\circ} \mathrm{C}\right)$.

4.2.4 $\mathrm{H}_{2} \mathrm{~S}$ and $\mathrm{SO}_{2}$. Both $\mathrm{H}_{2} \mathrm{~S}$ and $\mathrm{SO}_{2}$ are hazardous gases and atmospheric pollutants. $\mathrm{H}_{2} \mathrm{~S}$ smells like rotten eggs and irritates people's eyes, nose, and throat. Long-term exposure to $\mathrm{H}_{2} \mathrm{~S}$ above $100 \mathrm{ppm}$ can cause death. In the human body, $\mathrm{H}_{2} \mathrm{~S}$ is a kind of metabolic product that has an unpleasant odor and is associated with halitosis. $\mathrm{SO}_{2}$ is highly corrosive and easily oxidized to create sulfuric acid in the air. These two gases pose significant threats to the environment and human health and require accurate measurement.

PbS CQDs have been used as $\mathrm{H}_{2} \mathrm{~S}$ gas sensing materials, and

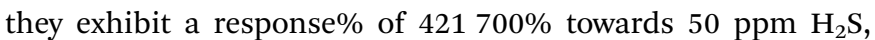
which is considerably high, and a fast response/recovery time of $23 \mathrm{~s} / 171 \mathrm{~s} .{ }^{101}$ Metal oxide/metal sulfide heterojunctions, such as $\mathrm{ZnS} / \mathrm{ZnO}^{132}$ and $\mathrm{CuS} / \mathrm{CuO}{ }^{229}$ have been employed for the detection of $\mathrm{H}_{2} \mathrm{~S}$ gas, see Fig. 29. Souda and Shimizu ${ }^{106}$ tested various metal monosulfide-based gas sensors (NiS, CdS, SnS, and $\mathrm{PbS}$ ), which showed a high $\mathrm{SO}_{2}$ response at $300-400{ }^{\circ} \mathrm{C}$. The CdS-based sensor has the best sensing performance, whose response was almost linear with the logarithm of $\mathrm{SO}_{2}$ concentration between 20 and $200 \mathrm{ppm}$. It has a $90 \%$ response $\%$ to $100 \mathrm{ppm} \mathrm{SO}_{2}$ but the response time is as long as 2-4 min and it works at $400{ }^{\circ} \mathrm{C}$. Zhang et al. ${ }^{90}$ fabricated a room-temperature (a)

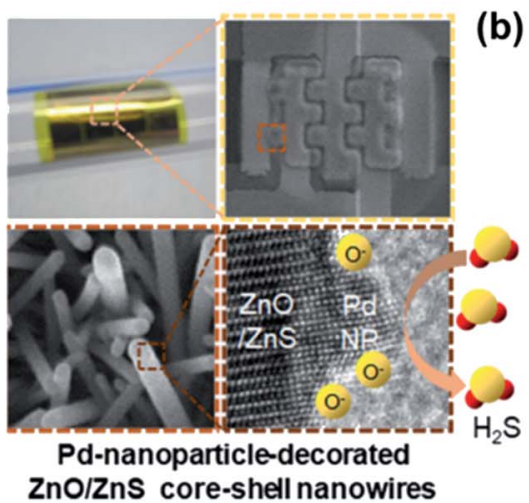

(b)

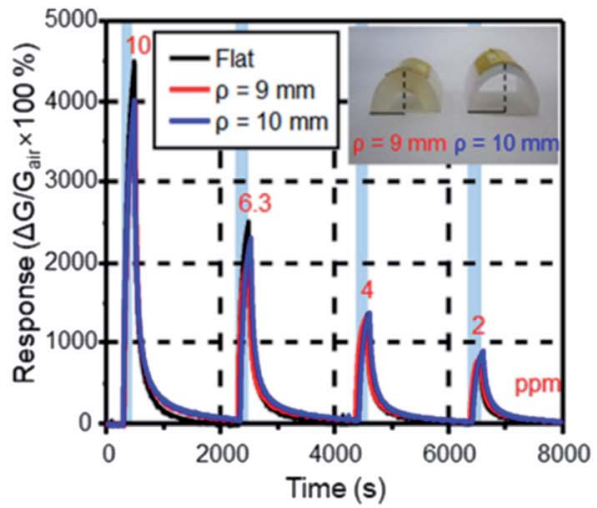

Fig. 29 (a) Photograph and SEM and TEM images of a $\mathrm{ZnO} / \mathrm{ZnS} \mathrm{NW}$ sensor on a flexible substrate and (b) the $\mathrm{H}_{2} \mathrm{~S}$ gas sensing result. Reprinted with permission from ref. 132. Copyright 2019, ACS Publishing. 
$\mathrm{SO}_{2}$ sensor using metal-doped $\mathrm{MoS}_{2}$ NFWs. The Ni-doped $\mathrm{MoS}_{2}$ showed the best performance among different metal-doped $\mathrm{MoS}_{2}$ (i.e., Ni-, Fe-, Co-doped $\mathrm{MoS}_{2}$ ) compounds and showed a $7.4 \%$ response \% toward 5 ppm $\mathrm{SO}_{2}$ and a low LOD of $250 \mathrm{ppb}$. Table 9 summarises the gas sensing properties of metal sulfidebased sensors for $\mathrm{CO}_{2}, \mathrm{O}_{2}, \mathrm{H}_{2} \mathrm{~S}$, and $\mathrm{SO}_{2}$. It is clear that $\mathrm{PbS}$ is an ideal candidate for $\mathrm{H}_{2} \mathrm{~S}$ gas detection, and there is room for functionalized $\mathrm{MoS}_{2}$ for the detection of other types of gases (i.e., $\mathrm{SO}_{2}$ and $\mathrm{O}_{2}$ ).

4.2.5 $\mathbf{H}_{2} \cdot \mathrm{H}_{2}$ is a colorless, tasteless, odorless, and flammable gas. It is an excellent candidate carrier in the clean energy area, such as for automobile engines and fuel cells. Thus it requires high-performance $\mathrm{H}_{2}$ sensors in mobile transportation as well as household environments. Hafeez et al. ${ }^{231}$ compared and analyzed the $\mathrm{H}_{2}$ gas-sensing performance of $\mathrm{ZnS}$ nanostructures with different morphologies (NWs, nanodots
(NDs), and nanoleaves (NLs)). They found that NWs have higher cohesive energy than others, which showed a response\% of $800 \%$ towards $50000 \mathrm{ppm}_{2}$ gas at an OT of $230{ }^{\circ} \mathrm{C}$. Sabah et $a l .{ }^{\mathbf{1 0 4}}$ prepared a CuS thin film by spray pyrolysis deposition using deionized water and used it for the detection of $\mathrm{H}_{2}$ gases. Linganiso et al. ${ }^{\mathbf{1 0 5}}$ synthesized NiS nanostructures and measured the $\mathrm{H}_{2}$ gas sensitivity, which has $158 \%$ response to 100 ppm $\mathrm{H}_{2}$ at $300{ }^{\circ} \mathrm{C}$. Baek and $\mathrm{Kim}^{\mathbf{1 0 7}}$ fabricated an $\mathrm{H}_{2}$ sensor with few-layered Pd-doped $\mathrm{MoS}_{2}$, which exhibited a $35.3 \%$ response $\%$ when exposed to a $1 \% \mathrm{H}_{2}$-containing gas. In contrast, the pristine $\mathrm{MoS}_{2}$ showed no reaction. Perrozzi et al. ${ }^{215}$ demonstrated that the $\mathrm{H}_{2}$ gas sensor based on $\mathrm{WS}_{2} / \mathrm{WO}_{3}$ hierarchical heterostructures with surface oxygen and sulfur vacancies had a high response $\%$ of $430 \%$ towards $500 \mathrm{ppm} \mathrm{H}_{2}$ and exhibited a low LOD of $1 \mathrm{ppm}$. The sensors showed no substantial humidity cross-sensitivity effects, indicating the

Table 9 Gas sensing properties of metal sulfide-based sensors for inorganic gases

\begin{tabular}{|c|c|c|c|c|c|c|c|c|c|}
\hline Material & Structure & Synthesis method & Analyte & Concentration & Response (\%) & LOD & $\tau_{\mathrm{s}} / \tau_{\mathrm{r}}$ & OT $\left({ }^{\circ} \mathrm{C}\right)$ & Ref. \\
\hline \multirow[t]{2}{*}{ CIS/ZnS (optical) } & QDs & Hydrothermal method & \multirow[t]{2}{*}{$\mathrm{CO}_{2}$} & 100 vol\% & $1240^{*}$ & - & - & RT & 223 \\
\hline & QDs & Hydrothermal method & & 100 vol\% & 99.6 & - & - & $\mathrm{RT}$ & 224 \\
\hline CdSe/ZnS (optical) & QDs & Hydrothermal method & $\mathrm{CO}_{2}$ & 100 vol $\%$ & $84^{*}$ & - & - & RT & 225 \\
\hline $\mathrm{MoS}_{2}$ & NPs & Chemical exfoliation & $\mathrm{O}_{2}$ & 2 vol\% & $769^{*}$ & $49.96 \mathrm{ppb}$ & - & 300 & 226 \\
\hline GaS & NSs & ME & $\mathrm{O}_{2}$ & - & - & - & - & - & 230 \\
\hline $\mathrm{SnS}_{2}$ & 2D flakes & Wet-chemical method & $\mathrm{O}_{2}$ & 2 vol\% & $160^{*}$ & - & $10 \mathrm{~min} / 15 \mathrm{~min}$ & 130 (UV) & 227 \\
\hline $\mathrm{SnS}-\mathrm{SnO}_{2}$ & Nanocomposite & Electrochemical deposition & $\mathrm{O}_{2}$ & 19 ppm & 21000 & $900 \mathrm{ppb}$ & $52 \mathrm{~s} / 38 \mathrm{~s}$ & 128 & 228 \\
\hline $\mathrm{PbS}$ & QDs & Deposition & $\mathrm{H}_{2} \mathrm{~S}$ & $500 \mathrm{ppm}$ & $421700^{*}$ & - & $23 \mathrm{~s} / 171 \mathrm{~s}$ & 135 & 101 \\
\hline $\mathrm{CuS} / \mathrm{CuO}$ & Nanocomposite & Solvothermal method & $\mathrm{H}_{2} \mathrm{~S}$ & $1.88 \%$ & 313900 & - & $75 \mathrm{~s} / 67 \mathrm{~s}$ & RT & 229 \\
\hline $\mathrm{ZnS} / \mathrm{ZnO}$ & Nanocomposite & Hydrothermal method & $\mathrm{H}_{2} \mathrm{~S}$ & $10 \mathrm{ppm}$ & 4491 & & $99 \mathrm{~s} / 88 \mathrm{~s}$ & 95 & 132 \\
\hline $\mathrm{CdS}$ & 2D flakes & Wet-chemical method & $\mathrm{SO}_{2}$ & $100 \mathrm{ppm}$ & - & - & $15 \mathrm{~min} / \mathrm{NA}$ & 400 & 106 \\
\hline Ni-doped $\mathrm{MoS}_{2}$ & NFWs & Hydrothermal method & $\mathrm{SO}_{2}$ & $5 \mathrm{ppm}$ & 7.4 & $250 \mathrm{ppb}$ & $51 \mathrm{~s} / 73 \mathrm{~s}$ & RT & 90 \\
\hline
\end{tabular}

Table 10 Gas sensing properties of metal sulfide-based sensors for $\mathrm{H}_{2}$

\begin{tabular}{|c|c|c|c|c|c|c|c|c|}
\hline Material & Structure & Synthesis method & Concentration & $\begin{array}{l}\text { Response } \\
(\%)\end{array}$ & LOD (ppm) & $\tau_{\mathrm{s}} / \tau_{\mathrm{r}}$ & OT $\left({ }^{\circ} \mathrm{C}\right)$ & Ref. \\
\hline $\mathrm{ZnS}$ & Nanostructures & PVD & $50000 \mathrm{ppm}$ & 800 & - & - & 230 & 231 \\
\hline $\mathrm{CuS}$ & Film & Spray pyrolysis & $1000 \mathrm{ppm}$ & 9890 & - & $16 / 34 \mathrm{~s}$ & $\mathrm{RT}$ & 104 \\
\hline Au-coated NiS & Nanostructures & Hydrothermal method & $95 \%$ & $58 *$ & - & $\sim 50 \mathrm{~s} / \sim 100 \mathrm{~s}$ & 300 & 105 \\
\hline Pd-doped $\mathrm{MoS}_{2}$ & NSs & Solution processing & $1 \%$ & 35.3 & 50 & $\sim 500 \mathrm{~s} / \sim 1200 \mathrm{~s}$ & RT & 107 \\
\hline $\mathrm{WS}_{2} / \mathrm{WO}_{3}$ & Nanocomposites & Oxidation & $500 \mathrm{ppm}$ & $430 *$ & 1 & - & 150 & 215 \\
\hline
\end{tabular}

(a)

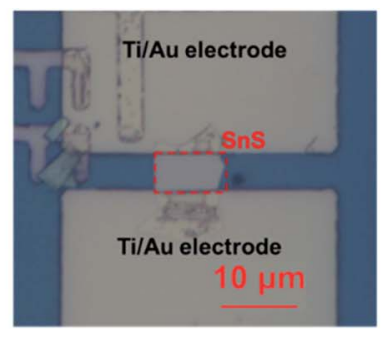

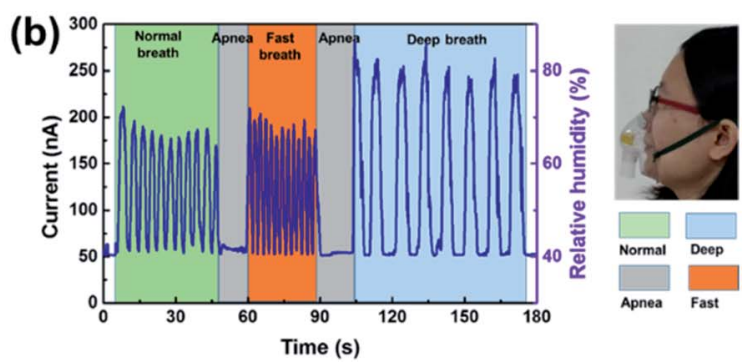

Fig. 30 (a) Optical image of a SnS nanoflake-based sensor. (b) Real-time respiration detection by using a SnS humidity sensor. Reprinted with permission from ref. 71. Copyright 2019, ( IOP Publishing. All rights reserved. 
Table 11 The humidity sensing performances of fibre-optic sensing devices in the literature

\begin{tabular}{lllll}
\hline Device structure & $\tau_{\mathrm{s}}(\mathrm{s})$ & $\tau_{\mathrm{r}}(\mathrm{s})$ & Dynamic range of response & Ref. \\
\hline $\mathrm{MoS}_{2}$-coated ESMF & 0.066 & 2.395 & $0.487 \mathrm{~dB} /(20-80 \% \mathrm{RH})$ & 237 \\
$\mathrm{MoS}_{2}$-coated SPF & 0.85 & 0.85 & $13.5 \mathrm{~dB} /(40-85 \% \mathrm{RH})$ & 138 \\
$\mathrm{WS}_{2}$-coated SPF & 1 & 4 & $9 \mathrm{~dB} /(37-90 \% \mathrm{RH})$ & 236
\end{tabular}

great potential application in real-world $\mathrm{H}_{2}$ detection. Various metal sulfide-based $\mathrm{H}_{2}$ gas sensors are listed in Table 10.

4.2.6 Humidity sensor. Humidity sensors have been successfully used in various fields, such as environmental monitoring, industrial production, and the medical instrumentation field. Tang et al. ${ }^{71}$ demonstrated that SnS NFKs could be used for real-time respiration detection due to their high response \% of $2491000 \%$ and fast response/recovery time (6 s/4 s), suitable for health monitoring, see Fig. 30. Guo et al. fabricated transparent and flexible $\mathrm{WS}_{2}$ based humidity sensors for electronic skin, with a wide relative humidity range (up to 90\%) with fast response and recovery in a few seconds. ${ }^{232}$ Feng et al. ${ }^{233}$ fabricated a flexible touchless positioning interface based on a highly sensitive $\mathrm{VS}_{2}$ NS humidity sensor. However, $\mathrm{VS}_{2}$ ultrathin NSs have poor stability. To improve the stability, Chen et al. proposed a $\mathrm{MoS}_{2} / \mathrm{VS}_{2}$ (ref. 35) sensor; after 30 days its response \% was maintained at around $579750 \%$, indicating that the nanocomposite sensor has good long-term stability. Chemiresistor sensors based on $\mathrm{ReS}_{2} \mathrm{NSs}^{234}$ and $\mathrm{MoS}_{2}$ decorated with $\mathrm{Pt} \mathrm{NPs}^{\mathbf{2 3 5}}$ were reported. The Pt-MoS ${ }_{2}$ sensor showed a high and stable response $\%$ of $400000 \%$ at $85 \%$ RH when tested over a few months.

Apart from the chemiresistor sensor, the optical, impedance, and capacitive sensors were employed for the detection of humidity. Luo et al. ${ }^{236}$ and Li et al. ${ }^{138}$ demonstrated all-fibreoptic humidity sensors comprising a $\mathrm{WS}_{2}$ and $\mathrm{MoS}_{2}$ film overlay on an SPF, respectively. They used a $1550 \mathrm{~nm}$ laser with SPF, which removes a portion of the cladding to form a polished region; propagated light confined in the core can escape out to this polished surface via evanescent waves, giving rise to strong interactions between light and the external environment. The responses of different types of fibre-optic humidity sensors are listed in Table 11. It is found that the $\mathrm{MoS}_{2}$-coated SPF sensor has a high response, and the $\mathrm{MoS}_{2}$-coated ESMF has a fast response time, which enables the fibre-optic sensor to monitor different breathing patterns of human beings. The impedance and capacitive humidity sensors are listed in Table 12. All of them show ultra-high sensing response, for instance, the sensing response of $\mathrm{SmFeO}_{3}$-modified $\mathrm{MoS}_{2}$ nanocomposites is more than five orders of magnitude (10 598 100\%) within the whole $\mathrm{RH}$ range of $11 \%$ to $95 \% \mathrm{RH}$ at $10 \mathrm{~Hz}$. Moreover, the combination of a polymeric material, $\operatorname{poly}(3,4-$ ethylenedioxythiophene) polystyrene sulfonate (PEDOT:PSS), and $\mathrm{MoS}_{2}$ 2D NFKs gives a humidity sensor with an ultra-fast response and excellent recovery with values of $0.5 \mathrm{~s}$ and $0.8 \mathrm{~s}$, respectively.

All the mentioned metal sulfide-based humidity sensors can work at room temperature, leading to wearable electronics applications. Among these four types of humidity sensors, fibre-

Table 12 Comparison of different metal sulfide-based humidity sensors

\begin{tabular}{|c|c|c|c|c|c|c|c|c|}
\hline Material & Structure & Synthesis method & Type & $\begin{array}{l}\text { RH range } \\
(\%)\end{array}$ & Response (\%) or Sensitivity & $\tau_{\mathrm{s}} / \tau_{\mathrm{r}}$ & $\begin{array}{l}\mathrm{OT} \\
\left({ }^{\circ} \mathrm{C}\right)\end{array}$ & Ref. \\
\hline $\mathrm{SnS}$ & Nanoflakes & LPE & Resistive & $3-99$ & $2491000(99 \% \mathrm{RH})$ & $6 \mathrm{~s} / 4 \mathrm{~s}$ & RT & 71 \\
\hline $\mathrm{WS}_{2}$ & Thin film & CVD & Resistive & $25-90$ & $235600 *(90 \% \mathrm{RH})$ & $\sim 5 \mathrm{~s} / \sim 6 \mathrm{~s}$ & RT & 232 \\
\hline $\operatorname{ReS}_{2}$ & Nanosheets & CVD & Resistive & $30-80$ & $600(70 \% \mathrm{RH})$ & $20 \mathrm{~s} / 10 \mathrm{~s}$ & RT & 234 \\
\hline $\mathrm{VS}_{2}$ & Nanosheets & LPE & Resistive & $0-90$ & $2900 *(90 \% \mathrm{RH})$ & $\begin{array}{l}30-40 \mathrm{~s} / 12- \\
50 \mathrm{~s}\end{array}$ & RT & 233 \\
\hline $\mathrm{Pt}-\mathrm{MoS}_{2}$ & NFKs & Solution methods & Resistive & $35-85$ & $400000(85 \% \mathrm{RH})$ & $\begin{array}{l}91.2 \mathrm{~s} / 153.6 \\
\mathrm{~s}\end{array}$ & RT & 235 \\
\hline $\mathrm{TaS}_{2}$ & Nanosheets & CVD & Impedance & $11-95$ & $20190(11 \% \mathrm{RH})$ & $0.6 \mathrm{~s} / 2 \mathrm{~s}$ & RT & 238 \\
\hline $\mathrm{MoS}_{2}$ & Nanospheres & Hydrothermal method & Capacitive & $17.2-89.5$ & $81.9 \mathrm{pF} / \% \mathrm{RH}$ (sensitivity) & $140 \mathrm{~s} / 80 \mathrm{~s}$ & RT & 239 \\
\hline $\mathrm{MoS}_{2}$ & QDs & LPE & Impedance & $10-95$ & $2.21 \mathrm{M} \Omega / \% \mathrm{RH}$ (sensitivity) & $14 \mathrm{~s}$ & RT & 240 \\
\hline $\mathrm{MoS}_{2} / \mathrm{VS}_{2}$ & Nanocomposite & Hydrothermal method & Impedance & $11-95$ & $579750 *(95 \% \mathrm{RH})$ & $23 \mathrm{~s} / 13 \mathrm{~s}$ & RT & 35 \\
\hline $\mathrm{MoS}_{2} / \mathrm{ZnO}$ & Nanocomposites & $\begin{array}{l}\text { Hydrothermal \& chemical } \\
\text { method }\end{array}$ & Impedance & 11-95 & - & $1 \mathrm{~s} / 20 \mathrm{~s}$ & RT & 241 \\
\hline $\mathrm{MoS}_{2} / \mathrm{Ag}$ & Nanocomposites & Mixture dispersion & Capacitive & $11-97$ & $21112 \mathrm{pF} / \% \mathrm{RH}$ (sensitivity) & $\sim 1.5 \mathrm{~s}$ & RT & 242 \\
\hline $\mathrm{MoS}_{2} / \mathrm{SnO}_{2}$ & Nanocomposite & Hydrothermal method & Capacitive & $0-97$ & $3285000(97 \% \mathrm{RH})$ & $5 / 13 \mathrm{~s}$ & RT & 243 \\
\hline $\mathrm{SmFeO}_{3} @ \mathrm{MoS}_{2}$ & Nanocomposites & Hydrothermal method & Impedance & $11-95$ & $10598100^{*}(95 \% \mathrm{RH})$ & $1.5 \mathrm{~s} / 29.8 \mathrm{~s}$ & RT & 244 \\
\hline $\begin{array}{l}\text { PEDOT:PSS/ } \\
\mathrm{MoS}_{2}\end{array}$ & Nanocomposites & Exfoliation \& deposition & Impedance & $0-80$ & $\begin{array}{l}50 \mathrm{k} \Omega / \% \mathrm{RH}, 850 \mathrm{~Hz} / \% \mathrm{RH} \\
\text { (sensitivity) }\end{array}$ & $0.5 \mathrm{~s} / 0.8 \mathrm{~s}$ & RT & 245 \\
\hline $\mathrm{SnS}_{2} / \mathrm{GO}$ & Nanocomposites & $\begin{array}{l}\text { Solvothermal method, } \\
\text { mixture }\end{array}$ & Impedance & $11-97$ & $6539600(97 \%$ RH $)$ & $0.9 \mathrm{~s} / 10 \mathrm{~s}$ & RT & 246 \\
\hline $\mathrm{SnS}_{2} / \mathrm{TiO}_{2}$ & Nanohybrid film & LBL self-assembly & Impedance & $11-97$ & $442000 \Omega / \% \mathrm{RH}$ (sensitivity) & $<58 \mathrm{~s}$ & RT & 247 \\
\hline $\mathrm{SnS}_{2} / \mathrm{Zn}_{2} \mathrm{SnO}_{4}$ & Nanohybrid & Solvothermal method & Capacitive & $0-97$ & 10709 pF/\% RH (sensitivity) & $18 \mathrm{~s} / 1 \mathrm{~s}$ & RT & 248 \\
\hline $\mathrm{ZnO} \mathrm{NDs} / \mathrm{WS}_{2}$ & Heterostructure & Evaporation & Capacitive & $18-85$ & $101.71 \mathrm{fF} / \% \mathrm{RH}$ (sensitivity) & $\begin{array}{l}74.51 \mathrm{~s} / 25.67 \\
\mathrm{~s}\end{array}$ & RT & 249 \\
\hline $\mathrm{WS}_{2} / \mathrm{SnO}_{2}$ & Nanocomposites & LBL self-assembly & Capacitive & $11-97$ & $\begin{array}{l}14125900 \text { (97\% RH) } \\
21112 \text { pF/\% RH (sensitivity) }\end{array}$ & $100 \mathrm{~s} / 100 \mathrm{~s}$ & RT & 250 \\
\hline
\end{tabular}


optic sensors have ultrafast response speed and low response and a complex measurement setup. However, it is necessary to find a way to easily integrate the fibre-optic sensor into one package that can be used for gas testing. Besides, humidity sensors can not only be used to monitor the patient's respiration profile continuously but also to determine the dehydration state. Highly sensitive and fast response and recovery humidity sensors are urgently required in real-world applications.

\section{Summary and perspectives}

This review shows a systematic summary of the crystal structure and gas sensing mechanism of metal sulfide nanomaterials, as well as the gas-sensing performance of metal sulfide-based devices. Here, to summarise the state-of-the-art metal sulfide gas sensors and analyse future and perspectives of the metal sulfide sensor market, we further provide a brief StrengthsWeaknesses-Opportunities-Threats (SWOT) analysis of metal sulfide technology for gas sensing.

\subsection{Strengths}

(1) Mechanism analysis. This is an efficient way to analyze and predict the gas sensing properties by combining theoretical (DFT) and experimental (i.e., materials characterization and gas testing) methods. For instance, the higher the adsorption energy, the higher the selectivity toward this kind of gas molecule; the ELF plot can reflect the chemical bond between the gas molecule and metal sulfides, which affect the nature of physisorption and chemisorption and further influence the recovery time of the device; the charge transfer between the gases and metal sulfides can reveal the donor or acceptor of the gases, which is associated with the change of conductivity.

(2) Improvements in gas sensing performance.

(i) Functionalization of metal sulfides. To further improve the sensitivity, doping and defect substitution are the most commonly used tools in functionalization and are efficient methods to change the band structure, modify the electronic and transport properties, and enhance the gas sensing applications. However, most of the gas sensing behaviours of functionalized metal sulfides were analyzed through DFT calculations. There are a lack of experimental reports on the influence of defects on the metal sulfide-based devices' gassensing performance.

(ii) Schottky junction and heterojunction gas sensors. They are based on band alignment theory, which can significantly improve the gas sensing response and LOD. Most of them have excellent sensing performances, including high response, fast response time, wide detection range, and low LOD. Thus, more people are focusing on junction-based gas sensors.

(iii) FET gas sensors. Most FET gas sensors ultimately modify the sensitivity towards a target gas by changing the energy landscape of the sensor surface. This type of sensing device has been used to detect many types of gases, such as $\mathrm{CO}, \mathrm{NO}, \mathrm{NH}_{3}$, $\mathrm{NO}_{2}, \mathrm{SO}_{2}, \mathrm{H}_{2}$, and VOCs. However, most of the FET gas sensors are still not satisfactory in the aspects of device instability and limited large-scale production, even though they have a fast response and selectivity.

(iv) Other sensing mechanisms. The optical gas sensor has been employed to detect non-polar gases, such as $\mathrm{CH}_{4}$, due to its high accuracy. Most of them are fibre optic gas sensors based on the reduction in the effective refractive index and showed high selectivity to methanol among VOCs. SAW gas sensors can detect a low concentration of $\mathrm{NO}_{2}$ gas at room temperature with good efficiency and selectivity, and they are coated with polymers for the identification of breath biomarkers and the diagnosis of various diseases.

(3) Applications. Suitable applications for each type of gas sensor are found according to the specific gas-sensing performance of various metal sulfides. It is found that the IV-VI compound pristine metal sulfides, such as $\mathrm{SnS}, \mathrm{PbS}$, and GeS, show fast response and recovery time. The II-VI compound semiconductors, such as CdS and $\mathrm{ZnS}$, have high response and selectivity to VOCs. However, most of their OTs are relatively high. Most of the transition metal sulfides have a larger electronegativity, potentially increasing the number of gas adsorption sites, and have been used for gas sensing of $\mathrm{NO}_{x}, \mathrm{NH}_{3}, \mathrm{O}_{2}$, and ethanol. With respect to VOCs, various pristine metal sulfides can be used for the detection of acetone, while functionalized or heterojunction-based metal sulfides are applied for sensing benzene, methane, formaldehyde, ethanol, and LPG. Most of them work at low temperatures, except for the detection of ethanol, whose OT is usually higher than $150{ }^{\circ} \mathrm{C}$. In the aspect of inorganic gases, all types of metal sulfides are used for sensors. Heterojunction-based and FET-based metal sulfide devices are promising candidates for gas sensing. They can take advantage of metal sulfide and other materials (such as metal, dissimilar metal sulfide, metal oxide, and organic materials) as well as the field-effect induced by back gate bias. The large surface to volume ratio combined with significant changes in the measured signals upon gas adsorption induce high sensitivity and selectivity and low LOD. Besides, to improve their performance, researchers used light illumination to stimulate the charge transfer between the gas molecules and metal sulfide. ${ }^{251}$ Thus, the light source can be integrated into the device in the future.

\subsection{Weaknesses}

(1) Lack of a low LOD. Biomarkers, such as $\mathrm{NO}_{x}, \mathrm{NH}_{3}$, and $\mathrm{CH}_{4}$, are at hundreds or tens of ppb in people. It is challenging to detect lung diseases, i.e., asthma, by the detection of $\mathrm{NO}_{x}$ in exhaled breath. $\mathrm{MoS}_{2} / \mathrm{ZnO}$ has the lowest LOD for $\mathrm{NH}_{3}$, which is $12 \mathrm{ppb}$. $\mathrm{Au} / \mathrm{Gr}-\mathrm{MoS}_{2}-\mathrm{Gr} / \mathrm{Au}$ can detect $0.1 \mathrm{ppb} \mathrm{NO}_{2}$, and $\mathrm{Ni}$ -

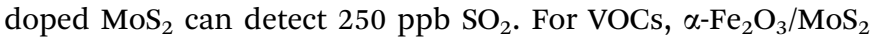
has a LOD of $1 \mathrm{ppm}$ toward ethanol at room temperature. However, it is not as low as the LOD requirement for biomarker detection.

(2) Insufficient gas selectivity. Most gas testing reported in previous work was conducted in dry atmospheres. In contrast, the working environment may be under high humidity conditions in the real world; for instance, exhaled human breath contains almost saturated moisture; the RH level is higher in 
the basin area. This thereby affects the sensitivity and selectivity of sensors. The effect of humidity could be reduced significantly by using a moisture absorber, increasing the OT, or optimizing the morphology or architecture of the materials. However, it is challenging to distinguish the specified concentration of the target gas in a mixture. For instance, the automobile exhaust pollutants primarily include $\mathrm{CO}$, hydrocarbons, $\mathrm{NO}, \mathrm{SO}_{2}$, particles (i.e., some lead compounds, oil mist, and heavy metal compounds), and odour (i.e., formaldehyde). The large-sized particles may cover the surface of the material and further affect the response to $\mathrm{NO}, \mathrm{CO}$, or $\mathrm{SO}_{2}$. Similarly, in the aspect of lung cancer detection, because there is no single biomarker for lung cancer, it is much more difficult than detecting asthma, diabetes, and halitosis. More work needs to be done in this field.

(3) Lack of reproducibility. 2D/nanostructured metal sulfides have large surface areas and abundant adsorption sites, which possess high adsorption energies towards gas molecules, especially chemisorbed gases. It is challenging to desorb them from the metal sulfides without external stimulation (high temperature, high bias voltage, or light illumination). Therefore, the devices could not be recovered to the initial state. Besides, the experimental conditions are hard to reproduce, and there are a lack of standardized methods to carry out the testing. Moreover, the absence of standardization, quality assurance, and reliable benchmarking are still crucial issues that hinder the applications of metal sulfides in the healthcare area.

(4) Lack of precise mechanism analysis. Most of the reported mechanisms are analyzed through DFT calculations. Sometimes, the simulation model cannot consider every detail shown in the experiment, which induces deviations between the simulation and experimental results. It is necessary to find an efficient tool or method to realize the benchmark.

All metal sulfide-based devices face the same problem as all solid-state sensors, such as translation from academic to industrial research, reproducibility of the lab conditions, batch production, integration/communication/power supply and realworld detection.

\subsection{Opportunities}

(1) New nanomaterials are emerging. Nanostructured metal sulfides with different forms, such as nanowires, nanoflowers, nanopores, and nanorods; or combined with hybrid materials, e.g., materials decorated with metal or semiconductor particles, Schottky junctions with a metal layer or CNMs, and heterostructures with hBN, MXene, and MOFs; or those using novel substrates, such as PVP, PI, PDMS, and other flexible substrates, can help to realize skin patching of human beings or can be integrated into a textile.

(2) The matching between materials and circuit electrodes, such as the energy band and work function, needs to be considered in terms of device design. Meanwhile, real-time detection applications, signal processing, low energy consumption, intelligent operation, and integration with sensor networks (e.g., internet of things) need to be considered. The combinations of 2D gas sensors with artificial intelligence in smart cities, smart homes, and smart hospitals are hot topics for the future.

(3) FET devices can effectively improve the gas sensing performance, but it is necessary to control their energy consumption and turn-on voltage reasonably in the future. Device performance can be enhanced by designing the device structure (shape and size of gate-drain electrodes), selecting the dielectric layer, and selecting the substrate. Some metal sulfides (such as $\mathrm{MoS}_{2}$ and $\mathrm{WS}_{2}$ ) could play an important role in electronics for logic, memory, and connections, enabling the extension of Moore's law, ${ }^{252}$ as well as the Paradigm of "More than Moore". ${ }^{253,254}$ There are primarily three challenges for these materials to meet industry needs in practical devices, such as the accuracy of the predicting properties, the methods of growing and testing high-quality materials, and the assessment of the device's performance.

\subsection{Threats}

The improvements of metal sulfide-based nanomaterials and other nanotechnologies in the gas-sensing performance are still being analyzed. The equipment used for the nanomaterialbased device should be different from those for traditional Sibased devices. For the future, the application of new nanomaterial devices still has a long way to go. For example, the current of the metal sulfide device is too small, and it is necessary to implement signal acquisition and intelligent control through a precise amplifier circuit. Defective materials are difficult to desorb, and additional UV light sources are needed to achieve rapid desorption, increasing the overall size and cost of the device. Time will be needed to reach market readiness and to overcome the reluctance to accept and introduce new technology, which now remains a severe hindrance in incorporating the production chain.

In this review, we listed the latest progress made in improving the field of 2D-metal sulfide-based gas sensors to overview the developments seen in this area extending from crystal features to device engineering. The crystal structures of metal sulfides and the gas sensing mechanism based on DFT analysis are introduced first. Various types of metal sulfidebased gas-sensing devices, including chemiresistors, functionalized-metal sulfides, Schottky diodes, heterojunctions, field-effect transistors, and optical, impedance, capacitive and SAW sensors, are compared and presented. We then discuss the extensive applications of metal sulfide-based sensors in gas sensing. Various gas sensors for the detection of VOC biomarkers (e.g., acetone, benzene, methane, formaldehyde, and ethanol) and inorganic gases (e.g., $\mathrm{CO}_{2}, \mathrm{NH}_{3}, \mathrm{H}_{2} \mathrm{~S}$, NO, and humidity) were discussed. There is a fabulous opportunity right now for developing 2D metal sulfides as gas sensors and use them for gas sensing, even integrated into the IoT system. However, they still have some shortcomings that need to be overcome, such as a high LOD, effect of a high humidity environment, insufficient gas selectivity, and low reproducibility in gas detection. It is necessary to develop new materials or construct advanced nanostructures to improve the 
performances. Additionally, from a device architecture perspective, implementation of the new signal-processing technology and recognition algorithms based on a single-chip system using multiplex detection channels is a significant and promising route for the development of gas sensing platforms.

\section{Conflicts of interest}

The authors declare no conflict of interest.

\section{References}

1 J. Zhang, X. Liu, G. Neri and N. Pinna, Adv. Mater., 2016, 28, 795-831.

2 A. Afroozeh, E. Akbari and P. Yupapin, J. Nanoelectron. Optoelectron., 2019, 14, 1225-1229.

3 S. Feng, F. Farha, Q. Li, Y. Wan, Y. Xu, T. Zhang and H. Ning, Sensors, 2019, 19, 3760.

4 S. Das and M. Pal, J. Electrochem. Soc., 2020, 167, 037562.

5 S. Orzechowska, A. Mazurek, R. Świsłocka and W. Lewandowski, Materials, 2019, 13, 80.

6 A. Roine, E. Veskimäe, A. Tuokko, P. Kumpulainen, J. Koskimäki, T. A. Keinänen, M. R. Häkkinen, J. Vepsäläinen, T. Paavonen, J. Lekkala, T. Lehtimäki, T. L. Tammela and N. K. J. Oksala, J. Urol., 2014, 192, 230-235.

7 J.-C. Juncker, Official Journal of the European Union, 2017, 6, 115-120, https://eur-lex.europa.eu/legal-content/EN/TXT/? uri=uriserv\%3AOJ.L_.2017.027.01.0115.01.ENG.

8 D. J. Buckley, N. C. G. Black, E. G. Castanon, C. Melios, M. Hardman and O. Kazakova, 2D Mater., 2020, 7, 032002.

9 G. Korotcenkov, Mater. Sci. Eng., B, 2007, 139, 1-23.

10 Y. Pang, J. Jian, T. Tu, Z. Yang, J. Ling, Y. Li, X. Wang, Y. Qiao, H. Tian, Y. Yang and T.-L. Ren, Biosens. Bioelectron., 2018, 116, 123-129.

11 L. Sacco, S. Forel, I. Florea and C.-S. Cojocaru, Carbon, 2020, 157, 631-639.

12 V. Schroeder, S. Savagatrup, M. He, S. Lin and T. M. Swager, Chem. Rev., 2019, 119, 599-663.

13 H. T. Kim, H. Y. Kim, Y. S. Park, Y. S. Kim and W. H. Jang, Chemosensors, 2017, 5, 15.

14 N. Taguchi, Japanese patent, 4538200, 1962.

15 W.-T. Koo, S.-J. Choi, N.-H. Kim, J.-S. Jang and I.-D. Kim, Sens. Actuators, B, 2016, 223, 301-310.

16 D. Kwak, M. Wang, K. J. Koski, L. Zhang, H. Sokol, R. Maric and Y. Lei, ACS Appl. Mater. Interfaces, 2019, 11, 1069710706.

17 J.-S. Jang, S.-J. Choi, S.-J. Kim, M. Hakim and I.-D. Kim, Adv. Funct. Mater., 2016, 26, 4740-4748.

18 W. Liu, L. Xu, K. Sheng, X. Zhou, B. Dong, G. Lu and H. Song, NPG Asia Mater., 2018, 10, 293-308.

19 Y. Chen, L. Yu, Q. Li, Y. Wu, Q. Li and T. Wang, Nanotechnology, 2012, 23, 415501.

20 Y. Deng, Semiconducting Metal Oxides for Gas Sensing, Springer, 2019.

21 E. Gabal, S. Chatterjee, F. K. Ahmed and K. A. Abd-Elsalam, in Carbon Nanomaterials for Agri-Food and Environmental
Applications, ed. K. A. Abd-Elsalam, Elsevier, 2020, pp. 133-153, DOI: 10.1016/B978-0-12-819786-8.00007-4.

22 C. R. Minitha, V. S. Anithaa, V. Subramaniam and R. T. Rajendra Kumar, ACS Omega, 2018, 3, 4105-4112.

23 R. Sha, S. K. Puttapati, V. V. S. S. Srikanth and S. Badhulika, J. Electroanal. Chem., 2017, 785, 26-32.

24 S. Kubendhiran, S. Sakthinathan, S.-M. Chen, P. Tamizhdurai, K. Shanthi and C. Karuppiah, J. Colloid Interface Sci., 2017, 497, 207-216.

25 F. Rigoni, S. Tognolini, P. Borghetti, G. Drera, S. Pagliara, A. Goldoni and L. Sangaletti, Analyst, 2013, 138, 7392-7399.

26 E. Singh, M. Meyyappan and H. S. Nalwa, ACS Appl. Mater. Interfaces, 2017, 9, 34544-34586.

27 E. Lee, Y. S. Yoon and D.-J. Kim, ACS Sens., 2018, 3, 20452060.

28 C.-H. Lai, M.-Y. Lu and L.-J. Chen, J. Mater. Chem., 2012, 22, 19-30.

29 M. Donarelli, S. Prezioso, F. Perrozzi, F. Bisti, M. Nardone, L. Giancaterini, C. Cantalini and L. Ottaviano, Sens. Actuators, B, 2015, 207, 602-613.

30 Z. Tian, C. Guo, M. Zhao, R. Li and J. Xue, ACS Nano, 2016, 11, 2219.

31 A. S. Rodin, L. C. Gomes, A. Carvalho and A. H. Castro Neto, Phys. Rev. B, 2016, 93, 045431.

32 S. Zhang, N. Wang, S. Liu, S. Huang, W. Zhou, B. Cai, M. Xie, Q. Yang, X. Chen and H. Zeng, Nanotechnology, 2016, 27, 274001.

33 J. Wang, G. Lian, Z. Xu, C. Fu, Z. Lin, L. Li, Q. Wang, D. Cui and C.-P. Wong, ACS Appl. Mater. Interfaces, 2016, 8, 95459551.

34 M. F. Afsar, M. A. Rafiq and A. I. Y. Tok, $R S C A d v .$, 2017, 7, 21556-21566.

35 X. Chen, K. Yu, Y. Shen, Y. Feng and Z. Zhu, ACS Appl. Mater. Interfaces, 2017, 9, 42139-42148.

36 W. Zhou, X. Zou, S. Najmaei, Z. Liu, Y. Shi, J. Kong, J. Lou, P. M. Ajayan, B. I. Yakobson and J.-C. Idrobo, Nano Lett., 2013, 13, 2615-2622.

37 J. Zhu, H. Zhang, Y. Tong, L. Zhao, Y. Zhang, Y. Qiu and X. Lin, Appl. Surf. Sci., 2017, 419, 522-530.

38 F. K. Perkins, A. L. Friedman, E. Cobas, P. M. Campbell, G. G. Jernigan and B. T. Jonker, Nano Lett., 2013, 13, 668673.

39 Z. Ashkavand, E. Sadeghi, R. Parvizi and M. Zare, ACS Appl. Mater. Interfaces, 2020, 12, 34283-34296.

40 S. Chandrasekaran, L. Yao, L. Deng, C. Bowen, Y. Zhang, S. Chen, Z. Lin, F. Peng and P. Zhang, Chem. Soc. Rev., 2019, 48, 4178-4280.

41 Y. Cui, Z. Zhou, T. Li, K. Wang, J. Li and Z. Wei, Adv. Funct. Mater., 2019, 29, 1900040.

42 S. Manzeli, D. Ovchinnikov, D. Pasquier, O. V. Yazyev and A. Kis, Nat. Rev. Mater., 2017, 2, 17033.

43 W. Choi, N. Choudhary, G. H. Han, J. Park, D. Akinwande and Y. H. Lee, Mater. Today, 2017, 20, 116-130.

44 J. Ping, Z. Fan, M. Sindoro, Y. Ying and H. Zhang, Adv. Funct. Mater., 2017, 27, 1605817.

45 Z. Xie, D. Wang, T. Fan, C. Xing, Z. Li, W. Tao, L. Liu, S. Bao, D. Fan and H. Zhang, J. Mater. Chem. B, 2018, 6, 4747-4755. 
46 S. Kouser, A. Thannikoth, U. Gupta, U. V. Waghmare and C. N. R. Rao, Small, 2015, 11, 4723-4730.

47 R. M. Martin, Phys. Rev. B: Solid State, 1970, 1, 4005-4011. 48 V. Lantto and V. Golovanov, Sens. Actuators, B, 1995, 25, 614-618.

49 Y. Rodríguez-Lazcano, H. Martínez, M. Calixto-Rodríguez and A. Núñez Rodríguez, Thin Solid Films, 2009, 517, 5951-5955.

50 D. G. Bell, D. M. Hum, L. Pincherle, D. W. Sciama, P. M. Woodward and N. F. Mott, Proc. R. Soc. London, Ser. A, 1953, 217, 71-91.

51 J. Tian and G. Cao, Nano Rev., 2013, 4, 22578.

52 J. Trahan, R. G. Goodrich and S. F. Watkins, Phys. Rev. B: Solid State, 1970, 2, 2859-2863.

53 Z. Wang, S. Ning, T. Fujita, A. Hirata and M. Chen, ACS Nano, 2016, 10, 10308-10316.

54 A. Splendiani, L. Sun, Y. Zhang, T. Li, J. Kim, C.-Y. Chim, G. Galli and F. Wang, Nano Lett., 2010, 10, 1271-1275.

55 T. A. J. Loh and D. H. C. Chua, J. Phys. Chem. C, 2015, 119, 27496-27504.

56 L. A. Burton, D. Colombara, R. D. Abellon, F. C. Grozema, L. M. Peter, T. J. Savenije, G. Dennler and A. Walsh, Chem. Mater., 2013, 25, 4908-4916.

57 L. Li, X. Fang, T. Zhai, M. Liao, U. K. Gautam, X. Wu, Y. Koide, Y. Bando and D. Golberg, Adv. Mater., 2010, 22, 4151-4156.

58 K. Xu, Z. Wang, F. Wang, Y. Huang, F. Wang, L. Yin, C. Jiang and J. He, Adv. Mater., 2015, 27, 7881-7887.

59 Y. Kim, K. C. Kwon, S. Kang, C. Kim, T. H. Kim, S.-P. Hong, S. Y. Park, J. M. Suh, M.-J. Choi, S. Han and H. W. Jang, ACS Sens., 2019, 4, 2395-2402.

60 Q. He, Q. Ma, B. Chen, Z. Yin, Z. Zeng, S. Wu, X. Cao, X. Kong and H. Zhang, APL Mater., 2014, 2, 092506.

61 S. Liu, W. Xiao, M. Zhong, L. Pan, X. Wang, H.-X. Deng, J. Liu, J. Li and Z. Wei, Nanotechnology, 2018, 29, 184002.

62 N. Rafiefard, A. Iraji zad, A. Esfandiar, P. Sasanpour, S. Fardindoost, Y. Zou, S. J. Haigh and S. H. H. Shokouh, Microchim. Acta, 2020, 187, 117.

63 Y.-R. Tao, X.-C. Wu and W.-W. Xiong, Small, 2014, 10, 49054911.

64 W.-W. Xiong, J.-Q. Chen, X.-C. Wu and J.-J. Zhu, J. Mater. Chem. C, 2014, 2, 7392-7395.

65 C. C. Mayorga-Martinez, Z. Sofer, J. Luxa, ک̌. Huber, D. Sedmidubský, P. Brázda, L. Palatinus, M. Mikulics, P. Lazar, R. Medlín and M. Pumera, ACS Nano, 2018, 12, 464-473.

66 W. Huang, L. Gan, H. Yang, N. Zhou, R. Wang, W. Wu, H. Li, Y. Ma, H. Zeng and T. Zhai, Adv. Funct. Mater., 2017, 27, 1702448.

67 U. G. E. Perera, H. J. Kulik, V. Iancu, L. G. G. V. Dias da Silva, S. E. Ulloa, N. Marzari and S. W. Hla, Phys. Rev. Lett., 2010, 105, 106601.

$68 \mathrm{C} . \mathrm{Xu}, \mathrm{X}$. Huang, X. Xu, X. Zhang and H. Zhang, Int. J. Quantum Chem., 2020, 120, e26120.

69 A. Savin, R. Nesper, S. Wengert and T. F. Fässler, Angew. Chem., Int. Ed. Engl., 1997, 36, 1808-1832.
70 J. K. Burdett and T. A. McCormick, J. Phys. Chem. A, 1998, 102, 6366-6372.

71 H. Tang, Y. Li, H. Ye, f. Hu, C. Gao, L.-Q. Tao, T. Tu, G. Gou, X. Chen, X. Fan, T.-L. Ren and G. Zhang, Nanotechnology, 2019, 31, 055501.

72 F. Hu, H. Tang, C. Tan, H. Ye, X. Chen and G. Zhang, IEEE Electron Device Lett., 2017, 38, 983-986.

73 S.-J. Choi and I.-D. Kim, Electron. Mater. Lett., 2018, 14, 221260.

74 Q. Yue, Z. Shao, S. Chang and J. Li, Nanoscale Res. Lett., 2013, 8, 425.

75 S. Zhao, J. Xue and W. Kang, Chem. Phys. Lett., 2014, 595596, 35-42.

76 J. Cha, K.-A. Min, D. Sung and S. Hong, Curr. Appl. Phys., 2018, 18, 1013-1019.

77 S. Ma, D. Yuan, Y. Wang and Z. Jiao, J. Mater. Chem. C, 2018, 6, 8082-8091.

78 D. B. Putungan, S.-H. Lin and J.-L. Kuo, Phys. Chem. Chem. Phys., 2015, 17, 21702-21708.

79 Y. Linghu and C. Wu, J. Phys. Chem. C, 2019, 123, 1033910345.

80 Q. Tang and D.-e. Jiang, Chem. Mater., 2015, 27, 3743-3748. 81 Z. Qin, D. Zeng, J. Zhang, C. Wu, Y. Wen, B. Shan and C. Xie, Appl. Surf. Sci., 2017, 414, 244-250.

82 H. Li, Z. Yin, Q. He, H. Li, X. Huang, G. Lu, D. W. H. Fam, A. I. Y. Tok, Q. Zhang and H. Zhang, Small, 2012, 8, 63-67.

83 D. J. Late, Y.-K. Huang, B. Liu, J. Acharya, S. N. Shirodkar, J. Luo, A. Yan, D. Charles, U. V. Waghmare, V. P. Dravid and C. N. R. Rao, ACS Nano, 2013, 7, 4879-4891.

84 Y. Li, X. Zhang, D. Chen, S. Xiao and J. Tang, Appl. Surf. Sci., 2018, 443, 274-279.

85 H. Luo, Y. Cao, J. Zhou, J. Feng, J. Cao and H. Guo, Chem. Phys. Lett., 2016, 643, 27-33.

86 H. Wei, Y. Gui, J. Kang, W. Wang and C. Tang, Nanomaterials, 2018, 8, 646.

87 A. Sharma, Anu, M. S. Khan, M. Husain, M. S. Khan and A. Srivastava, IEEE Sens. J., 2018, 18, 2853-2860.

88 D. Ma, W. Ju, T. Li, X. Zhang, C. He, B. Ma, Z. Lu and Z. Yang, Appl. Surf. Sci., 2016, 383, 98-105.

89 R. Zhang, D. Fu, J. Ni, C. Sun and S. Song, Chem. Phys. Lett., 2019, 715, 273-277.

90 D. Zhang, J. Wu, P. Li and Y. Cao, J. Mater. Chem. A, 2017, 5, 20666-20677.

91 Y. Kadioglu, G. Gökoğlu and O. Üzengi Aktürk, Appl. Surf. Sci., 2017, 425, 246-253.

92 V. Q. Bui, T.-T. Pham, D. A. Le, C. M. Thi and H. M. Le, J. Phys.: Condens. Matter, 2015, 27, 305005.

93 C. Zhou, W. Yang and H. Zhu, J. Chem. Phys., 2015, 142, 214704.

94 B. Zhao, C. Shang, N. Qi, Z. Y. Chen and Z. Q. Chen, Appl. Surf. Sci., 2017, 412, 385-393.

95 F. Li and C. Shi, Appl. Surf. Sci., 2018, 434, 294-306.

96 J. M. Jasmine, A. Aadhityan, C. Preferencial kala and D. J. Thiruvadigal, Appl. Surf. Sci., 2019, 489, 841-848.

97 H. Li, M. Huang and G. Cao, Phys. Chem. Chem. Phys., 2016, 18, 15110-15117.

98 L. A. Currie, Anal. Chim. Acta, 1999, 391, 105-126. 
99 J. Burgués, J. M. Jiménez-Soto and S. Marco, Anal. Chim. Acta, 2018, 1013, 13-25.

100 S. T. Navale, D. K. Bandgar, M. A. Chougule and V. B. Patil, RSC Adv., 2015, 5, 6518-6527.

101 H. Liu, M. Li, G. Shao, W. Zhang, W. Wang, H. Song, H. Cao, W. Ma and J. Tang, Sens. Actuators, B, 2015, 212, 434-439.

102 X.-H. Liu, P.-F. Yin, S. A. Kulinich, Y.-Z. Zhou, J. Mao, T. Ling and X.-W. Du, ACS Appl. Mater. Interfaces, 2017, 9, 602-609.

103 X. Wang, Z. Xie, H. Huang, Z. Liu, D. Chen and G. Shen, J. Mater. Chem., 2012, 22, 6845-6850.

104 F. A. Sabah, N. M. Ahmed, Z. Hassan and H. S. Rasheed, Sens. Actuators, A, 2016, 249, 68-76.

105 E. C. Linganiso, B. W. Mwakikunga, S. D. Mhlanga, N. J. Coville, B. T. Sone and M. Maaza, Sensors, 2012, 1-4.

106 N. Souda and Y. Shimizu, J. Mater. Sci., 2003, 38, 43014305.

107 D.-H. Baek and J. Kim, Sens. Actuators, B, 2017, 250, 686691.

108 A. A. Ramanathan, IOP Conf. Ser.: Mater. Sci. Eng., 2018, 305, 012001.

109 Z. Qin, K. Xu, H. Yue, H. Wang, J. Zhang, C. Ouyang, C. Xie and D. Zeng, Sens. Actuators, B, 2018, 262, 771-779.

110 R. T. Tung, Appl. Phys. Rev., 2014, 1, 011304.

111 Y. Kim, S.-K. Kang, N.-C. Oh, H.-D. Lee, S.-M. Lee, J. Park and H. Kim, ACS Appl. Mater. Interfaces, 2019, 11, 3890238909.

112 V. Van Quang, N. Van Dung, N. Sy Trong, N. Duc Hoa, N. Van Duy and N. Van Hieu, Appl. Phys. Lett., 2014, 105, 013107.

113 X. Zheng, A. Calò, E. Albisetti, X. Liu, A. S. M. Alharbi, G. Arefe, X. Liu, M. Spieser, W. J. Yoo, T. Taniguchi, K. Watanabe, C. Aruta, A. Ciarrocchi, A. Kis, B. S. Lee, M. Lipson, J. Hone, D. Shahrjerdi and E. Riedo, Nat. Electron., 2019, 2, 17-25.

114 T. Pham, G. Li, E. Bekyarova, M. E. Itkis and A. Mulchandani, ACS Nano, 2019, 13, 3196-3205.

115 M.-L. Tsai, S.-H. Su, J.-K. Chang, D.-S. Tsai, C.-H. Chen, C.-I. Wu, L.-J. Li, L.-J. Chen and J.-H. He, ACS Nano, 2014, 8, 8317-8322.

116 T. Ihn, Semiconductor Nanostructures: Quantum States and Electronic Transport, Oxford University Press, 2010.

117 K. Xu, N. Li, D. Zeng, S. Tian, S. Zhang, D. Hu and C. Xie, ACS Appl. Mater. Interfaces, 2015, 7, 11359-11368.

118 X. Wang, L. Huang, Y. Peng, N. Huo, K. Wu, C. Xia, Z. Wei, S. Tongay and J. Li, Nano Res., 2016, 9, 507-516.

119 H. Yan, P. Song, S. Zhang, Z. Yang and Q. Wang, RSC Adv., 2015, 5, 79593-79599.

120 X.-Q. Qiao, Z.-W. Zhang, D.-F. Hou, D.-S. Li, Y. Liu, Y.-Q. Lan, J. Zhang, P. Feng and X. Bu, ACS Sustainable Chem. Eng., 2018, 6, 12375-12384.

121 Y. Han, Y. Ma, Y. Liu, S. Xu, X. Chen, M. Zeng, N. Hu, Y. Su, Z. Zhou and Z. Yang, Appl. Surf. Sci., 2019, 493, 613-619.

122 X. Wang, Y. Sang, D. Wang, S. Ji and H. Liu, J. Alloys Compd., 2015, 639, 571-576.

123 S. Park, S. An, Y. Mun and C. Lee, ACS Appl. Mater. Interfaces, 2013, 5, 4285-4292.
124 W. Zeng, Y. Liu, J. Mei, C. Tang, K. Luo, S. Li, H. Zhan and Z. He, Sens. Actuators, B, 2019, 301, 127010.

125 A. Katoch, J.-H. Kim and S. S. Kim, ACS Appl. Mater. Interfaces, 2014, 6, 21494-21499.

126 G.-J. Sun, J. K. Lee, S. Choi, W. I. Lee, H. W. Kim and C. Lee, ACS Appl. Mater. Interfaces, 2017, 9, 9975-9985.

127 E. Espid and F. Taghipour, Sens. Actuators, B, 2017, 241, 828-839.

128 Z. Li, Y. Liu, D. Guo, J. Guo and Y. Su, Sens. Actuators, B, 2018, 271, 306-310.

129 Q. Zhang, S. Ma, R. Zhang, K. Zhu, Y. Tie and S. Pei, J. Alloys Compd., 2019, 807, 151650.

130 M. Li, W. Ren, R. Wu and M. Zhang, Sensors, 2017, 17, 1577. 131 J. Zhai, L. Wang, D. Wang, H. Li, Y. Zhang, D. q. He and T. Xie, ACS Appl. Mater. Interfaces, 2011, 3, 2253-2258.

132 D. Yang, I. Cho, D. Kim, M. A. Lim, Z. Li, J. G. Ok, M. Lee and I. Park, ACS Appl. Mater. Interfaces, 2019, 11, 2429824307.

133 S. Park, G.-J. Sun, H. Kheel, T. Ko, H. W. Kim and C. Lee, Appl. Phys. A: Mater. Sci. Process., 2016, 122, 504.

134 F. Schedin, A. K. Geim, S. V. Morozov, E. W. Hill, P. Blake, M. I. Katsnelson and K. S. Novoselov, Nat. Mater., 2007, 6, 652-655.

135 P. Bondavalli, P. Legagneux and D. Pribat, Sens. Actuators, $B, 2009$, 140, 304-318.

136 K. S. Kim, C. H. Ahn, S. H. Jung, S. W. Cho and H. K. Cho, ACS Appl. Mater. Interfaces, 2018, 10, 10185-10193.

137 B. Du, Y. Ruan, T.-T. Ly, P. Jia, Q. Sun, Q. Feng, D. Yang and H. Ebendorff-Heidepriem, Sens. Actuators, B, 2020, 305, 127513.

138 D. Li, H. Lu, W. Qiu, J. Dong, H. Guan, W. Zhu, J. Yu, Y. Luo, J. Zhang and Z. Chen, Opt. Express, 2017, 25, 28407-28416.

139 H. Jin, X. Tao, S. Dong, Y. Qin, L. Yu, J. Luo and M. J. Deen, J. Micromech. Microeng., 2017, 27, 115006.

140 H. Li, M. Li, H. Kan, C. Li, A. Quan, C. Fu, J. Luo, X. Liu, W. Wang, Z. Yang, Q. Wei and Y. Fu, Surf. Coat. Technol., 2019, 362, 78-83.

141 R. Atkinson, Atmos. Environ., 2000, 34, 2063-2101.

142 M. Hakim, Y. Y. Broza, O. Barash, N. Peled, M. Phillips, A. Amann and H. Haick, Chem. Rev., 2012, 112, 5949-5966.

143 J.-S. Kim, H.-W. Yoo, H. O. Choi and H.-T. Jung, Nano Lett., 2014, 14, 5941-5947.

144 L. Zhang, K. Khan, J. Zou, H. Zhang and Y. Li, Adv. Mater. Interfaces, 2019, 1901329.

145 H. E. Lebovitz, Lancet, 1995, 345, 767-772.

146 C. Deng, J. Zhang, X. Yu, W. Zhang and X. Zhang, J. Chromatogr. B: Anal. Technol. Biomed. Life Sci., 2004, 810, 269-275.

147 A. Giberti, A. Gaiardo, B. Fabbri, S. Gherardi, V. Guidi, C. Malagù, P. Bellutti, G. Zonta, D. Casotti and G. Cruciani, Sens. Actuators, B, 2016, 223, 827-833.

148 D. Gu, X. Li, Y. Zhao and J. Wang, Sens. Actuators, B, 2017, 244, 67-76.

149 M. Leidinger, M. Rieger, T. Sauerwald, C. Alépée and A. Schütze, Sens. Actuators, B, 2016, 236, 988-996. 
150 World Health Organization, WHO guidelines for indoor air quality: selected pollutants, World Health Organization, Regional Office for Europe, Copenhagen, 2010.

151 H. Fan, Z. Peng, H. Yang and K. Zhou, Anal. Methods, 2016, 8, 1257-1264.

152 C. B. Hirschmann, S. Sinisalo, J. Uotila, S. Ojala and R. L. Keiski, Vib. Spectrosc., 2013, 68, 170-176.

153 D. Zhang, C. Jiang and X. Zhou, Talanta, 2018, 182, 324332.

154 D. Zhang, J. Wu, P. Li, Y. Cao and Z. Yang, ACS Appl. Mater. Interfaces, 2019, 11, 31245-31256.

155 D. Baek, K. Lee, S. Pyo, J. Choi and J. Kim, 2015 18th International Conference on Solid-State Sensors, Actuators and Microsystems (TRANSDUCERS), Anchorage, AK, 2015, pp. 618-621.

156 U. S. O. o. M. t. P. Earth, Scientific Assessment of Ozone Depletion, 1994, World Meteorological Organization, 1995.

157 A. Takahashi, Y. Urano, K. Tokuhashi, N. Hidekazu, M. Kaise and S. Kondo, J. Loss Prev. Process Ind., 1998, 11, 353-360.

158 A. J. Zehnder and T. D. Brock, J. Bacteriol., 1979, 137, 420.

159 A. Mosahebfard, H. D. Jahromi and M. H. Sheikhi, IEEE Sens. J., 2016, 16, 4174-4179.

160 H. Roshan, A. Mosahebfard and M. H. Sheikhi, IEEE Sens. J., 2018, 18, 1940-1945.

161 A. Mosahebfard, H. Roshan and M. H. Sheikhi, IEEE Sens. J., 2017, 17, 3375-3380.

162 H. Roshan, M. H. Sheikhi, M. K. F. Haghighi and P. Padidar, IEEE Sens. J., 2020, 20, 2526-2532.

163 F. Wang, H. Liu, K. Hu, Y. Li, W. Zeng and L. Zeng, Ceram. Int., 2019, 45, 22981-22986.

164 A. A. Sergeev, K. A. Sergeeva, A. A. Leonov, I. V. Postnova and S. S. Voznesenskiy, Semiconductors, 2018, 52, 18461848.

165 S. Hussain, T. Liu, M. S. Javed, N. Aslam and W. Zeng, Sens. Actuators, B, 2017, 239, 1243-1250.

166 X. Li, J. Wang, D. Xie, J. Xu, Y. Xia, W. Li, L. Xiang, Z. Li, S. Xu and S. Komarneni, Nanotechnology, 2017, 28, 325501.

167 D. Zhang, C. Jiang and J. Wu, Sens. Actuators, B, 2018, 273, 176-184.

168 D. Zhang, Y. Cao, Z. Yang and J. Wu, ACS Appl. Mater. Interfaces, 2020, 12, 11979-11989.

169 U. S. D. O. Labor, Occupational Safety and Health Standards, in Toxic and Hazardous Substances, United States, 2013.

170 D. Zhang, X. Fan, A. Yang and X. Zong, J. Colloid Interface Sci., 2018, 523, 217-225.

171 A. Giberti, D. Casotti, G. Cruciani, B. Fabbri, A. Gaiardo, V. Guidi, C. Malagù, G. Zonta and S. Gherardi, Sens. Actuators, B, 2015, 207, 504-510.

172 X. L. Yu, Y. Wang, H. L. W. Chan and C. B. Cao, Microporous Mesoporous Mater., 2009, 118, 423-426.

173 R. Souissi, N. Bouguila and A. Labidi, Sens. Actuators, B, 2018, 261, 522-530.

174 H. Yan, P. Song, S. Zhang, Z. Yang and Q. Wang, J. Alloys Compd., 2016, 662, 118-125.
175 P. X. Zhao, Y. Tang, J. Mao, Y. X. Chen, H. Song, J. W. Wang, Y. Song, Y. Q. Liang and X. M. Zhang, J. Alloys Compd., 2016, 674, 252-258.

176 S. V. Patil, P. R. Deshmukh and C. D. Lokhande, Sens. Actuators, B, 2011, 156, 450-455.

177 R. D. Ladhe, P. K. Baviskar, S. M. Pawar, J. H. Kim and B. R. Sankapal, Sens. Actuators, A, 2017, 267, 187-193.

178 R. D. Ladhe, P. K. Baviskar, W. W. Tan, J. B. Zhang, C. D. Lokhande and B. R. Sankapal, J. Phys. D: Appl. Phys., 2010, 43, 245302.

179 N. B. Sonawane, P. K. Baviskar, R. R. Ahire and B. R. Sankapal, Mater. Chem. Phys., 2017, 191, 168-172.

180 N. B. Sonawane, K. V. Gurav, R. R. Ahire, J. H. Kim and B. R. Sankapal, Sens. Actuators, A, 2014, 216, 78-83.

181 L. Yadava, R. Verma and R. Dwivedi, Sens. Actuators, B, 2010, 144, 37-42.

182 D. S. Dhawale, D. P. Dubal, V. S. Jamadade, R. R. Salunkhe, S. S. Joshi and C. D. Lokhande, Sens. Actuators, B, 2010, 145, 205-210.

183 S. Singh, A. Singh, B. C. Yadav, P. Tandon, S. Kumar, R. R. Yadav, S. I. Pomogailo, G. I. Dzhardimalieva and A. D. Pomogailo, Sens. Actuators, B, 2015, 207, 460-469.

184 R. A. Michaels, Environ. Health Perspect., 1999, 107, 617627.

185 S. E. Zohora, A. M. Khan and N. Hundewale, in Advances in Computing and Information Technology, Springer, Berlin, Heidelberg, 2013, vol. 178, pp. 177-184.

186 B. Liu, L. Chen, G. Liu, A. N. Abbas, M. Fathi and C. Zhou, ACS Nano, 2014, 8, 5304-5314.

187 X. Li, X. Li, Z. Li, J. Wang and J. Zhang, Sens. Actuators, B, 2017, 240, 273-277.

188 Y. Xiong, W. Xu, D. Ding, W. Lu, L. Zhu, Z. Zhu, Y. Wang and Q. Xue, J. Hazard. Mater., 2018, 341, 159-167.

189 N. Huo, S. Yang, Z. Wei, S.-S. Li, J.-B. Xia and J. Li, Sci. Rep., 2014, 4, 5209.

190 S. Yang, J. Kang, Q. Yue, J. M. D. Coey and C. Jiang, Adv. Mater. Interfaces, 2016, 3, 1500707.

191 D. Zhang, C. Jiang and Y. e. Sun, J. Alloys Compd., 2017, 698, 476-483.

192 D. Zhang, C. Jiang, P. Li and Y. e. Sun, ACS Appl. Mater. Interfaces, 2017, 9, 6462-6471.

193 S. Zhang, J. Wang, N. L. Torad, W. Xia, M. A. Aslam, Y. V. Kaneti, Z. Hou, Z. Ding, B. Da, A. Fatehmulla, A. M. Aldhafiri, W. A. Farooq, J. Tang, Y. Bando and Y. Yamauchi, Small, 2019, 1901718.

194 Z. Qin, C. Ouyang, J. Zhang, L. Wan, S. Wang, C. Xie and D. Zeng, Sens. Actuators, B, 2017, 253, 1034-1042.

195 S. G. Leonardi, W. Wlodarski, Y. Li, N. Donato, A. Bonavita and G. Neri, J. Alloys Compd., 2019, 781, 440-449.

196 Y. Liu, L. Wang, H. Wang, M. Xiong, T. Yang and G. S. Zakharova, Sens. Actuators, B, 2016, 236, 529-536.

197 T. Fu, Sens. Actuators, B, 2009, 140, 116-121.

198 W. Shi, L. Huo, H. Wang, H. Zhang, J. Yang and P. Wei, Nanotechnology, 2006, 17, 2918-2924.

199 B. Cho, J. Yoon, S. K. Lim, A. R. Kim, D.-H. Kim, S.-G. Park, J.-D. Kwon, Y.-J. Lee, K.-H. Lee, B. H. Lee, H. C. Ko and 
M. G. Hahm, ACS Appl. Mater. Interfaces, 2015, 7, 1677516780.

200 S. Sharma, A. Kumar, N. Singh and D. Kaur, Sens. Actuators, $B, 2018,275,499-507$.

201 C. W. Spicer, D. V. Kenny, G. F. Ward and I. H. Billick, Air Waste, 1993, 43, 1479-1485.

202 A. Afzal, N. Cioffi, L. Sabbatini and L. Torsi, Sens. Actuators, $B, 2012$, 171-172, 25-42.

203 K. Alving, E. Weitzberg and J. M. Lundberg, Eur. Respir. J., 1993, 6, 1368.

204 P. J. Barnes, R. A. Dweik, A. F. Gelb, P. G. Gibson, S. C. George, H. Grasemann, I. D. Pavord, F. Ratjen, P. E. Silkoff, D. R. Taylor and N. Zamel, Chest, 2010, 138, 682-692.

205 R. K. Sonker, B. C. Yadav, V. Gupta and M. Tomar, Mater. Chem. Phys., 2020, 239, 121975.

206 S. T. Navale, A. T. Mane, M. A. Chougule, N. M. Shinde, J. Kim and V. B. Patil, RSC Adv., 2014, 4, 44547-44554.

207 V. V. Burungale, R. S. Devan, S. A. Pawar, N. S. Harale, V. L. Patil, V. K. Rao, Y. R. Ma, J. Eun Ae, J. H. Kim and P. S. Patil, Mater. Sci., 2016, 34, 204-211.

208 T. Xu, Y. Liu, Y. Pei, Y. Chen, Z. Jiang, Z. Shi, J. Xu, D. Wu, Y. Tian and X. Li, Sens. Actuators, B, 2018, 259, 789-796.

209 Y.-H. Kim, D.-T. Phan, S. Ahn, K.-H. Nam, C.-M. Park and K.-J. Jeon, Sens. Actuators, B, 2018, 255, 616-621.

210 J. Z. Ou, W. Ge, B. Carey, T. Daeneke, A. Rotbart, W. Shan, Y. Wang, Z. Fu, A. F. Chrimes, W. Wlodarski, S. P. Russo, Y. X. Li and K. Kalantar-zadeh, ACS Nano, 2015, 9, 1031310323.

211 K. Y. Ko, J.-G. Song, Y. Kim, T. Choi, S. Shin, C. W. Lee, K. Lee, J. Koo, H. Lee, J. Kim, T. Lee, J. Park and H. Kim, ACS Nano, 2016, 10, 9287-9296.

212 H. Tabata, Y. Sato, K. Oi, O. Kubo and M. Katayama, ACS Appl. Mater. Interfaces, 2018, 10, 38387-38393.

213 S. Zhao, G. Wang, J. Liao, S. Lv, Z. Zhu and Z. Li, Appl. Surf. Sci., 2018, 456, 808-816.

214 S. Shao, L. Che, Y. Chen, M. Lai, S. Huang and R. Koehn, J. Alloys Compd., 2019, 774, 1-10.

215 F. Perrozzi, S. M. Emamjomeh, V. Paolucci, G. Taglieri, L. Ottaviano and C. Cantalini, Sens. Actuators, B, 2017, 243, 812-822.

216 Y. Han, Y. Liu, C. Su, S. Wang, H. Li, M. Zeng, N. Hu, Y. Su, Z. Zhou, H. Wei and Z. Yang, Sens. Actuators, B, 2019, 296, 126666.

217 H. Tang, Y. Li, R. Sokolovskij, L. Sacco, H. Zheng, H. Ye, H. Yu, X. Fan, H. Tian, T.-L. Ren and G. Zhang, ACS Appl. Mater. Interfaces, 2019, 11, 40850-40859.

218 K. C. Kwon, J. M. Suh, T. H. Lee, K. S. Choi, K. Hong, Y. G. Song, Y.-S. Shim, M. Shokouhimehr, C.-Y. Kang, S. Y. Kim and H. W. Jang, ACS Sens., 2019, 4, 678-686.

219 J. Wu, Z. Wu, H. Ding, Y. Wei, W. Huang, X. Yang, Z. Li, L. Qiu and X. Wang, Sens. Actuators, B, 2020, 305, 127445.

220 X. Xin, Y. Zhang, X. Guan, J. Cao, W. Li, X. Long and X. Tan, ACS Appl. Mater. Interfaces, 2019, 11, 9438-9447.

221 K. S. Kim, C. H. Ahn, S. H. Jung, S. W. Cho and H. Cho, ACS Appl. Mater. Interfaces, 2018, 10, 10185-10193.
222 H.-S. Jeong, M.-J. Park, S.-H. Kwon, H.-J. Joo and H.-I. Kwon, Sens. Actuators, B, 2019, 288, 625-633.

223 C.-S. Chu and M.-W. Hsieh, in 2017 25th Optical Fiber Sensors Conference (OFS), Jeju, 2017, pp. 1-4.

224 C.-S. Chu and M.-W. Hsieh, Opt. Mater. Express, 2019, 9, 2937-2945.

225 C.-S. Chu and J.-C. Lo, in Proc. SPIE 11205, Seventh International Conference on Optical and Photonic Engineering (icOPEN 2019), vol. 112050Y, 2019.

226 Y. H. Kim, K. Y. Kim, Y. R. Choi, Y.-S. Shim, J.-M. Jeon, J.-H. Lee, S. Y. Kim, S. Han and H. W. Jang, J. Mater. Chem. A, 2016, 4, 6070-6076.

227 Y. Li, S. G. Leonardi, A. Bonavita, G. Neri and W. Wlodarski, Procedia Eng., 2016, 168, 1102-1105.

228 H. Karami and S. Babaei, Int. J. Electrochem. Sci., 2013, 8, 12078.

229 T. Fu, Electrochim. Acta, 2013, 112, 230-235.

230 S. Yang, Y. Li, X. Wang, N. Huo, J.-B. Xia, S.-S. Li and J. Li, Nanoscale, 2014, 6, 2582-2587.

231 M. Hafeez, U. Manzoor and A. S. Bhatti, J. Mater. Sci.: Mater. Electron., 2011, 22, 1772-1777.

232 H. Guo, C. Lan, Z. Zhou, P. Sun, D. Wei and C. Li, Nanoscale, 2017, 9, 6246-6253.

233 J. Feng, L. Peng, C. Wu, X. Sun, S. Hu, C. Lin, J. Dai, J. Yang and Y. Xie, Adv. Mater., 2012, 24, 1969-1974.

234 A. Yang, J. Gao, B. Li, J. Tan, Y. Xiang, T. Gupta, L. Li, S. Suresh, J. C. Idrobo, T.-M. Lu, M. Rong and N. Koratkar, 2D Mater., 2016, 3, 045012.

235 D. Burman, S. Santra, P. Pramanik and P. K. Guha, Nanotechnology, 2018, 29, 115504.

236 Y. Luo, C. Chen, K. Xia, S. Peng, H. Guan, J. Tang, H. Lu, J. Yu, J. Zhang, Y. Xiao and Z. Chen, Opt. Express, 2016, 24, 8956-8966.

237 B. Du, D. Yang, X. She, Y. Yuan, D. Mao, Y. Jiang and F. Lu, Sens. Actuators, B, 2017, 251, 180-184.

238 Y. Feng, S. Gong, E. Du, K. Yu, J. Ren, Z. Wang and Z. Zhu, J. Mater. Chem. C, 2019, 7, 9284-9292.

239 Y. Tan, K. Yu, T. Yang, Q. Zhang, W. Cong, H. Yin, Z. Zhang, Y. Chen and Z. Zhu, J. Mater. Chem. C, 2014, 2, 5422-5430.

240 S. Yadav, P. Chaudhary, K. N. Uttam, A. Varma, M. Vashistha and B. C. Yadav, Nanotechnology, 2019, 30, 295501.

241 L. Ze, G. Yueqiu, L. Xujun and Z. Yong, Appl. Surf. Sci., 2017, 399, 330-336.

242 N. Li, X. Chen, X. Chen, X. Ding and X. Zhao, IEEE Electron Device Lett., 2017, 38, 806-809.

243 D. Zhang, Y. e. Sun, P. Li and Y. Zhang, ACS Appl. Mater. Interfaces, 2016, 8, 14142-14149.

244 Y. Zhang, H. Zou, J. Peng, Z. Duan, M. Ma, X. Xin, W. Li and X. Zheng, Sens. Actuators, B, 2018, 272, 459-467.

245 G. U. Siddiqui, M. Sajid, J. Ali, S. W. Kim, Y. H. Doh and K. H. Choi, Sens. Actuators, B, 2018, 266, 354-363.

246 D. Zhang, X. Zong and Z. Wu, Sens. Actuators, B, 2019, 287, 398-407.

247 D. Zhang, X. Zong, Z. Wu and Y. Zhang, Sens. Actuators, B, 2018, 266, 52-62. 
248 D. Zhang, X. Zong, Z. Wu and Y. Zhang, ACS Appl. Mater. Interfaces, 2018, 10, 32631-32639.

249 M. A. Dwiputra, F. Fadhila, C. Imawan and V. Fauzia, Sens. Actuators, B, 2020, 310, 127810.

250 D. Zhang, Y. Cao, P. Li, J. Wu and X. Zong, Sens. Actuators, B, 2018, 265, 529-538.

251 E. Espid and F. Taghipour, Crit. Rev. Solid State Mater. Sci., 2017, 42, 416-432.
252 M.-Y. Li, S.-K. Su, H. S. P. Wong and L.-J. Li, Nature, 2019, 567(2), 169-170.

253 G. Q. Zhang, M. Graef and F. v. Roosmalen, in 56th Electronic Components and Technology Conference 2006, IEEE, 2006, vol. 7.

254 G. Q. Zhang and A. van Roosmalen, More than Moore: Creating High Value Micro/Nanoelectronics Systems, Springer Science \& Business Media, 2010. 